Florida International University FIU Digital Commons

\title{
Detection and neutralization of bacterial biohazards via nanoencapsulation
}

Rosaura De Zayas

Florida International University

DOI: $10.25148 /$ etd.FI14062227

Follow this and additional works at: https://digitalcommons.fiu.edu/etd

Part of the Biomedical Engineering and Bioengineering Commons

\section{Recommended Citation}

De Zayas, Rosaura, "Detection and neutralization of bacterial biohazards via nanoencapsulation" (2006). FIU Electronic Theses and Dissertations. 2757.

https://digitalcommons.fiu.edu/etd/2757 
Miami, Florida

A thesis submitted in partial fulfillment of the

requirements for the degree of

MASTER OF SCIENCE

in

BIOMEDICAL ENGINEERING

by

Rosaura De Zayas 
To: Dean Vish Prasad

College of Engineering and Computing

This thesis, written by Rosaura De Zayas, and entitled Detection and Neutralization of Bacterial Biohazards via Nanoencapsulation, having been approved in respect to style and intellectual content, is referred to you for judgment.

We have read this thesis and recommend that it be approved.

Richard T. Schoephoerster

Nikolaos M. Tsoukias

Eric T. Crumpler, Major Professor

Date of Defense: August 18, 2006

The thesis of Rosaura De Zayas is approved.

Dean Vish Prasad College of Engineering and Computing

Dean George Walker University Graduate School

Florida International University, 2007 


\section{DEDICATION}

I would like to dedicate this thesis to all my family and friends that have guided me from the beginning to the end of my studies. If it was not for the inspiration that I received from my specials friends Mahwish Ahmed and Sara Nofallah, I would not have been able to finish this thesis. I would like to give extra gratitude to my fiancé Noel Artiles for his loving, caring, and most of all patience. Last but not least to my family for their continuous spiritual, emotional, and financial support for throughout every step in my academic career. 
ABSTRACT OF THE THESIS

DETECTION AND NEUTRALIZATION OF BACTERIAL BIOHAZARDS VIA

NANOENCAPSULATION

by

Rosaura De Zayas

Florida International University, 2007

Miami, Florida

Professor Eric T. Crumpler, Major Professor

Bacteria biohazards, such as Anthrax, are responsible for causing mild to serious illnesses in humans and animals. The primary aim of this research study was to develop a rapid one step assay to detect and neutralize bacteria-based biohazards, using an Immunoliposome-nanoparticle complex. An Anthrax model, Bacillus cereus, was grown for 3 hours and diluted 1:25 in media $\left(2.0 \times 10^{7} \mathrm{cfu} / \mathrm{ml}\right)$. The Bacillus cereus was

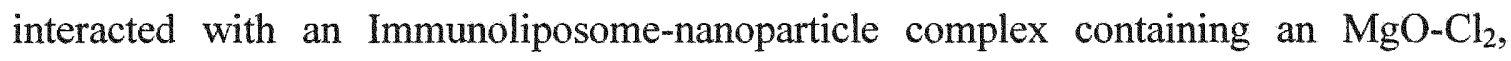
neutralization agent. The samples were analyzed via flow cytometry with a 1:8:1 ratio Bacillus cereus, Immunoliposome-nanoparticle complex, and Ethidium homodimer-1 for two hours. The results obtained showed when the Immunoliposome-nanoparticle complex were interacted with bacteria both detection and neutralization occurred immediately. As incubation time increased, fluorescence shifted closer to the control region. Therefore, bacteria can be immediately detected with the Immunoliposomenanoparticles complex, and high levels of neutralization can be achieved less than two hours of incubation. 


\section{TABLE OF CONTENTS}

CHAPTER

PAGE

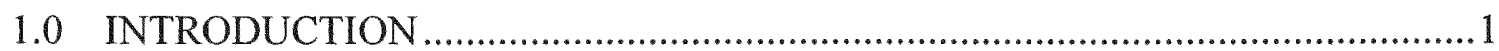

1.1 Research Objectives and Specific Aims .........................................................

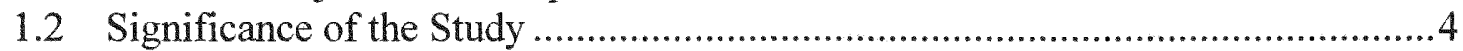

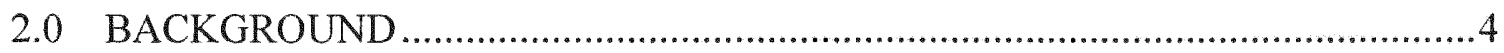

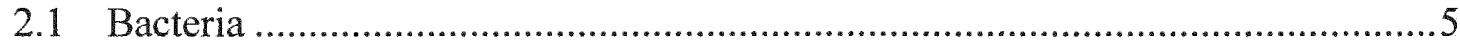

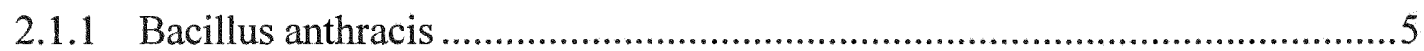

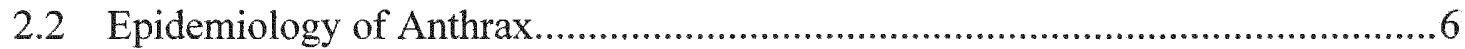

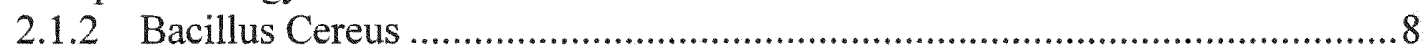

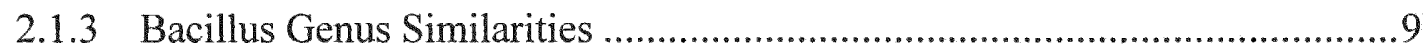

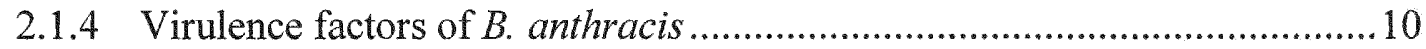

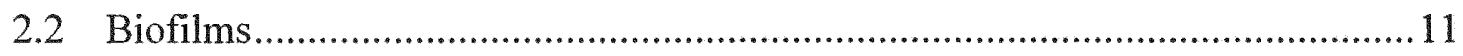

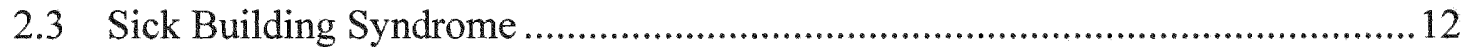

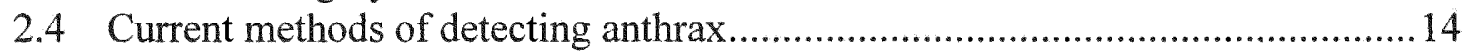

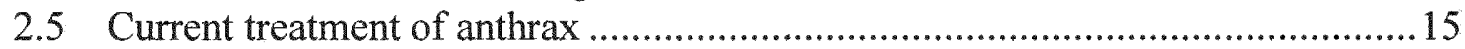

2.6 New neutralization agent for Bacteria strains ................................................15

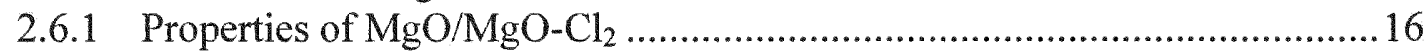

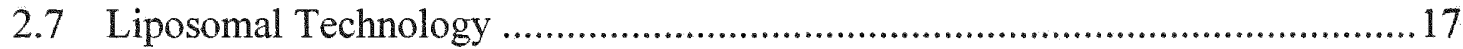

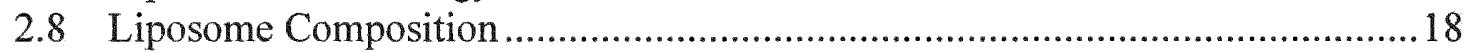

2.8.1 Types of Processes to Create liposomes................................................ 19

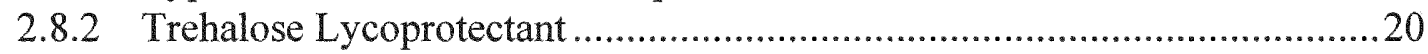

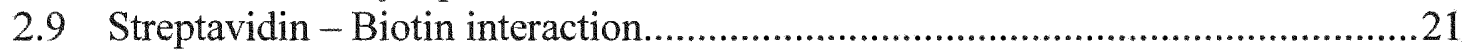

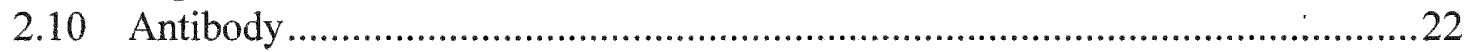

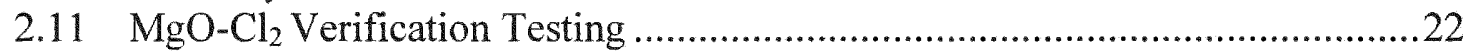

2.11.1 Presence of Chlorine in $\mathrm{MgO}-\mathrm{Cl}_{2}$ nanoparticles......................................22

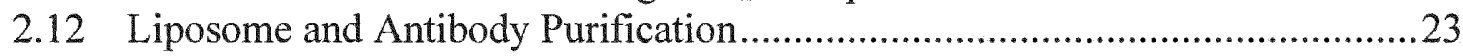

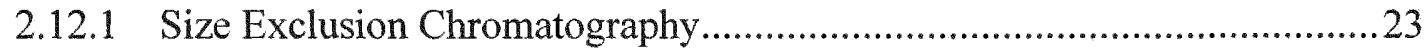

2.13 Antibody and Streptavidin Nanoparticle Synthesis Yield ............................22

2.13.1 Protein Concentration using Spectrophotometer .......................................23

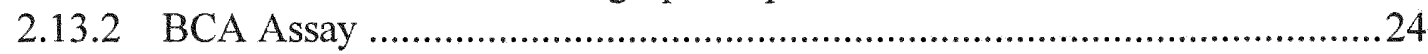

2.14 Bacteria and Immunoliposome-nanoparticle Complex Testing ........................225

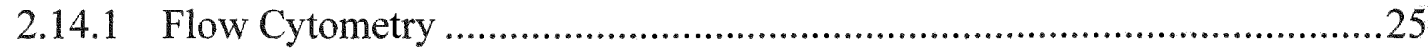

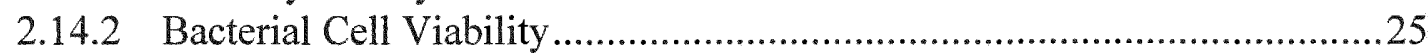

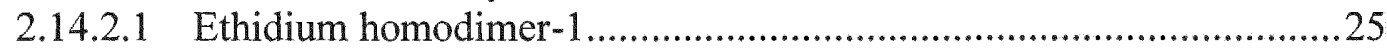

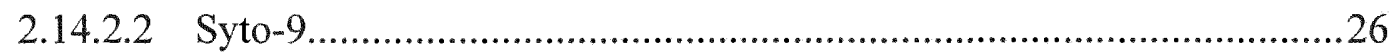

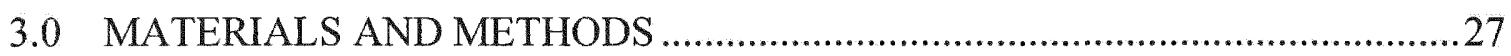

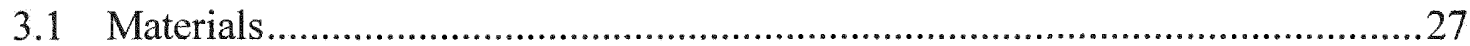

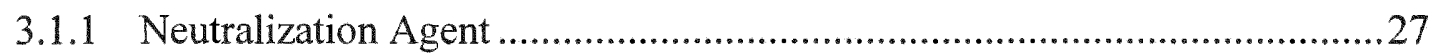

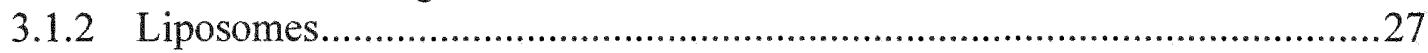

3.1.3 Antibody-Streptavidin Coated Nanoparticle complex .............................27 


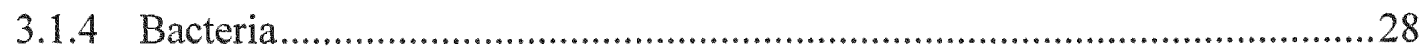

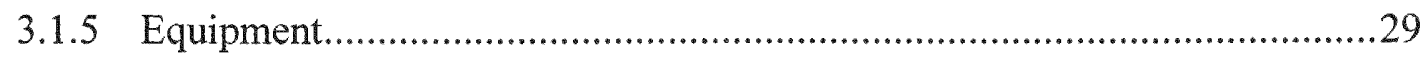

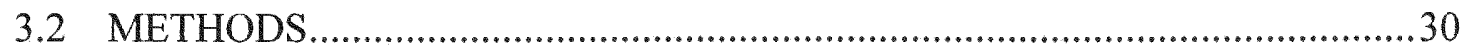

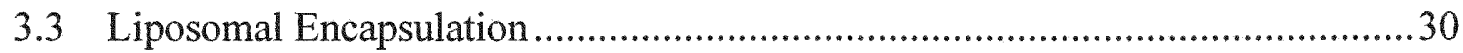

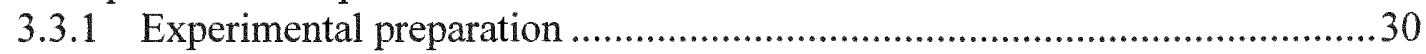

3.3.1.1 Determining concentration of liposome encapsulant, $\mathrm{MgO}-\mathrm{Cl}_{2} \ldots \ldots \ldots . .30$

3.3.2 Testing the Dilutions of $\mathrm{MgO}-\mathrm{Cl}_{2}$ with Mini extruder.............................. 31

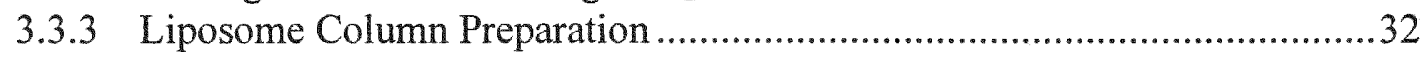

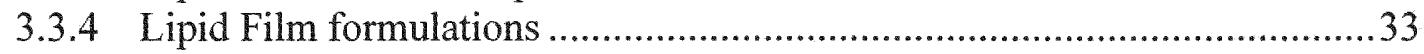

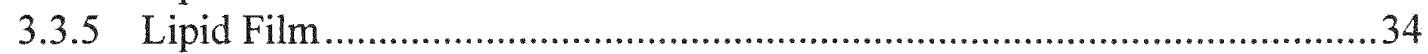

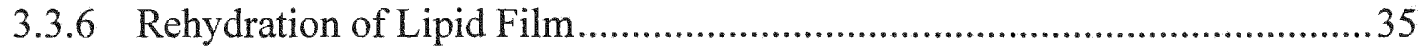

3.3.7 Extrusion of Large Unilmellar liposomes ................................................35

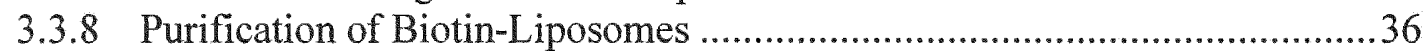

3.3.8.1 Sephadex Centrifuge Purification ........................................................36

3.3.9 Liposome Verification via Scanning Electron Microscopy (SEM) ..............37

3.4 Immunoliposome -nanoparticle complex synthesis .........................................38

3.4.1 Synthesis of Streptavidin-Nanoparticle antibody Complex .......................38

3.4.2 Streptavidin coated nanoparticle-MBS Synthesis.......................................38

3.4.3 Purification of Streptavidin-MBS complex..............................................39

3.4.3.1 Preparation of Centriprep 30 Ultrafiltration device .............................39

3.4.3.2 Purification of Streptavidin-MBS Complex ..........................................40

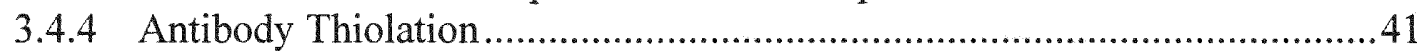

3.4.4.1 Antibody-Sh Sephadex column preparation.................................... 41

3.4.4.2 Thiolated Antibody Purification ………............................................42

3.4.4.3 Conjugation of Streptavidin-Antibody Complex .................................42

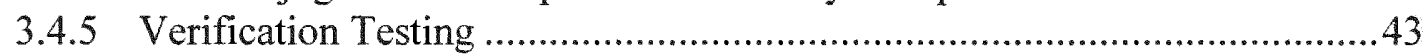

3.4.5.1 Protein Recovery Tecan Spectrophotometer ......................................43

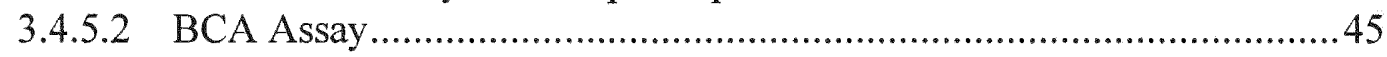

3.4.6 Immunoliposome-nanoparticle Complex Conjugation ..............................4

3.5 Live/Dead Bacteria Verification Testing ........................................................47

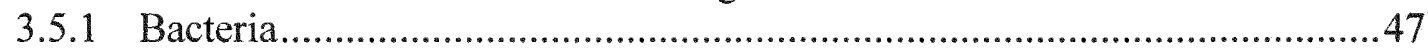

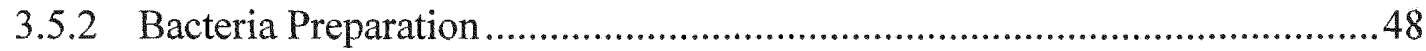

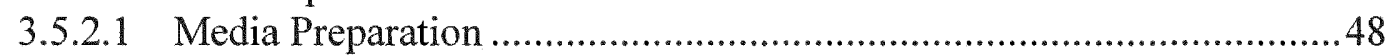

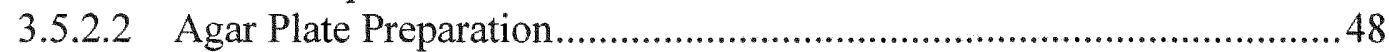

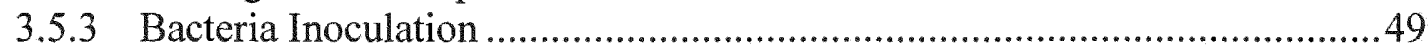

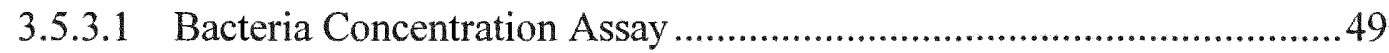

3.5.4 Bacteria and $\mathrm{MgO}-\mathrm{Cl}_{2}$ Interaction Control Testing ...................................50

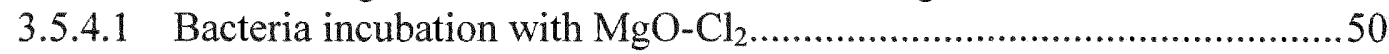

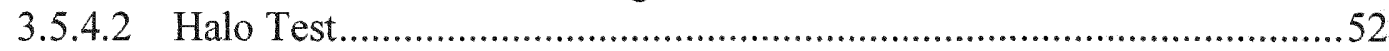

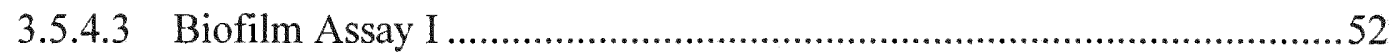

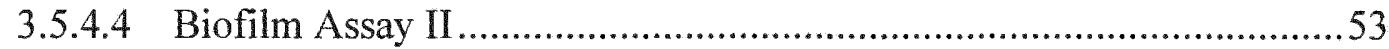

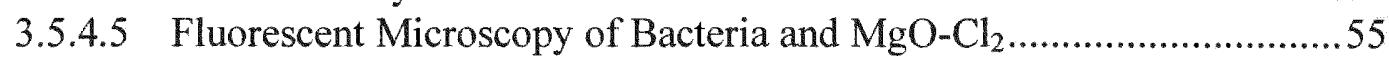

3.5.5 Bacteria testing with Immunoliposome-nanoparticle complex ...................56

3.5.5.1 Microscopy Bacteria and Immunoliposome-nanoparticle complex ......56 


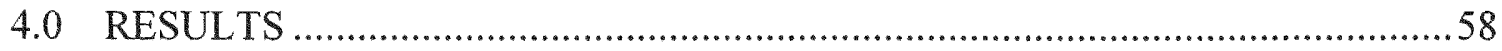

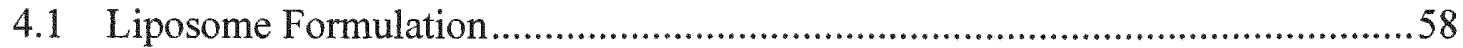

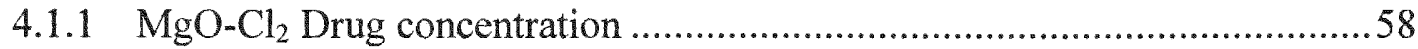

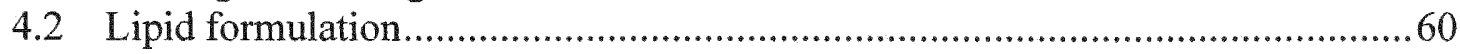

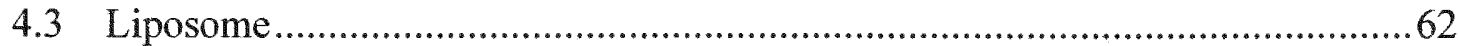

4.3.1 Liposome Purification verification .......................................................62

4.4 Streptavidin-nanoparticle antibody complex Synthesis ....................................64

4.4.1 Synthesis reaction of Antibody and Streptavidin........................................6. 64

4.4.1.1 Antibody and Streptavidin Yield ......................................................64

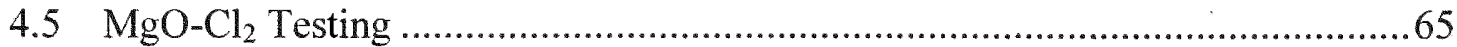

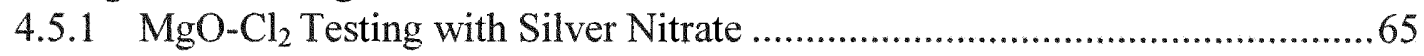

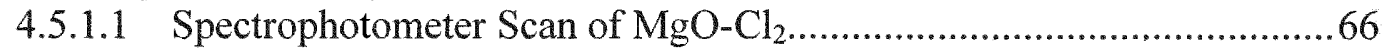

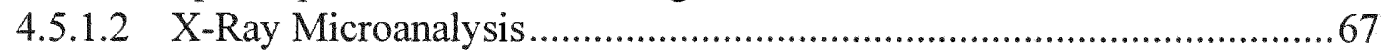

4.6 Live/Dead Bacteria Verification testing .......................................................68

4.6.1 Bacteria and $\mathrm{MgO}-\mathrm{Cl}_{2}$ Interaction Control Testing ...................................6.68

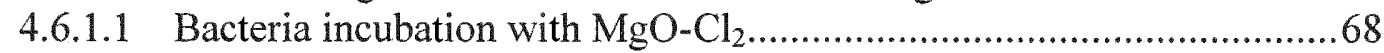

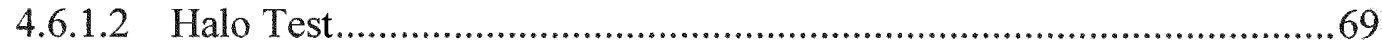

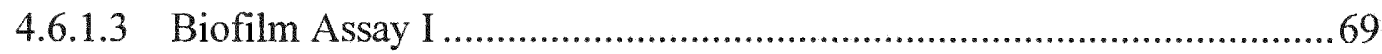

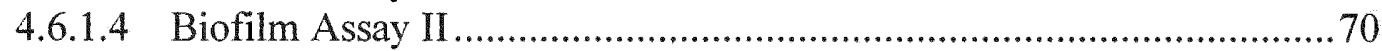

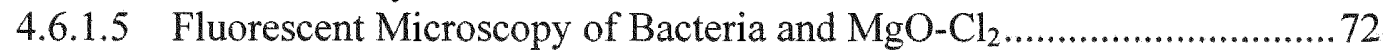

4.7 Bacteria Testing with Immunoliposome nanoparticle Complex .........................73

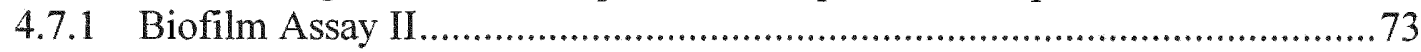

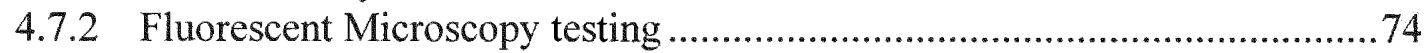

4.7.3 Data acquisition of Bacteria and Immunoliposome Flow Cytometry...........76

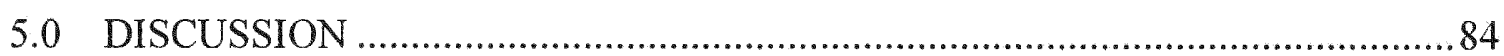

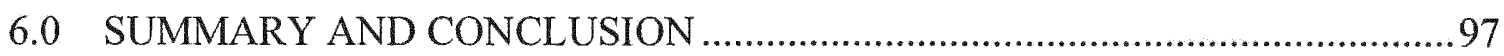

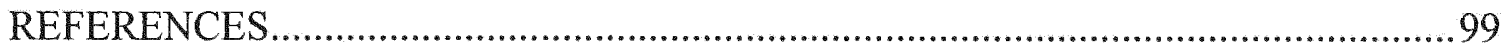




\section{LIST OF TABLES}

TABLE

PAGE

Table 1. Silver Nitrate Reactants and Color Observation ...........................................23

Table 2. Dilutions of $\mathrm{MgO}-\mathrm{Cl}_{2}$ in HEPES buffer .................................................... 31

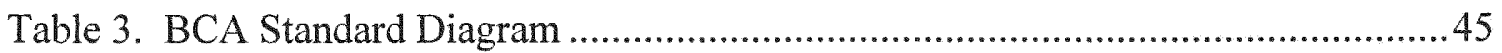

Table 4. Prepared MgO-Cl2 Concentrations …........................................................51

Table 5. Biofilm MgO-Cl $\mathrm{Cl}_{2}$ Testing ...................................................................5

Table 6. $\mathrm{MgO}-\mathrm{Cl}_{2}$ Plate layout for Biofilm Testing ..................................................5 54

Table 7. Fluorescent Microscopy testing with $\mathrm{MgO}-\mathrm{Cl}_{2}$ and B. cereus .........................55

Table 8. Fluorescent Microscopy testing with samples and B. cereus ..........................57

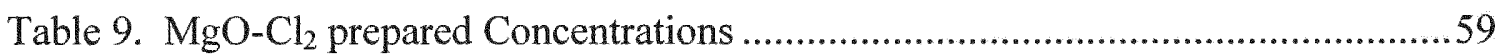

Table 10. $\mathrm{MgO}-\mathrm{Cl}_{2}$ testing with Mini extruder Apparatus .........................................6 60

Table 11. Liposome samples with corresponding formulation...................................61

Table 12. Silver Nitrate Test Results....................................................................66

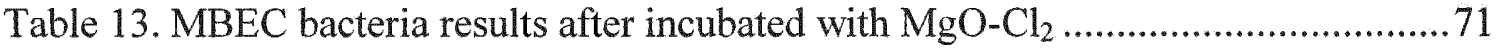




\section{LIST OF FIGURES}

FIGURE

PAGE

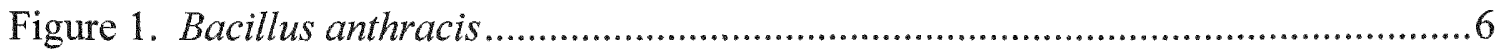

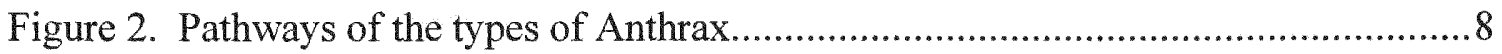

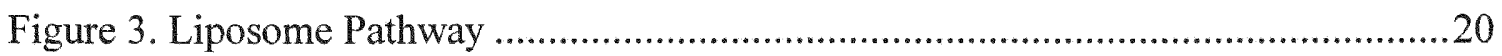

Figure 5. Ethidium homodimer-1 fluorescent spectrum..............................................26

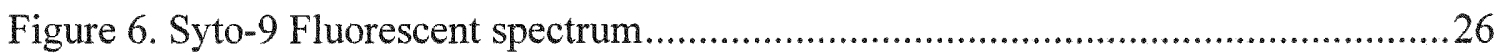

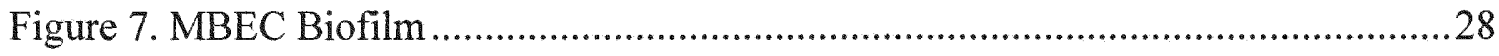

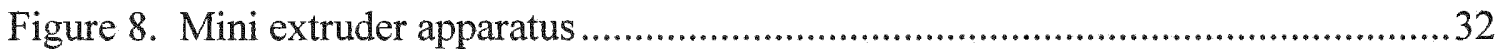

Figure 9. Assembly of filters and membranes into extruder......................................32

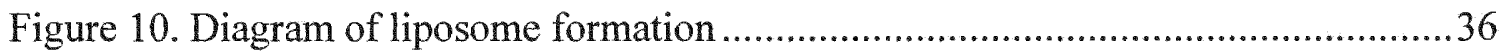

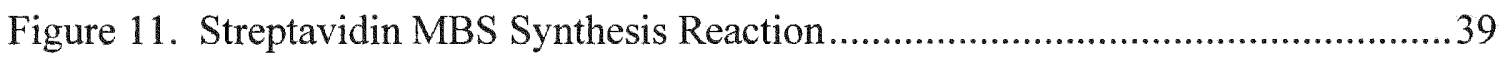

Figure 12. Centriprep Diagram. A. Centriprep 30 ultrafiltration device B. diagram.......40

Figure 13. Antibody and Traut's reagent reaction ...................................................4 41

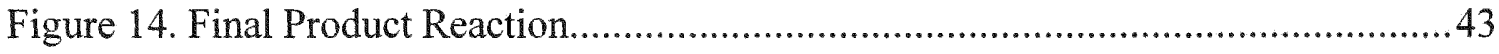

Figure 15. Recovered Antibody Sample Plate diagram ...............................................44

Figure 16. Recovered Streptavidin Sample Plate diagram ..........................................44

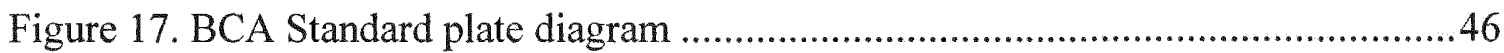

Figure 18. Immunoliposome-nanoparticle Complex.............................................47

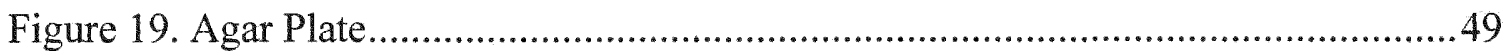

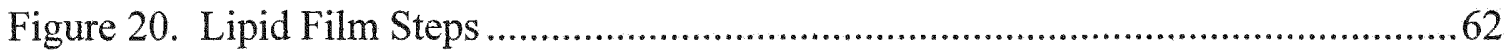

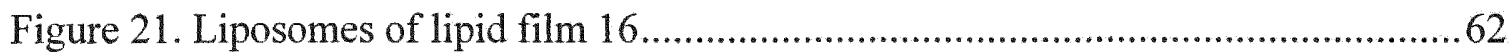

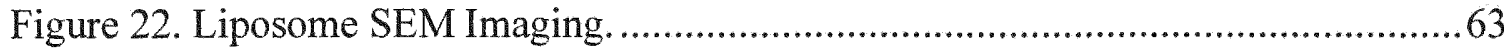


Figure 23. Purified liposome SEM.....................................................................63

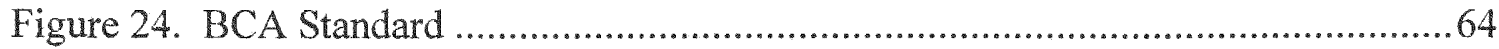

Figure 25. $\mathrm{MgO}_{-\mathrm{Cl}_{2}}$ Absorbance Scan ............................................................66

Figure 26. X-Ray microanalysis of $\mathrm{MgO}-\mathrm{Cl}_{2}$ nanoparticles.......................................6 68

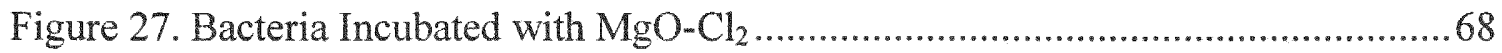

Figure 28. Halo test with Bacteria samples ..............................................................69

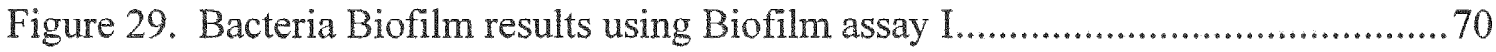

Figure 30. Fluorescent microscopy images of $B$. cereus and $\mathrm{MgO}-\mathrm{Cl}_{2} \ldots \ldots \ldots \ldots \ldots \ldots \ldots . . . . .72$

Figure 31. MBEC $B$. cereus biofilm results after incubated with Liposomes.................73

Figure 32. Fluorescent Microscopy Images of liposome and $B$. cereus......................74

Figure 33. Fluorescent microscopy images of $B$. cereus and liposomes........................74

Figure 34. Fluorescent microscopy images of $B$. subtilis with sample 13-5 ..................75

Figure 36. B. subtilis immunoliposomes-nanoparticle complex 13-5 at time zero...........77

Figure 37. B subtilis immunoliposomes-nanoparticle-complex after 2 hours..................77

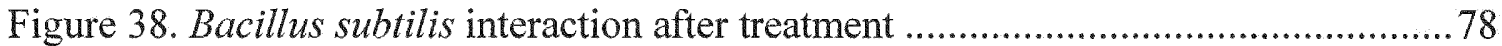

Figure 39. Overlap of complex 10 with $B$. cereus .......................................................79

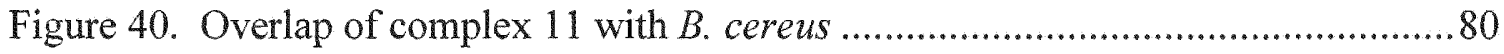

Figure 41. Immunoliposome Formulation (a) interacted with $B$. cereus........................8 81

Figure 42. Immunoliposome Formulation (b) interacted with B. cereus .....................8 82

Figure 43. Immunoliposome Formulation (c) interacted with B. cereus........................83

Figure 44. Immunoliposome Formulation (d) interacted with B. cereus ........................83 


\subsection{INTRODUCTION}

Bacteria biohazards are found in various everyday surfaces and are responsible for causing mild to serious illnesses in humans and animals. These bacteria biohazards are found in drainage pipes, sinks, air conditioning systems, and on any surface that provides a nutrient environment for bacteria proliferation'. These bacteria community sites are referred to as bacteria biofilms. The treatment and detection of these biofilms, or of any bacteria biohazards like anthrax, are of great concern for its abrupt catastrophic effects. The crucial need to rapidly identify and neutralize these pathogens for both the private and military sectors is of great importance; especially with current heighten awareness of the possible implications that could arise with the use of biological weapons.

One main obstacle in the detection and neutralization of bacteria is the lapse of time needed to identify the pathogen before severe irreversible illness occurs and the survival of the patient is jeopardized. For example, positive identification of Bacillus anthracis requires $24-48$ hours. If unidentified within this time period, this particular pathogen may have already progressed to the lethal phase. Once the lethal phase has been reached, the possibility of patient survival becomes slim. The inability to successfully identify this bacteria in a timely manner needed is the reason why biological agents such as anthrax are extremely effective as biological weapons. The lethal effectiveness of these agents when used in bio-terrorism makes it imperative to develop a novel assay that aims to rapidly detect and neutralize bacterial pathogens.

At this current moment, detection methods for bacteria involve the use of microbiology assays such as Polymerase Chain Reaction (PCR $)^{2}$. This assay functions by 
replicating the DNA of an unknown pathogen in order to identify bacteria or viruses. Several illnesses are identified by this technique, ranging from infectious diseases to hereditary illnesses. Unfortunately the PCR assay long procedure creates a problem for identifying specific bacteria species, and the detection and identification of the precise pathogen may not occur within the time needed ${ }^{3}$.

On a broader spectrum, bacteria biofilms contain various bacterial species. Current treatments for these biofilms involve the use of very high doses of drug containing detergents, with high levels of chlorine. These detergents are highly effective, but pathogenic drug resistance occurs over time ${ }^{1}$. The presence of biofilms in buildings has led to the classification of Sick building syndrome. Because detecting the bacteria or fungi is extremely difficult, there are limitations in treating these buildings. Currently, a new detergent called, biocide containing chlorine dioxide in a gaseous form, is being investigated to treat bacteria contamination ${ }^{4}$. Although, detergents such as this have been found to be highly successful in eradicating bacterial pathogens, one main problem still remains; the inability of identifying these pathogens in the time needed. In many cases once this treatment has been administered, a typical illness outbreak has already occurred. Additional emphasis has been focused towards the treatments of sick buildings. The growing number of sick buildings have been attributed to closed ventilation, which has led to high prevalence of bacterial biohazards ${ }^{5}$. For this reason, current studies are being performed to address this issue. The ideal treatment candidate should be an applicable single step identification method that can be used to cure these sick buildings.

Unfortunately, progress in developing methods for detection and neutralization of biohazards has been gradual. Currently, there are no topical assays that can be sprayed 
on a surface that can instantly detect and neutralize bacterial-like biohazards. Since time is a critical factor when dealing with hazardous life threatening substances, the inability to quickly determine the presence of pathogens has been a topic of interest since the events in the United States on September $11^{\text {th }}, 2001$. In the event of a biological attack, it is imperative that the pathogen be identified and neutralized both rapidly and easily.

The new detection and neutralization assay proposed could be administered to detect the presence of bacteria, specifically bacillus species. The neutralization section of this assay has incorporated liposomes, shown to be efficacious in various drug-delivery applications ${ }^{6}$. These liposomes contain targeting ligands that are highly specific to some bacterial species. As a result of incorporating these liposome's with a newly synthesized neutralization agent, $\mathrm{MgO}-\mathrm{Cl}_{2}$, we should expect to eradicate these bacteria pathogens quickly and effectively. In addition, the incorporation of fluorescent nanoparticles to these liposomes will enable the presence of bacteria to be detected prior to neutralization. This new assay aims to immediately detect and neutralize bacteria-like biohazards in any environment.

\subsection{Research Objectives and Specific Aims}

The primary aim of this research study was to develop a rapid one step assay to detect and neutralize bacteria-like biohazards using an Immunoliposome-nanoparticle complex. This complex has the potential to be administered on any surface and allow a quick notification and eradication of bacteria biohazards.

Neutralization of bacteria biohazards were enhanced by using liposome drug carriers encapsulated with a neutralization agent $\left(\mathrm{MgO}^{\left.-\mathrm{Cl}_{2}\right)}\right.$. Detection of bacteria was 
conducted by incorporating fluorescent nanoparticles to polyclonal antibodies. The combination of both the detection and neutralization portion of the assay, results in a one step detection and neutralization assay for bacteria-like biohazards. The aims of this study were optimized to enhance bacterial detection and decrease neutralization time in an in-vitro environment. The specific aims of the study were as follows:

1. Create $100 \mathrm{~nm}$ liposome size solution with high concentration of a neutralization agent $\mathrm{MgO}-\mathrm{Cl}_{2}$

2. Surface modification of the liposome in creating immunoliposomes attached to fluorescent $40 \mathrm{~nm}$ Streptavidin coated nanoparticles

3. Perform bacterial and Immunoliposome-nanoparticle complex interaction live/dead verification test.

\subsection{Significance of the Study}

This research study is significant because it will first; attempt to develop a new procedure to fluorescently detect the presence of bacteria biohazards. Secondly, create a novel drug-delivery technique to neutralize bacteria biohazards by using liposomes with a newly developed neutralization agent, $\mathrm{MgO}-\mathrm{Cl}_{2}$, and formulate various lipid formulations to determine an optimal release of the encapsulatant neutralization agent, $\mathrm{MgO}-\mathrm{Cl}_{2}$. Finally, develop a one step application that will detect and neutralize bacteria by using the Immunoliposome-nanoparticle complex that can be applicable on any surface to treat against bacteria cells and bacteria biofilms.

\subsection{BACKGROUND}

The events surrounding September $11^{\text {th }}$ heightened the awareness of the possible implications of using anthrax as a biological weapon. Since the 1900 s, very few cases of 
anthrax have been recorded in the United States. This increased in 2001, when twelve cases were reported, all of which, occurred in U.S. Government offices ${ }^{7}$. The sudden prevalence of hazardous infections heightened the publics' awareness of anthrax becoming the new weapon of choice.

Biological weapons have been a source of concern decades before September 11 . The United States experimented with biological weapons, including anthrax, from 1950 to $1960^{8}$. In 1970 , the world health organization published a report stating the possible devastating effects of an anthrax attack. In this report it was stated that if 50 kilograms of aerosolized Bacillus anthracis spores were disbursed from an airplane two kilometers upwind of a population center of 500,000 in ideal meteorological conditions, the spores would travel a distance greater than $50 \mathrm{~km}$ and kill approximately 95,000 people. The economic effect of such an attack would be approximately $\$ 26$ billion per 100,000 persons exposed ${ }^{8}$. These findings illustrate the gravity of the impact of an Anthrax attack. Anthrax, however, is not the only possible biological agent available to bioterrorists. There is a long list of other lethal bio-agents that can be used to cause similar catastrophic situations. For this reason, a new neutralization and detection method that is not species specific is in great demand.

\subsection{Bacteria}

\subsubsection{Bacillus anthracis}

Bacillus anthracis is a large, gram-positive aerobic spore forming bacteria that measures $1.0-1.5 \mu \mathrm{M}$ by 3.0 to $10.0 \mu \mathrm{M}$. Unlike other saprobic species (B. subtilis and B.cereus), Bacillus anthracis is non-motile ${ }^{7}$. It grows readily at $37^{\circ} \mathrm{C}$ and forms large 
colonies with irregular tapered outgrowths ${ }^{7}$. In-vitro, it grows in long chains, but in hosts it appears as a single organism or chains of two or three bacilli. These bacterial cells form mucoid colonies and exhibits prominent capsules when grown in nutrient agar ${ }^{7}$.

One of the characteristics of Bacillus anthracis is the ability to form a protective capsule when deprived of nutrients. This protective capsule is the primary indication of bacterial cell transformation into a spore. When the spores are formed, they can survive centuries in soil or in other organisms. Naturally, B. anthracis spores do not form in host tissues unless body fluids are exposed to ambient air. B. anthracis germinates when exposed to nutrient-rich environments, such as the tissue or blood of an animal or human host. Anthrax longevity, virulence and adaptability make it an ideal candidate as a bioterrorism agent.

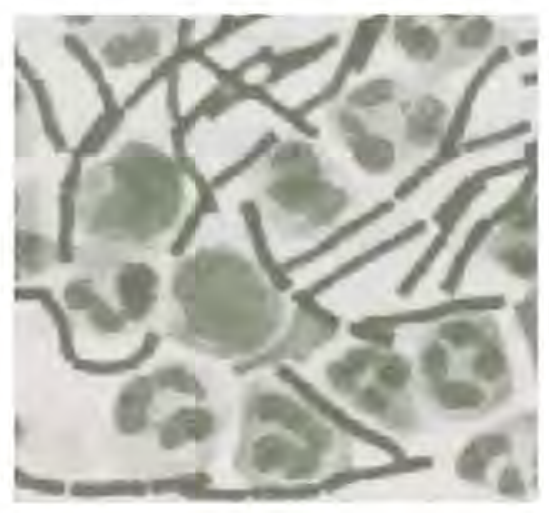

Figure 1. Bacillus anthracis ${ }^{9}$

\subsection{Epidemiology of Anthrax}

Understanding the mechanism by which anthrax operates is extremely important when attempting neutralization. Anthrax is subdivided into three clinical types: Cutaneous anthrax, Inhalation anthrax, and Gastrointestinal anthrax.

Cutaneous anthrax constitutes more than $95 \%$ of naturally occurring anthrax. It is 
commonly found in soil and usually infects individuals handling livestock in developing countries $^{7}$. Infection initially occurs when the anthrax spore enters a cut or abrasion in the skin. The following day after infection, a papule forms around the endospore, the papule vesicle develops further, and edema in that vesicle starts to increase. At this stage of the illness low fever occurs, and the vesicle begins to undergo necrosis. Next, the vesicle ruptures forming an ulcer covered by a black eschar, which falls off after two weeks leaving behind little scarring ${ }^{7}$. These symptoms appear within one to seven days following infection. This type of anthrax is treatable, but without antibiotic treatment for mortality is approximately 20 percent.

Inhalation anthrax, the most lethal type of anthrax, attacks into two phases. Once the anthrax spores are inhaled, they travel immediately through the upper airways to the lungs. The spore size is approximately $2 \mu \mathrm{m}$, making it possible for the spores to reach the alveolar ducts and alveoli within the lungs. Once entrance into the lungs, they trigger an immediate immune response. Macrophages engulf the spores, and then transport them to the lymph nodes. This occurs in phase 1 of the illness, usually within a time period of 24-48 hrs following infection. At this time, an overwhelming concentration of toxins begins production by the spores, within the lymph nodes, and enters the systemic circulation where edema, hemorrhage, necrosis, and septic shock occur; usually resulting in the death. This is the second phase of the illness that occurs between 2 to 6 days following infection ${ }^{8}$.

Gastrointestinal anthrax is a subcategory of the anthrax illness, occurring upon ingestion of meat products infected by spores. Usually, symptoms associated with this illness occur two to five days after contaminated food has been ingested ${ }^{7}$. The first 
symptom the patient may often experience is throat pain or difficulty swallowing. As the illness progresses, patients experience additional symptoms, such as sores in the mouth and throat, severe bloody diarrhea, and intestinal lesions ${ }^{7}$. Due to the similarity of symptoms in other illnesses, gastrointestinal anthrax has a very high mortality rate.

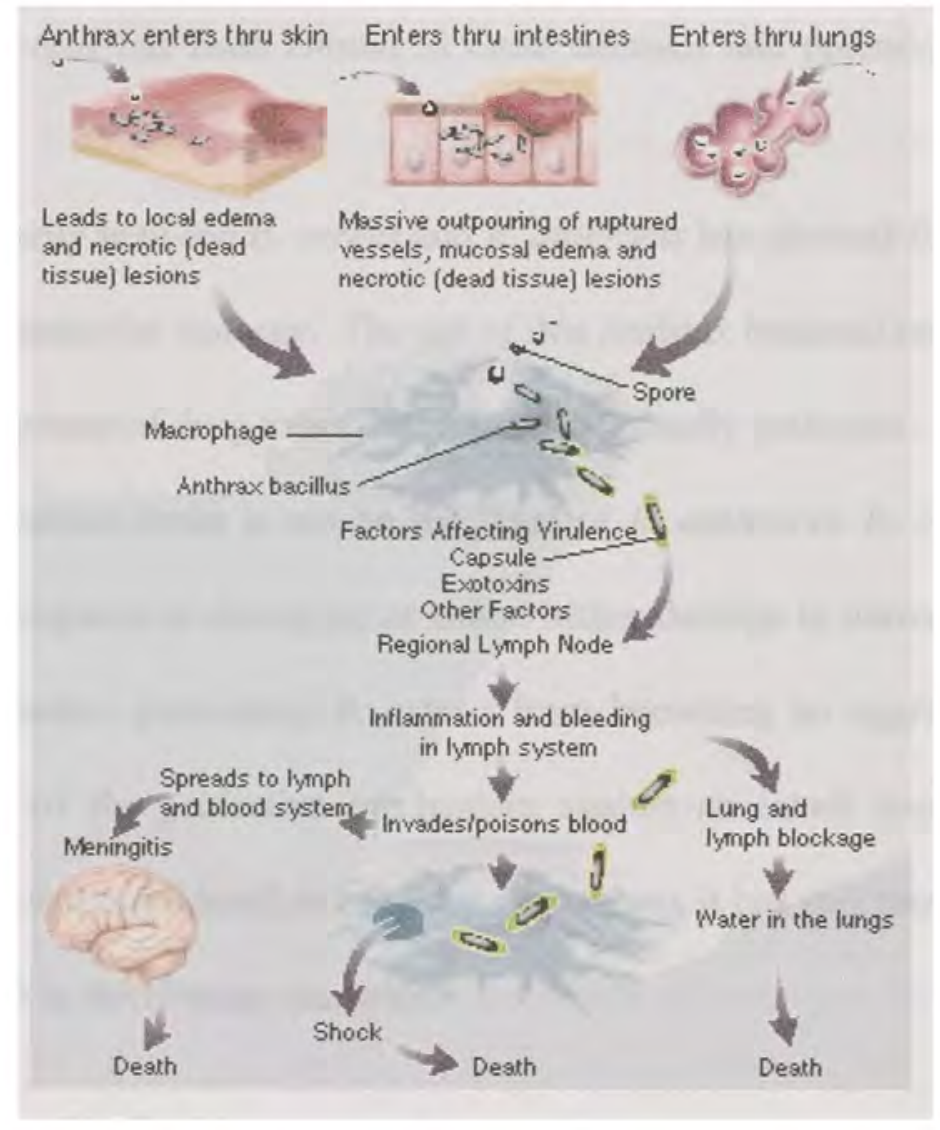

Figure 2. Pathways of the types of Anthrax ${ }^{10}$

\subsubsection{Bacillus Cereus}

Bacillus cereus is well defined as a rod shaped, gram positive spore forming bacteria, which is resistant to high temperatures ${ }^{11}$. These spores occur naturally in most foods, and have been linked to a wide range of illnesses ranging from blindness to food poisoning. The food poisoning illness have been subdivided into two specific types, an emetic illness or a diarrhoeal illness ${ }^{11}$. Emetic illness occurs 1-6 hours after ingestion of contaminated 
food containing pre-formed toxin, with symptoms of nausea and vomiting ${ }^{11}$. The diarrhoeal symptoms are attributed to the ingestion of vegetative organisms or spores. Subsequently multiplication and toxin production within the intestinal tract, result in abdominal pain, watery diarrhea and occasional nausea ${ }^{11}$. The intraocular infection associated with $B$. cereus has been known to cause necrosis and potentially blindness within 24-48 hours $^{12}$.

The genetic similarity between $B$. cereus and $B$. anthracis has allowed $B$. cereus to be used as an effective model for Anthrax. The use of this Anthrax bacterial model provides a platform for development of drug treatments against the deadly pathogen. Although the severity of Bacillus cereus strain is not on the level of B. anthracis, B. cereus is well armed with weapons capable of damaging or exacerbating damage to human and animal tissue. One of the factors preventing $B$. cereus from becoming an aggressive human pathogen is its lack of the protective mechanism against an intact immune system. Although $B$. cereus is not considered as hazardous as anthrax it has still been known as a serious health concern in developing countries.

\subsubsection{Bacillus Genus Similarities}

Within the genus of Bacillus, there are other bacteria that exhibit characteristics similar to those of Bacillus anthracis (B. anthracis); including Bacillus cereus (B. cereus), Bacillus thuringiensis (B. thuringiensis), and Bacillus subtilis (B. subtilis). It is speculated that $B$. cereus was the ancestral bacteria specie that underwent evolutionary mutations within the genetic material giving rise to other types of bacteria species, such as B. anthracis and B. thuringiensis ${ }^{13}$. The genetic characteristics of Bacillus 
thuringiensis and Bacillus cereus are almost indistinguishable, making them the closest bacterial relatives ${ }^{12}$. Moreover, the genetic or virulence factor of Bacillus thuringiensis can be transferred to $B$. cereus bacteria and inevitably transform $B$. cereus into $B$. thuringiensis. The only established difference between these two bacteria species is the presence of genes, found on plasmids, coding for insecticidal toxins.

B. cereus and B. anthracis are almost indistinguishable from one another. Close similarity of the genomes of $B$. anthracis strains to those of $B$. cereus and $B$. thuringiensis strains demonstrate that they originated from the same species. What distinguish these bacteria from one another are the genes carried on the plasmids, as well as the virulence factors found in $B$. anthracis. For example, the distinctive characteristics of $B$. anthracis such as sensitivity to $\beta$-lactam antibiotics, lack of motility, and hemolytic activity may be caused by a difference of a single gene found in $B$. cereus ${ }^{13}$. Also, PlcR, a transcriptional regulator of extracellular virulence factors in both B. cereus and B.thuringiensis, has been found mutated in B. anthracis strains ${ }^{13}$. The severity of this mutation can be partially responsible for some of the features often associated with $B$. anthracis, such as lack of hemolytic activity. Because of the biochemical and physiological similarities between them it is possible to use B. cereus and B. subtilis as a model for anthrax.

\subsubsection{Virulence factors of $B$. anthracis}

The virulence factors of Bacillus anthracis are produced in two specific plasmids; PX01 and PX02 ${ }^{14}$, each encoding for specialized proteins with a specific function. PX01 produces a protective antigen protein, an edema factor protein, and a lethal factor protein. The protective antigen protein protects the Anthrax spores, while the edema factor 
protein is responsible of causing edema in the infected area on the organism. The lethal factor protein functions by blocking receptors that would typically be recognized by the immune system. The combination of these proteins, referred to as the toxin complex, is responsible for patient death ${ }^{14}$. The second plasmid, PX02, encodes for proteins required in the biosynthesis of protective polypeptide capsules which function by inhibiting immune system responses ${ }^{14}$.

\subsection{Biofilms}

A Biofilm is a community of bacteria, fungi, yeasts, protozoa, and other microorganisms attached to a solid surface. Due to the susceptibility to surfaces that provide adequate nutrients for microorganisms to grow ${ }^{1}$, biofilms pose a great threat and are attributed to a variety of widespread illnesses.. Biofilms have been found in numerous areas, such as medical devices, and household common areas including sinks and PVC pipes ${ }^{15}$.

Otitis media, which is the most common acute ear infection in children, is one illness in the U.S associated with biofilms. Other diseases include bacterial endocarditis (infection of the inner surface of the heart and its valves), cystic fibrosis (a chronic disorder resulting in increased susceptibility to serious lung infections), and Legionnaire's disease (an acute respiratory infection resulting from the aspiration of clumps of Legionnella biofilms detached from air and water heating/cooling and distribution systems). The degree of severity of illnesses caused by biofilms, can be more critical then others depending on location. For example, in hospitals, biofilm-related infections can include the surfaces of catheters, medical implants, wound dressings, or other types 
of medical devices. In patients whose immune system has been comprised, biofilms can lead to life threatening consequences, due to the antibiotic resistance. Usual treatments for biofilm infections require a long-term dosage for eradication ${ }^{1}$.

Another sector greatly affected by Biofilms, are manufacturing industries, where billions of dollars in productivity and capital equipment are lost each year ${ }^{1}$. Its presence in pipes has been known to cause severe corrosion and water contamination.

Currently, in the prevention of biofilm formation, treatment for surface coating requires the use of cocktails of drugs. Vancomycin is a drug often used to treat infections that occur on medical catheters ${ }^{15}$, due to the frequent occurrence of methicillin-resistant coagulase-negative staphylocci, including S. epidermis ${ }^{1}$. The effectiveness of treatments such as this are compromised if biofilm formation occurs during drug treatments. Biofilms drug resistance is attributed to its changes in cell wall and surface structure. Therefore, non-specie specific treatments that can effectively eradicate biofilms quickly are in great demand.

\subsection{Sick Building Syndrome}

Sick building Syndrome (SBS) are classified as building that have been known to contribute to several health issues, including upper respiratory symptoms, headaches, fatigue, and rash which are usually associated with a particular building by there temporal pattern of occurrence and clustering among inhabitants or colleagues experienced everyday ${ }^{5}$. The prevalence of closed ventilation and aged buildings has increased the occurrence of illnesses classified as sick building syndrome. The severity of these 
illnesses range from common colds to more severe respiratory illness, all of which have been attributed to the closed air ventilation system within buildings that allow indoor air contaminants to build up ${ }^{16}$.

Since the 1970 s, closed ventilation systems have increased worldwide to decrease energy consumption. The effect of decreasing energy consumption has lead to high prevalence of illnesses and higher susceptibility of hazardous molds and bacteria ${ }^{16}$. The most common bacteria found in indoor environments include Bacillus, Pseudomonas, Staphylococcus, Micrococcus, Methylobacterium and Flavobacterium ${ }^{I}$. The widespread accumulation of bacteria within the human body has been the primary means of dispersing bacteria.

Many bacterial and fungal species are isolated in indoor air, due to there dependence on a nutrient source, water availability, relative humidity, and temperature ${ }^{17}$. Sources of micro-organisms in indoor air include: cooling towers, water damaged materials, high humidity in indoor areas, damp organic material and porous wet surfaces $^{18}$. The porous wet surfaces provide a favorable environment for biofilm formation ${ }^{1}$.

These biofilms, composed of populations or communities of microorganisms adhering to environmental surfaces, are found on essentially any environmental surface in which sufficient moisture is present. Their development is most rapid in flowing systems where adequate nutrients are available. Current treatments for sick buildings require the use of a chlorine detergent, but these detergents are being examined for there effectiveness. Therefore, new modalities are being pursued to cure these sick building. 


\subsection{Current methods of detecting anthrax}

Traditional detection methods requires the growth of single bacteria into bacterial colonies in different types of media, followed by a lengthy identification process involving morphological and biochemical tests ${ }^{19}$. All of these procedures often provide very accurate results, but suffer from poor specificity. Additionally, they often require complicated interpretation with complete analysis time, typically approaching $72 \mathrm{hrs,}$ making them unsuitable for online rapid analysis ${ }^{3}$. Recent efforts have been directed towards developing approaches suitable for the entrapment or capture of bacteria, based on a combination of physical characteristics of the capturing medium and the affinity of the bacteria for a variety of chemical functionalities. While rapid, these methods are nonspecific, requiring completion of multi-step analysis for identification and quantification ${ }^{3}$.

Most commonly available assays for the detection of spores or bacteria involve the use of enzyme-linked immunosorbent assays (ELISA). This assay functions by using antibodies or antigens coupled to an enzyme that possesses a high turnover number ${ }^{10,20}$. ELISAs can provide a useful measurement of antigen or antibody concentration by demonstrating high specificity and reproducibility. A drawback of this method is it is usually a lengthy analysis process that is not suitable for real-time analysis.

A large amount of efforts have been made recently to decrease analysis time and improve sensitivity and selectivity through the application, modification, or combination of various techniques. Currently, Polymerase Chain Reaction (PCR) and fluorescent antibody staining are the two main detection methods utilized to detect $B$. anthracis. PCR is commonly used to replicate the genetic information to identify pathogens. The 
problems with both PCR and Fluorescent antibody testing is that they require culturing samples taken from the patient before it can be identified, this typically takes $24-48 \mathrm{hrs}^{2}$. After the sample is grown, a standard PCR test is performed. PCR, however, is not very sensitive to anthrax. Once the suspected stain is identified more vigorous testing is performed to positively identify anthrax. Other drawbacks include difficult sample preparation, long analysis time, the need for trained personnel, high reagent costs, potential contamination, false positives, and poor adaptability to multiplexing ${ }^{3}$.

\subsection{Current treatment of anthrax}

Antibiotics are the current treatment used to fight anthrax infections. The typical antibiotic treatments that are Center for Disease Control (CDC) approved include ciprofloxacin, doxycycline, penicillin, and multiple antibiotics ${ }^{21}$. In the case of inhalation anthrax or systemic involvement, the CDC recommends the use of multiple antibiotics.

One main issue in the actual treatment of anthrax is that the bacterium needs to be identified before treatment can be administered. Currently, positive identification of $B$. anthracis is a lengthy process, which can take up $48 \mathrm{hrs,} \mathrm{and} \mathrm{the} \mathrm{only} \mathrm{facilities} \mathrm{capable} \mathrm{of}$ detecting anthrax are the CDC laboratories. Delays in identification of anthrax are due to similarities between $B$. anthracis and B. cereus. Hence, the mortality rate of 99 percent associated with inhalation anthrax is mainly due to late identification and failure to administer treatment during the early phase of infection.

\subsection{New neutralization agent for Bacteria strains}

Nanomaterials are considered advanced materials that can be used for the decontamination of chemical and biological warfare agents. Nano-size metal oxides have 
been shown to be reactive absorbents of chemical and biological warfare agents ${ }^{22}$. Nanosize Magnesium Oxide (MgO), Calcium Oxide $(\mathrm{CaO})$, and Zinc Oxide $(\mathrm{ZnO})$ have been shown to possess strong antibacterial properties that can be used to absorb biohazardous materials ${ }^{23}$. Among these metallic oxides, $\mathrm{MgO}$ and $\mathrm{CaO}$ act upon both Gram-positive and Gram-negative bacteria in a bactericidal manner. On the other hand, $\mathrm{ZnO}$ displayed a stronger antibacterial activity against gram-negative bacteria ${ }^{24}$. It has also been found that the addition of $\mathrm{Cl}_{2}$ to $\mathrm{MgO}$ forms a new molecule called Magnesium oxide chloride $\left(\mathrm{MgO}-\mathrm{Cl}_{2}\right)$, which is highly reactive and absorbs more bacterial agents. It exhibits high activity against bacteria, spores, and viruses ${ }^{23}$.

\subsubsection{Properties of $\mathrm{MgO} / \mathrm{MgO}-\mathrm{Cl}_{2}$}

$\mathrm{MgO}$ nanoparticles have a large surface area with an abundance of unusual crystal morphologies, posing numerous edges/corners and other reactive sites ${ }^{25}$. These porous nanoparticles have the ability to adsorb and retain significant amounts of elemental chlorine and bromide for long periods of time ${ }^{25}$. Moreover, these $\mathrm{MgO}-\mathrm{Cl}_{2}$ nanoparticles have been shown to be quite active biocides, more than free $\mathrm{Cl}_{2}$ or $\mathrm{MgO}$ alone ${ }^{25}$.

$\mathrm{MgO}-\mathrm{Cl}_{2}$, positively charged particles, reacts with negatively charged bacteria and spores. The opposite charge attraction between bacteria and nanoparticle reveals one reason for the tight binding of nanoparticles to the bacteria surface. Due to the strength of both nanoparticle bacteria binding and neutralization properties of the nanoparticles, studies have shown significant cell envelope damage after 20 minutes of nanoparticle and E. coli bacteria incubation. Moreover, when this treatment was applied to B. subtilis spores similar destructive results were found. When images were captured after MgO- 
$\mathrm{Cl}_{2}$ were incubated with $B$. subtilis spores, visible "holes" in the cell wall were seen ${ }^{25}$. Both the damage to the cell envelope and holes in the spores indicated bacteria death ${ }^{25}$. For this reason, $\mathrm{MgO}-\mathrm{Cl}_{2}$ has shown promising ability to neutralize more bacterial agents in less time.

In addition, it has been found that smaller $\mathrm{MgO}$ nanoparticles are more efficient in neutralizing bacteria ${ }^{26}$. The distribution and the interaction among these particles result in a crystalline cluster, which cover the bacteria cells. This results in bringing the halogen reagent to an active form in high concentration within the proximity of the cell ${ }^{25}$. Thus, smaller $\mathrm{MgO}-\mathrm{Cl}_{2}$ nanoparticles can eradicate the bacteria faster and more efficiently.

\subsection{Liposomal Technology}

The mechanics of liposome drug-delivery systems can be modified to meet different needs. The drug concentration can vary among the different type of liposomes. Liposomes can be subdivided into three specific categories as follows:

1. Multilamellar vesicles

2. Small Unilamellar Vesicles

3. Large Unilamellar Vesicles

The differences between the types of liposome are due to the different processes used to create them. Each type of liposome is completely dependent on its drug delivery application. 
There are many advantages of using liposomes in drug delivery. One advantage is the liposomes ability to carry high concentrations of drug relative to their size. Another advantage of liposomes is their ability to be modified with tracers and/or antibodies to assist in reaching their target. The surface of liposomes can be modified through the attachment of protein, peptides, nanoparticles, and antibodies via a PEG linker chain ${ }^{27}$. It has been found that functionalization on the PEG group creates steric hindrance with the antibodies, thereby interfering with target site recognition ${ }^{28}$. Therefore, modifications via co-enzymes attached to PEG-liposomes are currently being used to prevent the steric hindrance and increase the possibility of liposomes to bind to their target site.

\subsection{Liposome Composition}

Liposomes are composed of hydrophobic chains and hydrophilic head groups forming a lipid bilayer. The polar head groups are oriented to the solution and within the inner cavity $^{29}$. The functionalized polar head groups are used to reduce liposome aggregation, and the hydrophobic regions are used to modify the properties of the liposome ${ }^{30}$. The phospholipid concentration can vary to achieve positively or negatively charged liposomes depending on which of the numerous advantages it is needed for in drug delivery. The addition of Cholesterol within the liposome membrane is often used to reduce membrane permeability to the encapsulated materials, creating a phospholipids/cholesterol ratio to mimic the makeup of a cell membrane. Cholesterol diverse function in membrane stability plays a vital role in the release of the encapsulated material. Therefore, the interaction between lipid membranes and biomolecules can be measured using liposome drug delivery. 


\subsubsection{Types of Processes to Create liposomes}

The three categories of liposomes are determined by the experimental procedure used to create them. Large Multilamellar Vesicles (LMV) are formed when films sheets are hydrated, and the films detach during agitation and self-close ${ }^{31}$. The size distribution of the LMV sample is around several microns ${ }^{32}$. The LMV size distribution is attributed to the rehydration of the lipid sheets, and the self-closure of the liposome vesicles.

When these LMVs are probe sonicated for an hour it results in the formation of Small Unilamellar Vesicles (SUV). The size range of the SUV liposomes range with diameters less than $40 \mathrm{~nm}^{32}$. The SUV have been shown to attain a smaller aqueous cavity within the lipid bilayer. These SUV have the ability of being further processed to create large unilamellar vesicles.

The SUV vesicles can be circulated through specific pore size filter membranes to create size specific Large Unilamellar Vesicles. These Large Unilamellar Vesicles (LUV) are the last type of liposomes that can be created after SUV. These LUV liposomes are created by an extrusion process, by which LMV solution is circulated within an extruder apparatus assembled with a size defining filter membrane. These filter membranes can be purchased with various pore size determining on the specific liposome size desired.

These LUV liposomes have a large aqueous cavity that provides high drug encapsulation. For this specific reason LUV has been favorable for a variety of different drug delivery procedures. The specific qualities of these liposomes are the ability for them to carry a high drug to lipid concentration within the aqueous cavity. A detailed visual liposome pathway is shown below. 


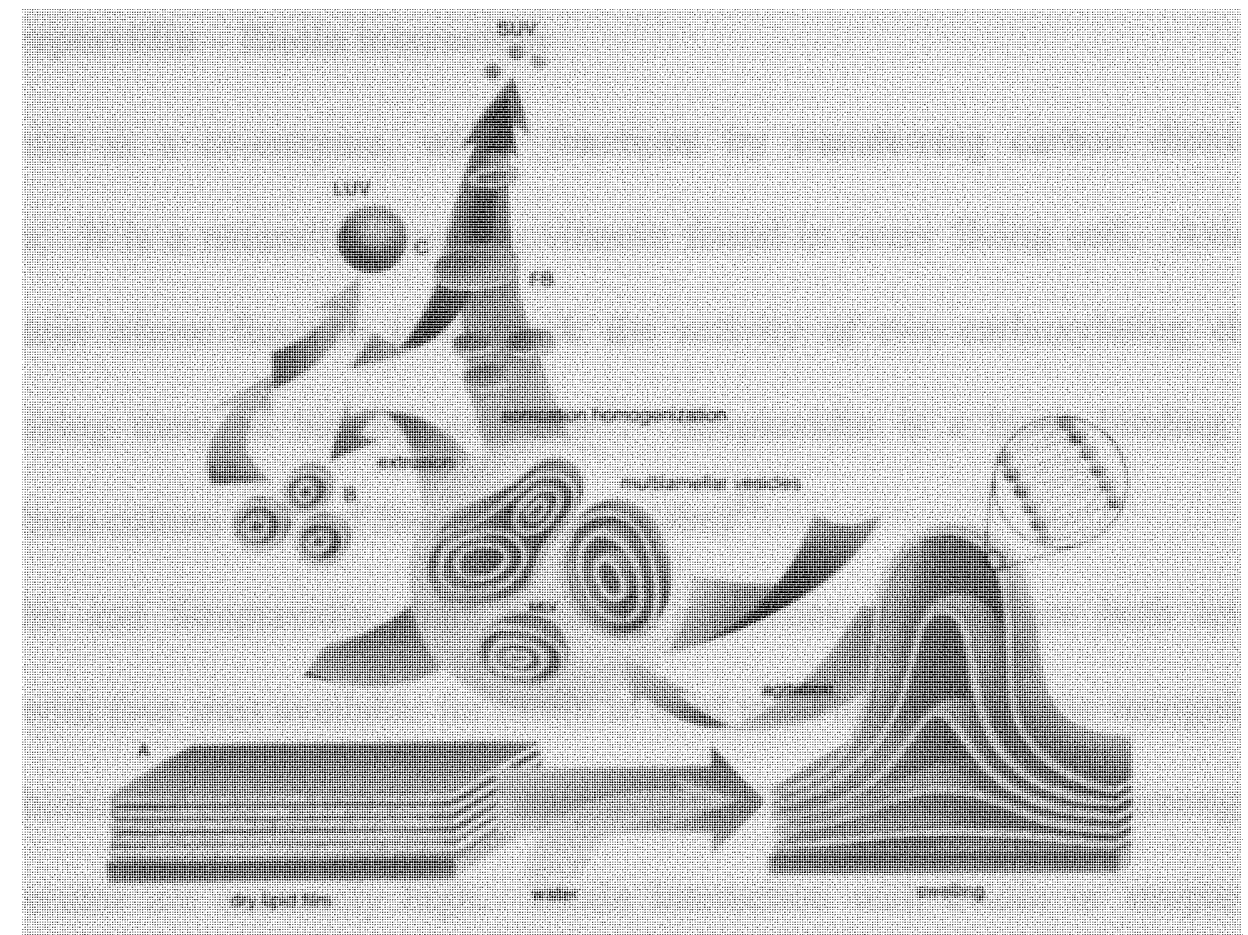

Figure 3. Liposome Pathway ${ }^{31}$

\subsubsection{Trehalose Lycoprotectant}

Trehalose is a disaccharide molecule that serves as lycoprotectant during freezedrying. Its lycoprotectant properties can be characterized into two processes; Glass formation and Interaction with phospholipids. During sugar glass formation an amorphous matrix is formed between liposome vesicles ${ }^{32}$.

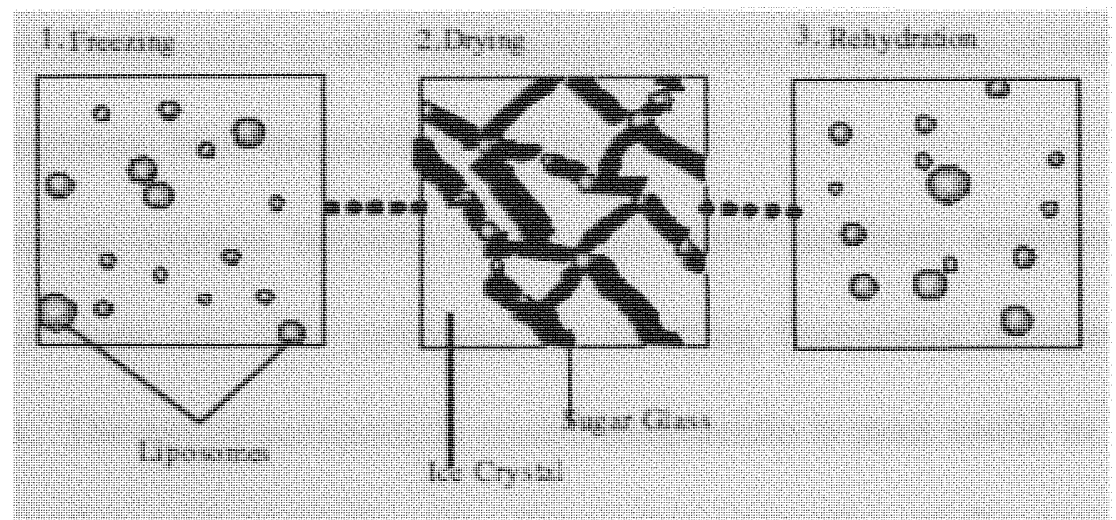

Figure 4. Function of Trehalose with liposomes ${ }^{31}$ 


\subsection{Streptavidin - Biotin interaction}

Biotin is a co-enzyme, which functions by transferring carbon dioxide into substrates. It is a naturally occurring vitamin found in every living cell. Avidin is a glycoprotein whose function is to block the activity of two carboxylating enzymes, characterizing them as biotinyl enzymes ${ }^{33}$. Streptavidin is a biotin-binding protein isolated from culture broth of Streptomyces auidinii ${ }^{33}$.

Avidin and Streptavidin share common properties, as they are both tetrameric proteins with four sites available for biotin to bind to. The binding ratio recognized is 1 mole of biotin for every $14,000 \mathrm{~g}$ of streptavidin. Thus, the interactions amongst these two molecules are extremely high. Biotin interaction with avidin or streptavidin is among the strongest non-covalent affinities known, exhibiting a dissociation constant of about $1.3 \times 10^{-15} 34$

Bioconjugation technique assays favor streptavidin protein, since an overcoming unspecific binding that occurs with avidin. This is owed to avidin's basic isoelectric $\mathrm{pH}$ (pl) of 5-6 compared to streptavidin's $\mathrm{pI}$ of $10^{34}$. The Differences in $\mathrm{pI}$ are due to the variations in the amino acid sequence in the proteins. Those differences do not affect the interactions with biotin, which is still very strong. Even in the presence of buffers and under acidic conditions, bond dissociation does not occur.

The biochemical reaction between avidin and biotin has been monitored using fluorescent microscopy and flow cytometry by attaching fluorescent nanoparticles to these molecules. The use of nanoparticle coated streptavidin is most useful in imaging, due to its interaction with biotin $^{35}$. The fluorescent properties of the nanoparticles interaction with bacteria are easily identified through flow cytometry ${ }^{36}$. 


\subsection{Antibody}

An immunoresponse is triggered by the production of antibodies called immunoglobulins. These antibodies all have the same basic similar structure of four polypeptide chains: two light chains and two heavy chains joined together by disulfide bonds, with an end result $\mathrm{Y}$ shape. Within the structure of the antibodies there are specific binding sites where it binds to an antigen specific epitope ${ }^{37}$.

Antibodies are classified under two categories, depending on epitope recognition ${ }^{37}$. These two types of categories are Monoclonal and Polyclonal. The monoclonal antibodies are highly specific; only bind to one antigen site. On the other hand, the polyclonal antibodies can bind to many different sites on the antigen ${ }^{38}$. The use of different types of antibodies depends solely on the application.

\section{$2.11 \mathrm{MgO}-\mathrm{Cl}_{2}$ Verification Testing}

\subsubsection{Presence of Chlorine in $\mathrm{MgO}-\mathrm{Cl}_{2}$ nanoparticles}

Silver nitrate $\left(\mathrm{AgNO}_{3}\right)$ is a chemical used to test the presence of halide ions. Since $\mathrm{MgO}-\mathrm{Cl}_{2}$ has chloride ions, the reaction with Silver Nitrate should result in a color change of a white precipitate. If several drops of $0.1 \mathrm{M} \mathrm{AgNO}_{3}$ is added into an unknown solution, the solution will immediately produce a white precipitate in the presence of chloride, bromide, and iodide. A reference list of the reaction of $\mathrm{AgNO}_{3}$ with halides in a solution is noted in the table below. Note, a color change is a result of the exact halide presence (refer to Table 1.) 


\begin{tabular}{|l|l|}
\hline Halide Ion & Observation with Silver Nitrate \\
\hline Chloride & White precipitate forms \\
\hline Bromide & Cream precipitate forms \\
\hline Iodide & Yellow precipitate forms \\
\hline
\end{tabular}

Table 1. Silver Nitrate Reactants and Color Observation

\subsection{Liposome and Antibody Purification}

\subsubsection{Size Exclusion Chromatography}

Size exclusion chromatography (SEC) is a widely used technique for separating impurities in samples. SEC is composed of porous particles (beads) that separate molecules based on their particle sizes and molecular weight. It is often used to separate biological molecules that are smaller than the pore size, that can enter the beads, while larger molecules are not retained in the beads and are eluted ${ }^{39}$. A variety of sizes of the sephadex beads are used for different purifications based on molecular weight, so that the unwanted material will be retained within the sephadex beads and the purified final sample is eluted.

\subsection{Antibody and Streptavidin Nanoparticle Synthesis Yield}

\subsubsection{Protein Concentration using Spectrophotometer}

The Tecan Genios Spectrophotometer measures the absorbance of the proteins in within a sample, in order to determine the concentration in the solution. Spectrophotometers functions by measuring the light absorbed or transmitted by 
molecules in solution using the beer-Lambert law. When a specific light wavelength is transmitted through the solution, the light energy absorbed [absorbance (A)] is proportional to:

1. The ability of the solute molecules to absorb the wavelength

2. The concentration of the solute

3. The length of the light path from its source through the solution to the phototube where the percentage of light energy transmitted or absorbed is measured.

The spectrophotometer absorbance readings are used to determine the concentration of protein in an unknown sample. By implementing the experimental reading within an equation you can theoretically determine the protein concentration $(\mathrm{mg} / \mathrm{ml})$ within a solution. The equation is as the follows:

$$
\text { Concentration }(\mathrm{mg} / \mathrm{ml})=(1.55 \times \mathrm{A} 280)-0.76 \times \mathrm{A} 260)^{40}
$$

\subsubsection{BCA Assay}

Bicinchoninic acid protein assay (BCA) has become the most popular colorimetric detection and quantitation assay for protein $^{41}$. This assay combines the well known reduction of $\mathrm{Cu}^{2+}$ to $\mathrm{Cu}^{1+}$ in the presence of protein in an alkaline medium, producing a highly selective colorimetric deter ion of the cuprous action by bicinchoninic acid $^{42}$. The protein is reacted with copper through a process of chelation, resulting in a blue colored solution. The biuret reaction occurs with the chelated protein giving a blue and violet color solution that absorbs light at $540 \mathrm{~nm}$. Since the working range for the biuret assay is from 5 to $160 \mathrm{mg} / \mathrm{ml}$, the biuret assay is used in clinical laboratories for the quantitation of total protein in serum ${ }^{42}$. 


\subsection{Bacteria and Immunoliposome-nanoparticle Complex Testing}

\subsubsection{Flow Cytometry}

Flow cytometry is a technology that measures and analyzes multiple physical characteristics of a single particle as they flow in a fluid stream through a beam of light. The optical properties measure the particle size and relative fluorescence intensity. In the flow cytometer, particles are carried to the laser intercept in a fluid stream, where the particles pass through a laser intercept, scattering light. When fluorescent particles are present they are fluoresce. Both the scatter and the fluorescent light are collected and are transformed into data displays ${ }^{43}$.

\subsubsection{Bacterial Cell Viability}

Bacteria cell viability can be determined by various techniques such as dilution method and fluorescence. Fluorescence testing is currently the fast method to determine if a bacteria culture is viable. These assays vary by the binding site of these fluorescent probes, such as DNA, cell membrane, and cellular respiration. The high specificity of fluorescence detection has made it a desirable assay for determining quantitative interactions among dyes, as well as displaying other interaction not possible by traditional methods ${ }^{44}$.

\subsubsection{Ethidium homodimer-1}

Among the fluorescent dyes, Ethidium homodimer-1 is used to identify dead bacteria cells. This dyes functions by binding to the DNA of bacteria cells that have been comprised emitting a deep read color. Since this dye is impermeable, the fluorescent 
signal is only achieved upon DNA binding. For this reason, Ethidium homodimer-1 is widely used to obtain a quantitative bacteria cell count of membrane-comprised cells by using Flow cytometry or Fluorescent Microscopy ${ }^{45}$.

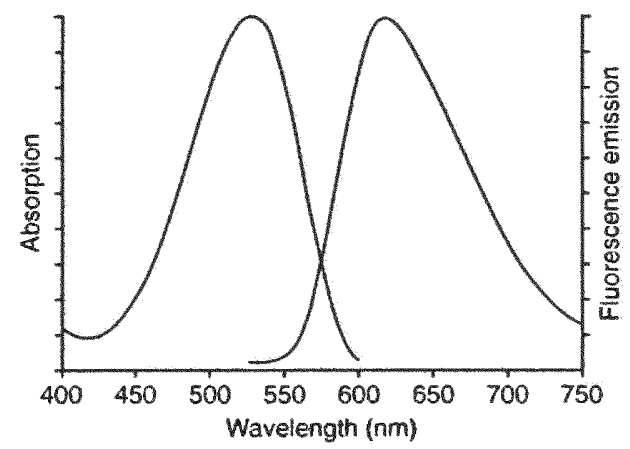

Figure 5. Ethidium homodimer-1 fluorescent spectrum ${ }^{45}$

\subsubsection{Syto-9}

Syto-9 is a green fluorescent dye that binds to cells with both intact membrane and disrupted membranes to determine if the bacteria cells are alive. The fluorescent property of Syto-9 is observed at excitation/emission $480 / 500 \mathrm{~nm}$ that emits a green fluorescence.

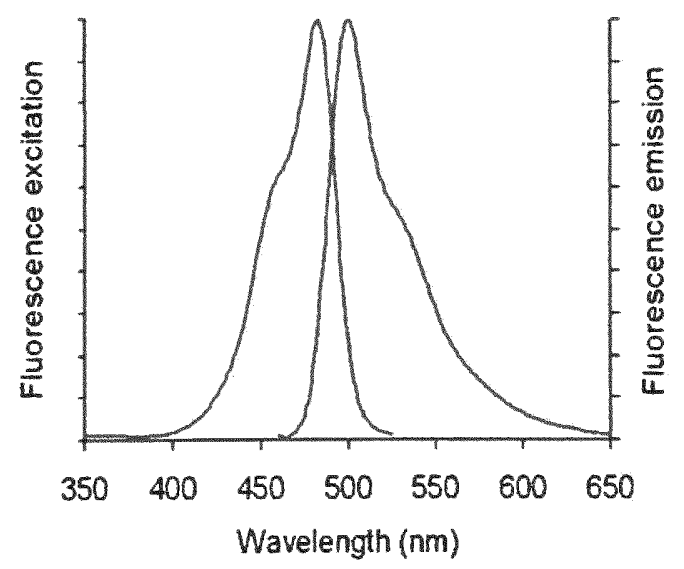

Figure 6. Syto-9 Fluorescent spectrum ${ }^{45}$ 


\subsection{MATERIALS AND METHODS}

\subsection{Materials}

\subsubsection{Neutralization Agent}

The neutralization agent, $\mathrm{MgO}-\mathrm{Cl}_{2}$ nanoparticles, were synthesized and analyzed by Nanomat Inc. The product information attained from Nanomat Inc, stated that these nanoparticles were approximately $5 \mathrm{~nm}$ in diameter and contained $4-5 \%$ Chlorine per weight.

\subsubsection{Liposomes}

The Liposome lipid materials were purchased from three companies, Northern Lipids, Avanti Polar Lipids, and Sigma-Aldrich. The first functional lipid, Biotin-DSPE was purchased from Northern Lipids, and the second functional lipid, Biotin cappedDSPE-PEG2000 and Cholesterol, were purchased from Avanti Polar Lipids. The Phosphatidylcholine (PC) lipid was purchased from Sigma-Aldrich. All these lipids were dissolved in ACS graded reagent Chloroform purchased from Fisher Scientific.

The lipid films were all reconstituted in HEPES buffers purchased from Gibco, and were circulated through a Mini extruder Apparatus with $100 \mathrm{~nm}$ filter supports and membranes purchased from Avanti polar lipids to create liposomes. Liposome purification was performed with Sephadex G-50 purchased from Sigma Aldrich.

\subsubsection{Antibody-Streptavidin Coated Nanoparticle complex}

The polyclonal antibody for $B$. anthracis was purchased from biodesign, and was chemically modified with a crosslinker, 2-Iminothiolane (Traut's Reagent) purchased 
from Sigma. After modification, the intermediate product was purified using Sephadex G-25 purchased from Amersham Biosciences.

The $40 \mathrm{~nm}$ streptavidin coated fluorescent nanoparticles were purchased from Fluka, and chemically modified with a specific crosslinker, m-Maleimidobenzoyl-Nhydroxysuccimide ester (MBS). After nanoparticle site modification, the sample was purified with a centriprep 30-ultrafiltration device purchased from Millipore.

\subsubsection{Bacteria}

All three bacteria species, B. cereus, B. subtilis, and B. thuringiensis, were purchased from ATCC. All three bacteria cultures were inoculated in Luria Broth growth media purchased from Sigma Aldrich.

Bacteria biofilm formations were created using two specific plates, Polyvinylchloride (PVC) and MBEC plate. The polyvinylchloride plates used in the Biofilm Assay I was purchased from Becton Dickinson and the second biofilm assay was performed using an MBEC device purchased from MBEC.

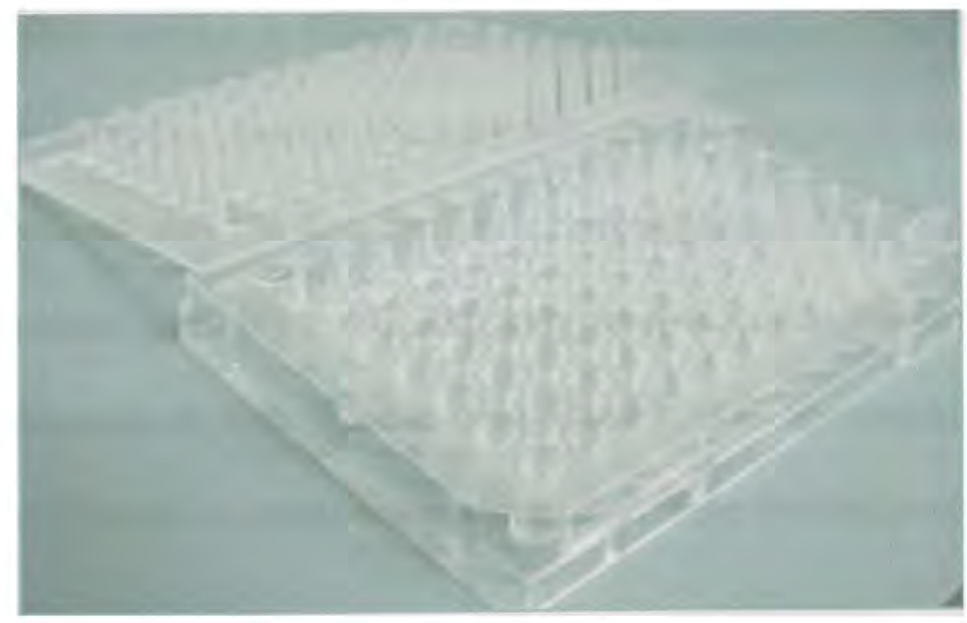

Figure 7. MBEC Biofilm 
All bacteria testing were performed with fluorescent viability dyes and analyzed with fluorescent Microscopy and Flow cytometry, donated by Christopher Sinigalliano from the Environmental Research Center. The fluorescent viability dyes was Ethidium homodimer-1 and Syto-9 that were initially purchased from molecular probes.

\subsubsection{Equipment}

Three specific types of equipment were used for liposome formation, these included: the Buchii Rotovap column distillation, used for lipid film formation, the Labonco Freeze Dry Chamber lyophilizer, used to remove excess solvent from the lipid film, and the Mini extruder apparatus, used to create liposomes. The size distributions of these liposomes were verified through SEM imaging analysis performed by the Nanofabrication facility.

Antibody and Streptavidin synthesis verification testing were performed by two specific techniques, Protein absorbance and BCA assay. The Tecan Genios was used to determine protein concentration by measuring the absorbance of the antibody and streptavidin intermediate samples at $260 \mathrm{~nm}$ and $280 \mathrm{~nm}$ wavelengths. The final product, streptavidin-antibody complex, protein recovery was determined with the $\mathrm{BCA}$ assay purchased from Pierce and analyzed with the Tecan Spectrophotometer.

All bacteria cultures were grown in a Shaking Incubator, and the bacteria culture concentration was determined with the use of a Biorad 3000 Spectrophotometer. A quantitative live/dead fluorescent assay was performed with the fresh bacteria culture and analyzed by flow cytometry. 


\subsection{METHODS}

\subsection{Liposomal Encapsulation}

Specific Aim I of this project consisted of creating $100 \mathrm{~nm}$ liposomes encapsulated with $\mathrm{MgO}-\mathrm{Cl}_{2}$ nanoparticles.

\subsubsection{Experimental preparation}

\subsubsection{Determining concentration of liposome encapsulant, $\mathrm{MgO}-\mathrm{Cl}_{2}$}

Before liposome formation, the maximum concentration of $\mathrm{MgO}-\mathrm{Cl}_{2}$ nanoparticles that could be circulated within the mini extruder had to be determined. Since the mini extruder apparatus is a manually driven device, high concentrations of $\mathrm{MgO}-\mathrm{Cl}_{2}$ nanoparticles result in high resistance and ruptured membranes. Therefore, one experimental aim was to determine, the nominal concentration of $\mathrm{MgO}-\mathrm{Cl}_{2}$ that could be circulated within the mini extruder apparatus, while still maintaining membrane integrity. Therefore, various $\mathrm{MgO}-\mathrm{Cl}_{2}$ concentrations were prepared by serial dilutions to assist in determining the optimal concentration that could be circulated within the mini extruder apparatus. First, five test tubes were labeled in numerical order, and were filled with $1 \mathrm{ml}$ of HEPES buffer. Secondly, a $5 \mathrm{mg} / \mathrm{ml}$ stock solution of $\mathrm{MgO}-\mathrm{Cl}_{2}$ was created and dispensed into test tube 1 and test tube 2. A 1:2 dilution was performed on the remaining test tubes until the last test tube had a theoretical concentration of 0.185 $\mathrm{mg} / \mathrm{ml}$. Reference for theoretical concentration corresponding to each sample are shown in Table 2. 


\begin{tabular}{|l|l|}
\hline $\begin{array}{l}\text { Test } \\
\text { tube no. }\end{array}$ & $\begin{array}{l}\text { Concentration } \\
(\mathrm{mg} / \mathrm{ml})\end{array}$ \\
\hline 1 & 5 \\
\hline 2 & 2.5 \\
\hline 3 & 1.25 \\
\hline 4 & 0.75 \\
\hline 5 & 0.37 \\
\hline 6 & 0.185 \\
\hline
\end{tabular}

Table 2. Dilutions of $\mathrm{MgO}-\mathrm{Cl}_{2}$ in HEPES buffer

\subsubsection{Testing the Dilutions of $\mathrm{MgO}-\mathrm{Cl}_{2}$ with $\mathrm{Mini}$ extruder}

The mini extruder apparatus (Figure 8) was prepared for $\mathrm{MgO}-\mathrm{Cl}_{2}$ serial dilution testing, by placing two filter supports on each membrane holder, and a $100 \mathrm{~nm}$ polycarbonate membrane sandwiched between both membranes holders, as shown on Figure 8 . Next, the joined membrane holders were set into the corresponding metal holders and placed on a hotplate. The hotplate temperature was adjusted to achieve a steady temperature of $62^{\circ} \mathrm{C}$. Once achieved, each serial diluted sample was vortexed and sonicated, until all the $\mathrm{MgO}-\mathrm{Cl}_{2}$ nanoparticles were suspended in the solvent creating a homogeneous solution. Next, $1 \mathrm{ml}$ of the homogeneous solution was extracted using an extruder syringe and set on one side of the Mini extruder apparatus. Next, the second extruder syringe was placed on opposite side of the extruder, as shown on Figure 9. Then, the serial diluted sample was circulated through the membrane, alternating syringes for a total of 10 times, while documenting all experimental observations. 
Each extrusion procedure performed on the serial diluted $\mathrm{MgO}-\mathrm{Cl}_{2}$ samples were examined for two experimental parameters; such as, resistance and product buildup on the filter supports. These two parameters were documented for each sample, and the experimental results were observed at the end of the overall experiments. The results were carefully examined, and it was concluded that the maximum concentration of $\mathrm{MgO}-$ $\mathrm{Cl}_{2}$ that could be circulated within the extruder was $0.37 \mathrm{mg} / \mathrm{ml}$.

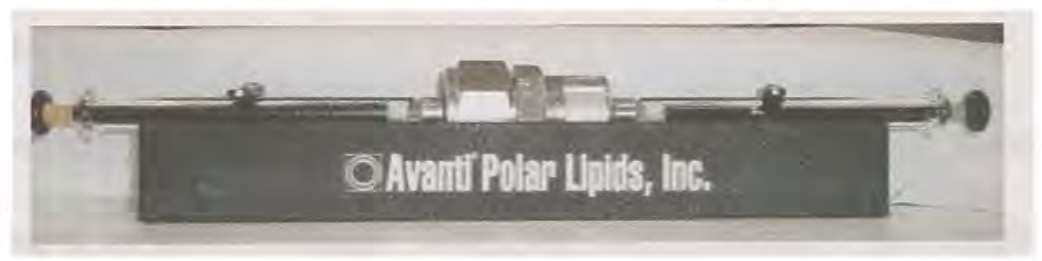

Figure 8. Mini extruder apparatus

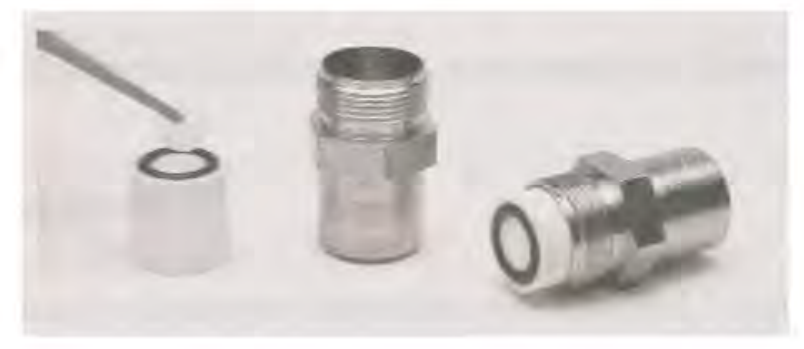

Figure 9. Assembly of filters and membranes into extruder

\subsubsection{Liposome Column Preparation}

Liposomes purification was performed with Size Exclusion Chromatography (SEC), specifically using Sephadex G-50. This type of sephadex was chosen for its bead pore size $(20-80 \mu \mathrm{m})$, and its ability to retain free-floating low molecular weight compounds, and elute pure liposomes. These Sephadex G-50 columns were prepared by swelling the sephadex beads in HEPES buffer, and then packing them into $5 \mathrm{ml}$ syringes, 
creating sephadex mini columns. The exact buffer and bead swelling information used followed the protocol where 1 gram of Sephadex G-50 required 9-11 $\mathrm{ml}$ of buffer to swell the sephadex beads. So for our experiments, $44 \mathrm{ml}$ of HEPES buffer and $4 \mathrm{~g}$ of sephadex were placed in a $50 \mathrm{ml}$ conical tube, and were allowed to swell for three hours at room temperature. As the sephadex beads swelled, the glass wool packing agent was soaked in HEPES buffer. Then, a small piece of soaked glass wool was packed tightly inside a $5 \mathrm{ml}$ plastic syringe.

Once the Sephadex had swelled, the sephadex conical tube was placed in a hot water bath for several minutes to degas. Then, the warm sephadex was carefully poured into the mini column until the bead height reached the $3.5 \mathrm{ml}$ mark on the syringe. Next, each mini column was carefully examined for the presence of air bubbles. Once no air bubbles were visible, the Sephadex G-50 columns were ready for liposome purification.

\subsubsection{Lipid Film formulations}

The lipid composition for liposome formation was attained followed from previous experiments from Creation of a novel, Magnetic Drug Delivery Complex, Danny Gonzalez. Specifically for this thesis, one main lipid formulations were created. Then two additional lipid formulations were created following the main formulation except with cholesterol concentrations variation. These additional lipid formulations were created to assist in determining if the actual concentration of cholesterol within the lipid film had a direct affect in the release of the encapsulant agent, $\mathrm{MgO}-\mathrm{Cl}_{2}$, in neutralizing bacteria. The following formulations were: 
1. Biotin-DSPE-PEG2000, Phosphatidylcholine, Cholesterol (Main Formulation) (1:9:5 Mole Ratio).

a. Biotin-DSPE-PEG2000, Phosphatidylcholine, Cholesterol, (1:9:9.9 Mole Ratio)

b. Biotin DSPE-PEG2000, Phosphatidylcholine (1:9 Mole Ratio)

An additional lipid formulation composed of a different Biotin linker was created to determine if the Biotin linker composition had an affect in bacteria detection. The formulation was the following:

2. Biotin-DSPE, DSPE-PEG2000, Phosphatidylcholine, Cholesterol $(1: .5,5,9)$.

\subsubsection{Lipid Film}

All the lipid films were created in chloroform pre-treated $50 \mathrm{ml}$ air free round bottom flasks. Two types of lipid film formulations were created, these included:

1. Biotin-Capped DSPE-PEG2000, Phosphatidylcholine, and Cholesterol (7.5 mg, $46 \mathrm{mg}, 13 \mathrm{mg}$ )

2. Biotin-DSPE-PEG2000, Phosphatidylcholine, Cholesterol, (7.5 mg, $46 \mathrm{mg}, 26 \mathrm{mg}$ )

3. Biotin DSPE-PEG2000, Phosphatidylcholine (7.5 mg, $46 \mathrm{mg}$ )

4. Biotin-DSPE, DSPE-PEG2000, Phosphatidylcholine, and Cholesterol (5 mg, $2.5 \mathrm{mg}, 34 \mathrm{mg}, 9.7 \mathrm{mg}$ )

The lipids were dispensed into a round bottom flask with $5 \mathrm{ml}$ of Chloroform solvent, immediately creating a homogenous solution. Next, the sample was placed on the Buchi Rotovap with specific settings to assist in lipid film formation, which included: Placing the round bottom flask at a $45^{\circ}$ angle, to prevent lipid clumps from forming on the bottom of the glassware. Adjusting the water circulator temperature to $14^{\circ} \mathrm{C}$ and the water bath to $38^{\circ} \mathrm{C}$. Set the rotational speed to $145 \mathrm{rpm}$ under vacuum pressure, for 
approximately an hour, to promote a thin lipid film formation. Once a thin lipid film was achieved, the lipid film was frozen in liquid nitrogen Lypholized overnight.

\subsubsection{Rehydration of Lipid Film}

The previously created freeze-dried lipid film was rehydrated with $7 \mathrm{ml}$ of a $10 \%$ trehalose $3 \mathrm{mM}$ HEPES solution with $2 \mathrm{mg}$ of $\mathrm{MgO}^{-\mathrm{Cl}_{2}}$. The rehydrated lipid film was placed on the Buchi Rotovap and spun at $165 \mathrm{rpm}$ with the water bath temperature set at $55^{\circ} \mathrm{C}$. As the lipid film was spun in suspension, the lipid film started to dissociate from the flask walls and emulsifies in the trehalose solution. After an hour the solution consisted of multilamellar vesicles (MLV), and was freeze-thawed five times under liquid nitrogen, to maximize $\mathrm{MgO}-\mathrm{Cl}_{2}$ concentration retained within the aqueous cavity of the liposome. Once this procedure was performed, the MLV solution was ready to be extruded to created $100 \mathrm{~nm}$ large unilamellar vesicles (LUV).

\subsubsection{Extrusion of Large Unilmellar liposomes}

A series of mini extruder preparation procedures were performed for the liposome rehydration process. The first step was to soak the filters and membranes in a $10 \%$ Trehalose $3 \mathrm{mM}$ HEPES buffer solution for several minutes. Next, two hydrated filter supports were inserted on both membrane holders, and a hydrated filter membrane sandwich between both membrane holders, shown in Figure 9. The apparatus was assembled, and was placed on a hotplate, where the temperature was set to reach a steady temperature of $62^{\circ} \mathrm{C}$. Once the temperature was achieved, $1 \mathrm{ml}$ of the previously freeze thawed liposome sample was drawn using the extruder syringe, and placed on one side of the mini extruder apparatus. Then, the second extruder syringe was placed on the 
opposite side of the mini extruder apparatus, as shown on Figure 9. The freeze-thawed MLV sample was circulated within the extruder membrane by passage through alternating syringes for a total of 10 times, creating $100 \mathrm{~nm}$ LUV. The LUV sample and residual MLV sample were dispensed into independent glass storage vial, and were stored at $-20^{\circ} \mathrm{C}$, until further use. The schematic diagram below shows liposome formation from start to finish.

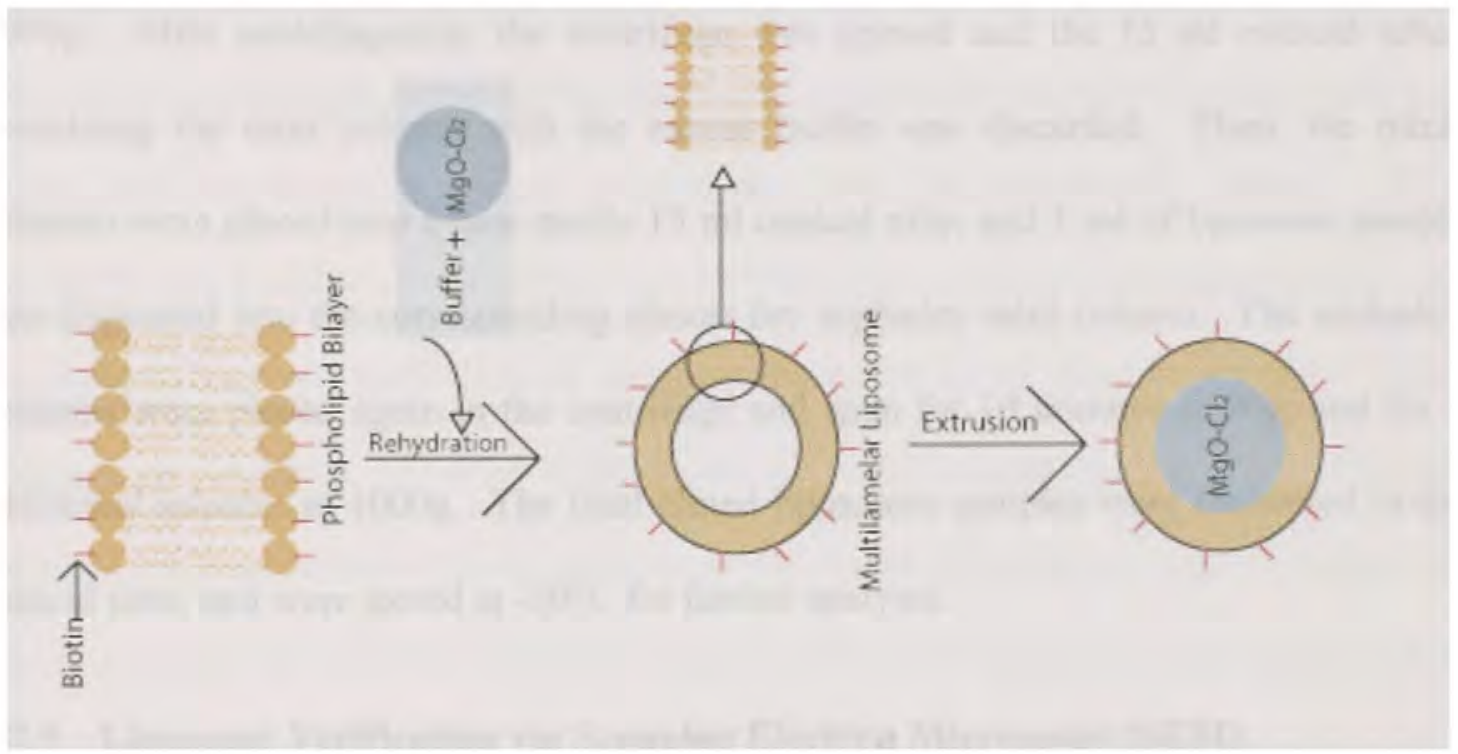

Figure 10. Diagram of liposome formation

\subsubsection{Purification of Biotin-Liposomes}

Each freshly extruded sample contained both liposomes and freed floating nonencapsulated $\mathrm{MgO}-\mathrm{Cl}_{2}$. So to achieve a pure liposomes solution, the samples were purified with Size Exclusion Chromatography (SEC).

\subsubsection{Sephadex Centrifuge Purification}

The second liposome purification procedure, involved dispensing the extruded liposome sample into a Sephadex G-50 mini columns, and centrifuging the mini column 
with the sample to eliminate free-floating $\mathrm{MgO}-\mathrm{Cl}_{2}$ in solution. This purification method was developed by Validimir Torchilin, and is widely accepted for achieving high recovered and non diluted liposome recovery ${ }^{32}$.

The liposome purification procedure was performed through a series of steps. First, the previously created sephadex mini columns were placed within a sterile $15 \mathrm{ml}$ conical tube, and loaded inside a swing rotor bucket centrifuge, spun for 3 minutes at $1000 \mathrm{~g}$. After centrifugation, the centrifuge was opened and the $15 \mathrm{ml}$ conical tubes containing the mini column with the excess buffer was discarded. Then, the minicolumns were placed into a new sterile $15 \mathrm{ml}$ conical tube, and $1 \mathrm{ml}$ of liposome sample was dispensed into the corresponding almost dry sephadex mini column. The sephadex columns were placed again in the centrifuge and spun for 10 minutes at $50 \mathrm{~g}$, and for 3 additional minutes at $1000 \mathrm{~g}$. The final eluted liposomes samples were recovered in the conical tube, and were stored at $-20^{\circ} \mathrm{C}$ for further analysis.

\subsubsection{Liposome Verification via Scanning Electron Microscopy (SEM)}

After liposome purification, the liposome samples were prepared for SEM analysis in order to verify liposome presence and size. $20 \mu \mathrm{l}$ of the liposome sample was dispensed onto the carbon nanotube substrate, and was immediately immersed into liquid nitrogen. Once the sample was frozen, it was immediately placed in the lypholizer overnight to remove the excess moisture. The following day, SEM imaging analysis was performed on the liposome sample. This preparation procedure was also performed on the non-purified liposome sample. 


\subsection{Immunoliposome-nanoparticle complex synthesis}

The second aim consisted of creating a non-specie specific detection system modified onto liposomes.

\subsubsection{Synthesis of Streptavidin-Nanoparticle antibody Complex}

The synthesis of the streptavidin-nanoparticles antibody complex consisted of a fluorescently labeled Streptavidin-nanoparticles modified with a polyclonal antibody. The specific polyclonal antibody utilized in this experiment targeted Bacillus anthracis spores, but recognized the antigens on the surface of the bacteria Bacillus subtilis (ATCC no. 9372) and Bacillus cereus (ATCC no. 11778). The actual antibody conjugation onto the nanoparticles was performed by targeting the prime amine functional group. These primary amine groups provided a target site for chemical synthesis to occur with the assistance of a crosslinker. These crosslinker allowed conjugation to occur, creating a 40 $\mathrm{nm}$ Streptavidin-nanoparticle-antibody complex. The final synthesis of the Streptavidinnanoparticle antibody complex was an easy procedure that utilizes the primary amine groups of both the antibody and Streptavidin coated nanoparticle.

\subsubsection{Streptavidin coated nanoparticle-MBS Synthesis}

The Streptavidin-nanoparticles synthesis reaction occurred by using a specific crosslinker, Maleimidobenzoyl-N-hydroxysuccinimide ester (MBS) that targets the primary amine of the Streptavidin molecule. These Streptavidin nanoparticles were received in a $1 \mathrm{ml}$ bottle with a concentration of $0.5 \% \mathrm{w} / \mathrm{w}$. Therefore, before any experiments were performed, calculations were performed to determine the concentration of nanoparticles and crosslinker necessary to produce a high yield. From these 
calculations, it was determined that only $0.2 \mathrm{mg}$ of nanoparticles were necessary for the synthesis reaction and $2 \mathrm{mg}$ of Maleimidobenzoyl-N-hydroxysuccinimide ester (MBS),

First, the Streptavidin coated nanoparticles bottle was vortexed and $40 \mu l$ of the suspension was extracted and dispensed into a $15 \mathrm{ml}$ conical tube with $4.3 \mathrm{ml}$ of deionized water and $0.7 \mathrm{ml}$ of HEPES buffer. Then a $40: 1$ molar excess of MBS solution was created, and $200 \mu 1$ the solution was dispensed into the conical tube containing the Streptavidin-nanoparticles. The conical tube containing the nanoparticles and MBS was placed in a water bath at room temperature and was gently stirred for an hour. This reaction occurred immediately, but to ensure high crosslinking the sample was incubated for a longer time. The chemical synthesis reaction is shown below.

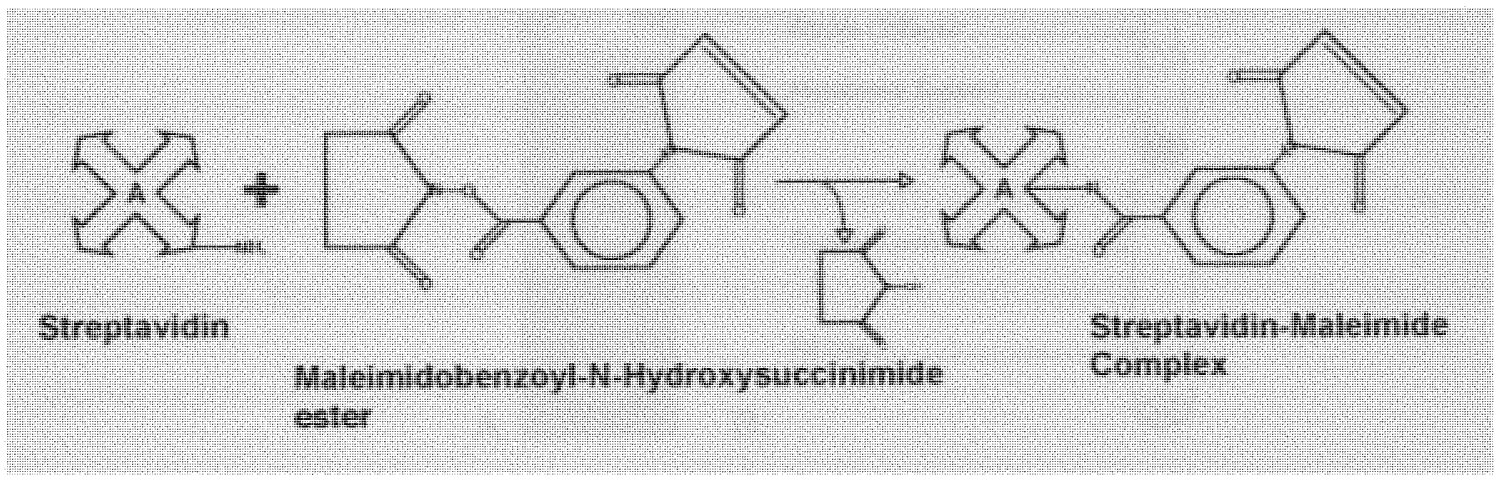

Figure 11. Streptavidin MBS Synthesis Reaction

\subsubsection{Purification of Streptavidin-MBS complex}

\subsubsection{Preparation of Centriprep 30 Ultrafiltration device}

While the Streptavidin-nanoparticles were reacting with MBS, the Centriprep 30 ultrafiltration device was prepared to purify the Streptavidin-nanoparticle-MBS sample. These glycerin coated Centriprep 30 ultrafiltration devices were rinsed in HEPES buffer to remove all traces of glycerin on the membranes. 
The Centriprep 30 ultrafiltration devices were disassembled and $15 \mathrm{ml}$ of HEPES buffer was added into the sample cavity, and then placed inside the centrifuge, and spun at $3000 \mathrm{~g}$ for 15 minutes. After centrifugation, the buffer was decanted from the filtrate cavity, and an additional $5 \mathrm{ml}$ of buffer was added into the sample cavity. The Centriprep 30 ultrafiltration device was spun again for an additional 15 minutes at the same conditions as previously set. After centrifugation, the filtrated sample was decanted from the filtrate collector, and centriprep was ready for the nanoparticle-mbs complex sample.

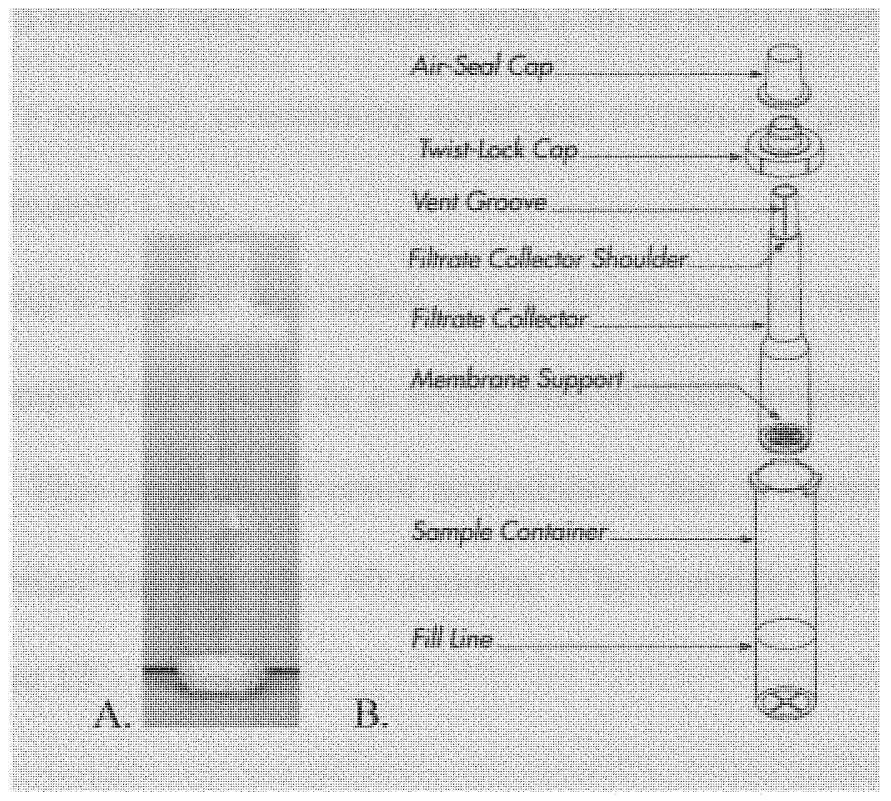

Figure 12. Centriprep Diagram. A. Centriprep 30 ultrafiltration device B. diagram

\subsubsection{Purification of Streptavidin-MBS Complex}

The Streptavidin-MBS complex was poured into the sample container of the Centriprep 30 ultrafiltration device, and was loaded into the Biofuge Primo R centrifuge, and spun at $3000 \mathrm{~g}$ for 5 minutes. Then, the Centriprep cap was removed and the filtrate collector sample was recovered in a $15 \mathrm{ml}$ conical tube. The purified sample was resuspended in $2 \mathrm{ml}$ of HEPES buffer, and the filtrate collector was pushed up and down 
against the buffer to release the nanoparticles adhered to inner surface. Once most of the nanoparticles were released, the purified Streptavidin-MBS intermediate sample was transferred into a $15 \mathrm{ml}$ conical tube and stored at $4^{\circ} \mathrm{C}$.

\subsubsection{Antibody Thiolation}

The polyclonal antibody sample $(4 \mathrm{mg} / \mathrm{ml})$ was taken out the refrigerator and vortexed for 10 seconds. Next, $40 \mu \mathrm{l}$ of the antibody sample $(0.2 \mathrm{mg})$ was extracted and dispensed into a $15 \mathrm{ml}$ conical tube, and diluted with $2 \mathrm{ml}$ of HEPES buffer. Next, the 2 iminothiolane (Traut's reagent), crosslinking agent was prepared to give a molar excess of $40: 1$, with approximately $1 \mathrm{mg}$.

Then, the Traut's reagent was added to the $15 \mathrm{ml}$ conical tube containing the antibody, and the sample was placed in a water bath at room temperature and gently stirred for an hour. This reaction occurred immediately, but to ensure high levels of crosslinking, the reaction was extended 60 minutes. The chemical synthesis reaction is shown below in Figure 13.

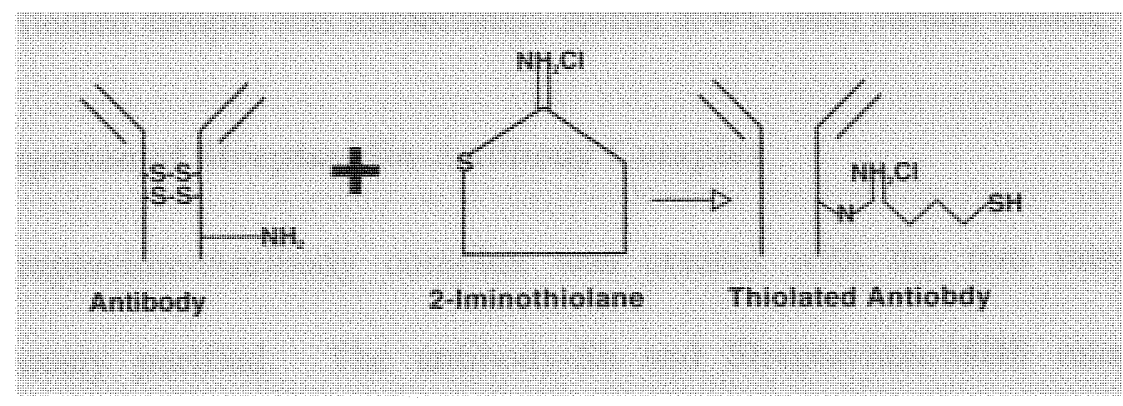

Figure 13. Antibody and Traut's reagent reaction

\subsubsection{Antibody-Sh Sephadex column preparation}

The Sephadex G-25 columns were prepared for antibody purification by swelling 5 $\mathrm{g}$ of Sephadex G-25 with $25 \mathrm{ml}$ of HEPES buffer for three hours. While the sephadex 
beads were swelling, the mini columns were prepared. The glass wool packing agent was placed in a beaker containing HEPES buffer for several minutes. Then, a piece of saturated glass wool was placed inside a plastic $5 \mathrm{ml}$ syringe, and was packed tightly to compact the glass wool within the mini column.

Next, the swelled sephadex was placed in a hot water bath for a minute to de-gas. Once the sephadex was hot, it was gently poured into the packed syringes until the bead height reached the $3.5 \mathrm{ml}$ mark on the syringe. Then, the mini columns were set on the benchtop, and were checked for the presence of air bubbles. If no air bubbles were present, the mini-columns were then ready for antibody purification.

\subsubsection{Thiolated Antibody Purification}

After an hour of the antibody and Traut's incubation, the sample was taken out of the water bath and immediately poured on the top of the sephadex column. The sample was allowed to elute under gravity for 5 minutes, and then $1 \mathrm{ml}$ of HEPES buffer was added to the sephadex column to assist in eluting the thiolated antibody. After several minutes, the collected sample was immediately stored at $4^{\circ} \mathrm{C}$ until further testing.

\subsubsection{Conjugation of Streptavidin-Antibody Complex}

The Streptavidin-Antibody complex was created with the two intermediate products previously purified. The antibody-Sh and Streptavidin-MBS intermediate products were taken out the refrigerator and allowed to reach room temperature. Once at ambient temperature, $150 \mu \mathrm{l}$ of Streptavidin-MBS complex and $500 \mu l$ of the antibody-Sh sample were extracted and dispensed into a $15 \mathrm{ml}$ conical tube. The final sample was shaken vigorously for 20 seconds, and then placed in a water bath at room temperature 
and gently stirred overnight. The following day the samples were stored at $-4^{\circ} \mathrm{C}$. The chemical synthesis reaction is shown below, in Figure 14.

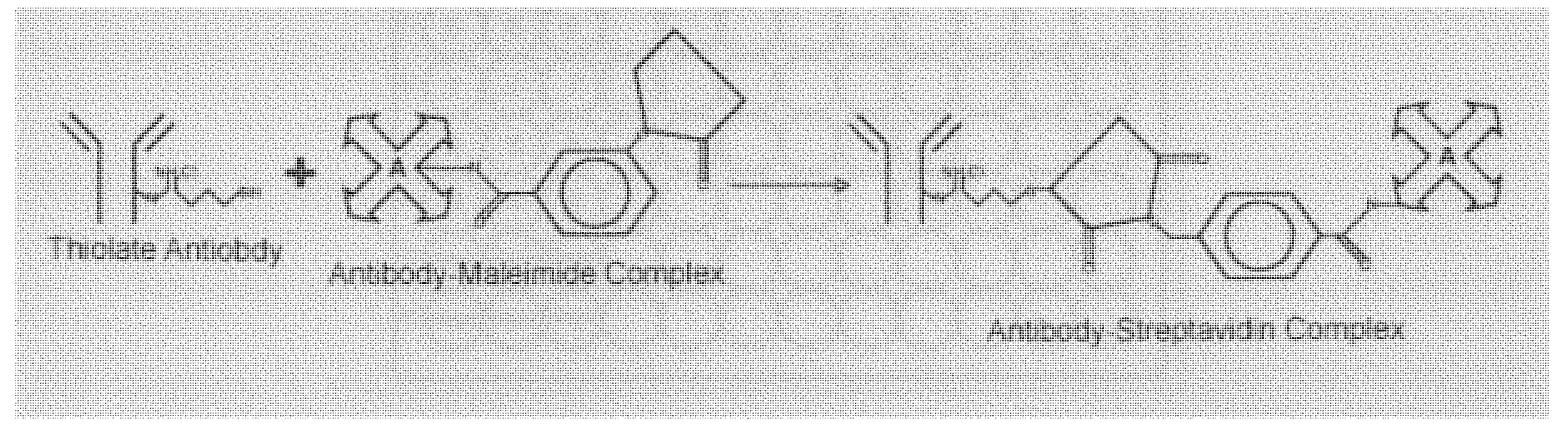

Figure 14. Final Product Reaction

\subsubsection{Verification Testing}

\subsubsection{Protein Recovery Tecan Spectrophotometer}

All quantitative protein recoveries for both intermediate synthesis reactions were determined by measuring the absorbance values of the samples at $280 \mathrm{~nm}$ and $260 \mathrm{~nm}$. By implementing these absorbance values into the formula below, an estimate of the protein recovery was determined.

$$
\text { Concentration } \left.(\mathrm{mg} / \mathrm{ml})=\left(1.55 \times \mathrm{A}_{280}\right)-0.76 \times \mathrm{A}_{260}\right)^{40}
$$

First, all the intermediate samples were allowed to thaw at room temperature. Then, $25 \mu \mathrm{l}$ of each antibody sample were dispensed into assigned positions on a sterile 96-well plate with $200 \mu \mathrm{l}$ of HEPES buffer added into each well. Lastly, the final column of the plate was filled with $225 \mu$ l of HEPES buffer as a control. The experimental design is shown on the plate diagram below (Figure 15). 


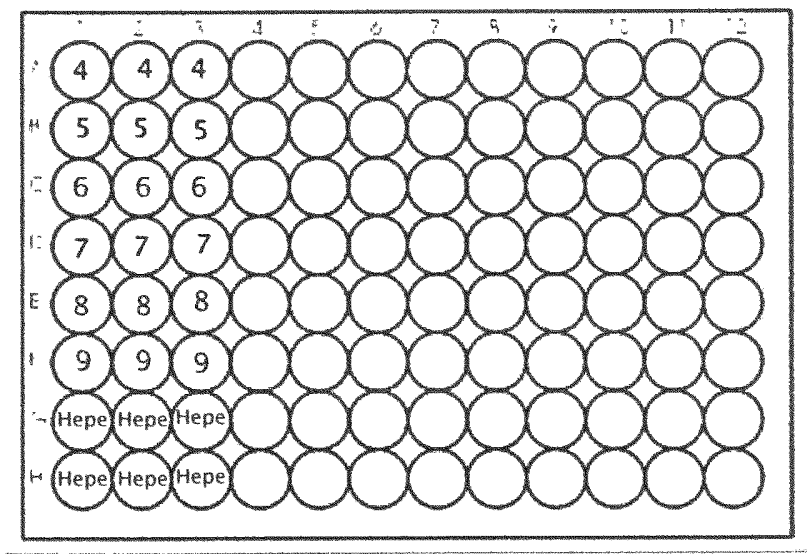

Figure 15. Recovered Antibody Sample Plate diagram

The second 96-well plate was prepared for the intermediate products of Streptavidin-mbs samples, following the same procedure as the antibody-Sh samples. 25 $\mu l$ of Streptavidin-mbs sample were dispensed into assigned well within a specific column. Then, $200 \mu$ l of HEPES buffer was added to each well containing Streptavidinmbs product, and finally $225 \mu \mathrm{l}$ of buffer was dispensed to the last column.

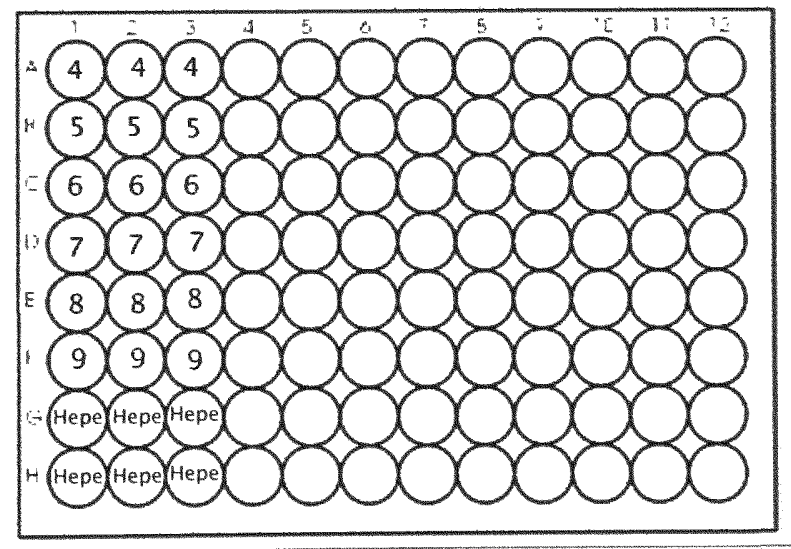

Figure 16. Recovered Streptavidin Sample Plate diagram

The antibody-Sh sample well plate was loaded into the plate stand within the Tecan Spectrophotometer and the sample was read at $280 \mathrm{~nm}$ and $260 \mathrm{~nm}$. The sample 
procedure performed for the antibody-Sh sample was performed for the Streptavidin-mbs samples. A total of two readings were performed for each plate at two independent wavelengths. All readings were recorded in excel for further analysis.

\subsubsection{BCA Assay}

The BSA assay was first prepared by creating a working reagent that consisted of two reagents, $A$ and $B$ creating a $50: 1$ solution. The working reagent was vortexed vigorously for several seconds, and then placed on the benchtop for further experiments. Next, Bovine Serum Albumin (BSA) standards were prepared by performing a series of dilutions. First, a $2 \mathrm{mg} / \mathrm{ml}$ BSA capsule was broken and carefully transferred to an eppendorf tube. A set of dilutions were prepared by using the stock BSA and HEPES buffer, as shown in the Table below.

\begin{tabular}{|l|l|l|l|}
\hline Vial & Volume of Dilutent $(\mu \mathrm{l})$ & Volume of BSA $(\boldsymbol{\mu l})$ & Final Concentration $(\mu \mathrm{g} / \mathrm{ml})$ \\
\hline A & 0 & 300 & 2000 \\
\hline B & 125 & 375 & 1500 \\
\hline C & 325 & 325 & 1000 \\
\hline D & 175 & 175 of vial B & 750 \\
\hline E & 325 & 325 of vial C & 500 \\
\hline F & 325 & 325 of vial E & 250 \\
\hline G & 325 & 325 of vial F & 125 \\
\hline H & 400 & 100 of vial G & 25 \\
\hline I & 400 & 0 & 0 \\
\hline
\end{tabular}

Table 3. BCA Standard Diagram

Once all the dilutions were performed for the standard assay, a sterile 96-well plate was obtained and each column was assigned to each sample dilution. Next $200 \mu \mathrm{l}$ of the working reagent was dispensed into every well on the 96-well plate, and $25 \mu \mathrm{l}$ of the freshly prepared sample was dispensed to the corresponding well, as shown below. The 
last column on the plate was filled with $225 \mu$ of HEPES buffer. Finally, the well plate was placed in a $37^{\circ} \mathrm{C}$ incubator for 2 hours.

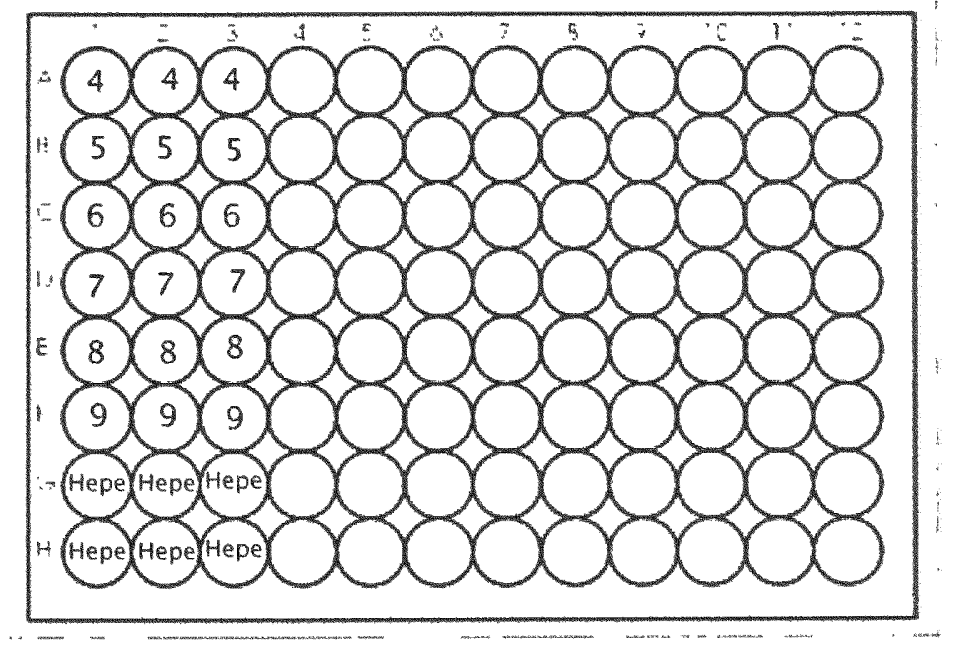

Figure 17. BCA Standard plate diagram

After the well plate had incubated for approximately 2 hours, it was taken out the incubator and allowed to cool at room temperature. Once cool, the sample well plate was loaded into the spectrophotometer and the sample was read at $595 \mathrm{~nm}$. The readings obtained were recorded were graphed in excel, and an equation of a line was obtained with an $\mathrm{R}^{2}$ value greater than 0.85 . This equation of the line was used to determine protein concentration.

The final streptavidin-antibody complex samples were taken out the refrigerator. While the samples reached room temperature, $200 \mu \mathrm{l}$ of the freshly created working reagent was dispensed into every well in the 96 -well plate, and $25 \mu 1$ of each streptavidinantibody complex sample were dispensed into the assigned column. The well plate was then placed in a $37^{\circ} \mathrm{C}$ incubator for two hours for the reaction to occur. After incubation 
the sample was loaded into the spectrophotometer and was read at $595 \mathrm{~nm}$. The values obtained were recorded in Excel for further analysis.

\subsubsection{Immunoliposome-nanoparticle Complex Conjugation}

A 1:1 ratio of the previously created immunoliposomes and streptavidin-antibody complexes was prepared in a $15 \mathrm{ml}$ conical tube. The reaction attachment occurred immediately, but reaction time was increased to 30 minutes to insure conjugation. After this time period, the samples were stored in at $-20^{\circ} \mathrm{C}$ until further testing. The schematic diagram of the final complex is shown below (Figure 18).

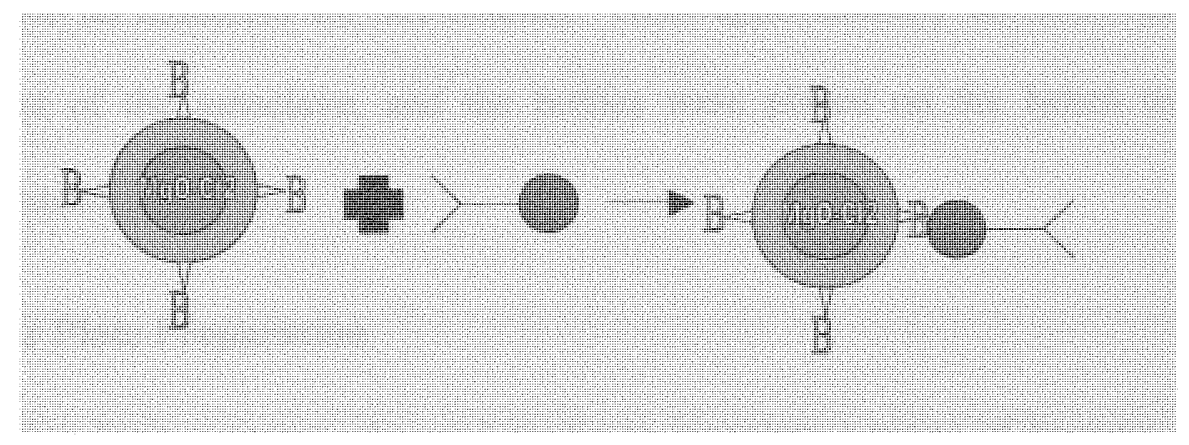

Figure 18. Immunoliposome-nanoparticle Complex

\subsection{Live/Dead Bacteria Verification Testing}

The third aim involved conducting feasibility studies on the newly created immunoliposome-nanoparticle complexes and bacteria to determine the time factor involved in detecting and neutralizing bacteria pathogens.

\subsubsection{Bacteria}

Three bacteria strains were analyzed, which were: Bacillus cereus, Bacillus, subtilis, and Bacillus, thuringiensis. 


\subsubsection{Bacteria Preparation}

\subsubsection{Media Preparation}

Fresh Luria Broth (LB) bacteria media was prepared through a series of steps. First, $1000 \mathrm{ml}$ of distilled water was poured into a $2000 \mathrm{ml}$ Erlenmeyer flask with $20 \mathrm{~g}$ of LB dry granules. Second, a magnetic rod was gently placed into the Erlenmeyer flask and set onto a stirring plate. Third, the stirring plate setting was set to stir on high, until a homogenous solution was created, within ten minutes.

After the media had been prepared, it was poured into three $500 \mathrm{ml}$ glass bottles, and placed into an autoclave for sterilization. After approximately an hour, the media was taken out of the autoclave, and the bottles were placed on the bench top until required for bacteria growth.

\subsubsection{Agar Plate Preparation}

Agar has been a commonly used media to inoculate a range of bacteria species from both gram positive to gram-negative bacteria. These plates were prepared for experimental drug bacteria interaction testing.

Agar was prepared by a series of steps. First, $500 \mathrm{ml}$ of de-ionized water was dispensed into a $1 \mathrm{~L}$ Erlenmeyer flask with $20 \mathrm{~g}$ of Agar. Second, the flask was placed on a heating/stirring plate and a large magnetic rod was gently placed into the flask and covered. Third, the flask was stirred and heated on low for several minutes until the entire agar granules had dissolved. Then the agar solution was immediately placed in an autoclave sterilizer for an hour. 
After the agar was cooled, it was poured halfway in each dish for a total of 20 Petri dishes. These dishes were allowed to cool at room temperature, until the agar had completely gelled. After gelation, the agar plates were stored in the refrigerator for further analysis.

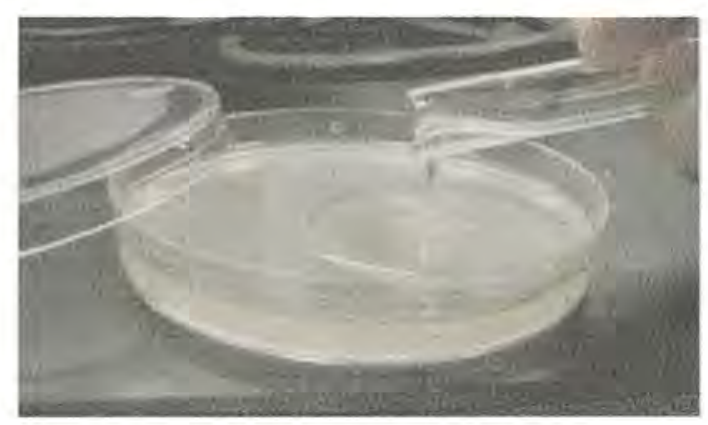

Figure 19. Agar Plate

\subsubsection{Bacteria Inoculation}

A small sample of the Bacillus cereus freezer vial was dispensed into a sterile 50 $\mathrm{ml}$ conical tube, with $5 \mathrm{ml}$ of freshly prepared LB media. Next, the bacteria conical tube was placed within a shaking $37^{\circ} \mathrm{C}$ incubator overnight for bacteria growth.

\subsubsection{Bacteria Concentration Assay}

Fresh overnight bacteria culture was dispensed into a $1 \mathrm{ml}$ plastic cuvette and was set-aside on a bench top. Then, a $1 \mathrm{ml}$ of LB media used in the same bacteria culture was dispensed into a plastic cuvette, and loaded into the spectrophotometer and read at $600 \mathrm{~nm}$ to blank the machine. Next, the sample plastic cuvette was loaded into the spectrophotometer, and an immediate absorbance value and concentration of the bacteria 
sample in cells/ml was obtained. From the obtained concentration, a dilution factor for each experiment was determined for further experiments.

\subsubsection{Bacteria and MgO-Cl Interaction Control Testing}

Three distinct assays were used to test the neutralization properties of $\mathrm{MgO}-\mathrm{Cl}_{2}$ against bacteria. The first assay consisted of incubating bacteria with various $\mathrm{MgO}-\mathrm{Cl}_{2}$ drug concentrations. The second assay, known as halo test, incubated bacteria with $\mathrm{MgO}-\mathrm{Cl}_{2}$ loaded in the middle of the Petri dish. The third assay consisted of bacteria biofilms treated with various $\mathrm{MgO}-\mathrm{Cl}_{2}$ concentrations. All these assays were used to determine the efficacious concentration of $\mathrm{MgO}-\mathrm{Cl}_{2}$ required to neutralize bacteria.

\subsubsection{Bacteria incubation with $\mathrm{MgO}-\mathrm{Cl}_{2}$}

Freshly grown, Bacillus cereus; bacteria sample in assumed exponential growth phase were examined by following the bacteria concentration assay to determine bacteria cell concentration in suspension. Once the concentration was obtained, a series of 1:10 dilutions were performed until the theoretical bacteria concentration was $10^{5}$ cells $/ \mathrm{ml}$.

Next, five sterile conical tubes were labeled with the corresponding specific drug concentration, and filled with fresh room temperature $50 \mathrm{ml}$ of PBS Buffer. Then, the various concentration of the neutralization agent $\left(\mathrm{MgO}-\mathrm{Cl}_{2}\right)$ were added into a specific labeled test tube, refer to Table 4.

Once the $\mathrm{MgO}-\mathrm{Cl}_{2}$ concentrations were added into each corresponding conical tube, the samples were sonicated vigorously for several minutes, until a homogenous solution was created. Then, $500 \mu \mathrm{l}$ of the fresh Bacillus cereus culture (cell/ $/ 110^{5}$ ) was 
dispensed into each conical tube and vortexed for several second before being placed in a shaking $37^{\circ} \mathrm{C}$ incubator overnight.

\begin{tabular}{|l|l|l|}
\hline Vial & Drug weighed (mg) & Final Concentration $(\mathrm{mg} / \mathrm{ml})$ \\
\hline A & 50 & 1 \\
\hline B & 25 & 0.5 \\
\hline C & 12.5 & 0.25 \\
\hline D & 6.25 & 0.125 \\
\hline E & 3.125 & 0.0625 \\
\hline F & 0 & 0 \\
\hline
\end{tabular}

Table 4. Prepared MgO-Cl2 Concentrations

Twenty-four hours after bacteria drug incubation, $500 \mu l$ of each sample were dispensed into the corresponding agar plate. The bacteria agar plates were tilted until the bacteria suspension completely covered the surface of the plate. Then each plate was placed inside a $37^{\circ} \mathrm{C}$ incubator for 24 hours, and the plates were examined during the 24 hours interval for bacteria growth.

After 24 hours, each plate was examined for bacteria colony formation, and each colony present was counted in specific plate regions. The overall bactericidal efficiency of $\mathrm{MgO}-\mathrm{Cl}_{2}$ was examined visibly. To future examine the bactericidal property of $\mathrm{MgO}-$ $\mathrm{Cl}_{2}$, an equation was created to determine the overall bactericidal property of $\mathrm{MgO}-\mathrm{Cl}_{2}$. The following equation shown below was used to determine bactericidal efficacy ${ }^{23}$.

Bactericidal efficacy $(\%)=$ Alive number in control- alive number in experimental group $x 100$ Alive number in control 


\subsubsection{Halo Test}

Fresh bacteria cultures, B. cereus, B. subtilis, and B. thuringiensis, were grown overnight, and analyzed following the concentration assay to obtain a bacterial cell concentration $(\mathrm{cell} / \mathrm{ml})$. Once the concentration of each sample was obtained, each bacterium sample was diluted with a 1:10 factor, until a theoretical concentration of $10^{5}$ was obtained. Then, $500 \mu \mathrm{l}$ of each diluted bacterium samples was dispensed into agar plates, and incubated at $37^{\circ} \mathrm{C}$ for 2 hours.

While the bacteria were proliferating, $\mathrm{MgO}-\mathrm{Cl}_{2}$ drug slurries were prepared with 3 mg of $\mathrm{MgO}^{-\mathrm{Cl}_{2}}$ in $200 \mu \mathrm{l}$ of HEPES buffer. After two hours of bacteria incubation, the plates were taken out of the incubator, and a sterile $50 \mathrm{ml}$ conical tube was pressed gently in the middle of each plate, leaving an indentation. Then, the drug slurry was carefully poured into the indented region and returned to the incubator, where the samples were allowed to incubate overnight. The following day, the plates were examined for bacteria colonies formation in the indented drug region.

\subsubsection{Biofilm Assay I}

Bacteria strains were grown overnight in LB media, and analyzed the following day with the concentration assay to determine the bacteria concentration in cells $/ \mathrm{ml}$. Once the concentration was obtained, the samples were diluted in LB media with a ratio of 1:100. Then, $100 \mu \mathrm{l}$ of the diluted bacteria samples were plated into 96-well PVC plates, and were placed in a microbiological incubator at $37^{\circ} \mathrm{C}$ for approximately 10 hours.

The following day, the freshly created biofilms samples were treated with a variety of $\mathrm{MgO}-\mathrm{Cl}_{2}$ concentrations. Each biofilm plate was treated with $100 \mu \mathrm{l}$ of each drug vial 
listed below, and were placed in an incubator overnight. Drug killing effect was determined by a plate-streaking assay that submerged a loop into random wells from each column, scraping the bottom of the biofilm, and streaking a specific area on an agar plate. Note, that each column was specific for a drug concentration, and was repeated for each PVC plate, until all the strains had been tested. Then, the agar plates were placed within an incubator for 48 hours. After two days, the plates were examined for bacteria growth, and each colony present on each plate was documented. The presence of colonies was used as positive indicator, if the varying the concentration of $\mathrm{MgO}_{-} \mathrm{Cl}_{2}$ had affected bacteria growth.

\begin{tabular}{|c|c|c|c|c|c|}
\hline Bacteria & \multicolumn{5}{|c|}{ Concentration of $\mathrm{MgO}-\mathrm{Cl}_{2}$} \\
\hline B. subtilis & \multirow{3}{*}{$1 \mathrm{mg} / \mathrm{ml}$} & \multirow{3}{*}{$0.5 \mathrm{mg} / \mathrm{ml}$} & \multirow{3}{*}{$0.25 \mathrm{mg} / \mathrm{ml}$} & \multirow{3}{*}{$0.125 \mathrm{mg} / \mathrm{ml}$} & \multirow{3}{*}{$\begin{array}{c}0.0625 \mathrm{mg} / \\
\mathrm{ml}\end{array}$} \\
\hline B. thuringiensis & & & & & \\
\hline B. cereus & & & & & \\
\hline
\end{tabular}

Table 5. Biofilm $\mathrm{MgO}-\mathrm{Cl}_{2}$ Testing

\subsubsection{Biofilm Assay II}

The MBEC assay was the second biofilm assay performed with bacteria, $B$. cereus, B. subtilis, and B. thuringiensis. Theses bacteria samples were grown overnight, and were analyzed by following the bacteria concentration assay. Next, the bacteria samples were diluted following a standard protocol, if $3.0 \times 10^{8}$ was the initial concentration obtained, then a $1 / 30$ dilution would be performed to obtain inoculums of $10^{7}$ cells $/ \mathrm{ml}$ 
Then, $150 \mu 1$ of the each diluted specie specific bacteria sample were plated onto a 96-well MBEC plate, and were positioned within a gyrating incubator, set to $150 \mathrm{rpm}$ and $35^{\circ} \mathrm{C}$ overnight.

The following day, rinsing plates were prepared by dispensing $200 \mu \mathrm{l}$ of sterile PBS in every well. Next, the challenge plates were prepared by dispensing $200 \mu \mathrm{l}$ of various $\mathrm{MgO}-\mathrm{Cl}_{2}$ into assigned columns in the 96-well plate, as shown below.

\begin{tabular}{|l|l|}
\hline Column Assignment well plate & $\mathrm{MgO}-\mathrm{Cl}_{2} \mathrm{mg} / \mathrm{ml}$ \\
\hline $12 \& 11$ & 0.5 \\
\hline $10 \& 9$ & 0.35 \\
\hline $8 \& 7$ & 0.125 \\
\hline $6 \& 5$ & 0.0625 \\
\hline $4 \& 3$ & 0 \\
\hline
\end{tabular}

Table 6. $\mathrm{MgO}-\mathrm{Cl}_{2}$ Plate layout for Biofilm Testing

The bacteria MBEC plates were taken out the incubator and placed in a sterile hood, where the MBEC lid pegs were transferred into the rinse plate for approximately one minute. Then the MBEC pegs were transferred into the $\mathrm{MgO}-\mathrm{Cl}_{2}$ challenge plate, and placed in the incubator for 24 hours.

On day three, the treatment plates were taken out the incubator and again positioned in a sterile hood. While the rinse and recovery plates were prepared, the MBEC biofilm lid from the challenge plate was transferred into the rinse plate with sterile PBS, for approximately 1 minute. Next, CAMHB media was poured into a Petri 
dish where $200 \mu \mathrm{l}$ were extracted and dispensed into the wells in the plate. After the pegs were rinsed, the MBEC peg lid was transferred to the CAMHB recovery plate where the plate was sonicated for 5 minutes to release biofilms from the pegs. Lastly, the plates were set in the incubator for 24 hours to initiate bacteria growth.

On day four, the plates were taken out the incubator and were examined for bacteria colonies both visually and with a spectrophotometer. The data obtained was statistically analyzed to determine at what concentration of $\mathrm{MgO}-\mathrm{Cl}_{2}$ inhibited bacteria growth.

\subsubsection{Fluorescent Microscopy of interaction between Bacteria and $\mathrm{MgO}-\mathrm{Cl}_{2}$}

Before initial testing were performed, the fluorescent dyes, Ethidium homodimer1 and Syto-9 were calibrated for microscopy testing. A $1 \mu l$ of the stock Ethidium homodimer-1 sample was diluted in $99 \mu 1$ of HEPES buffer, creating a 1:100 dilution. Next, $1 \mu$ of the stock, Syto-9 dye was diluted in $999 \mu$ l HEPES buffer, creating a 1:1000 dilution. Then, two sample concentrations of $\mathrm{MgO}-\mathrm{Cl}_{2}$ samples were prepared in HEPES buffer with a $24 \mathrm{mg} / \mathrm{ml}$ and $2 \mathrm{mg} / \mathrm{ml}$. Once all the $\mathrm{MgO}-\mathrm{Cl}_{2}$ preparation was finished fresh, B. cereus, bacteria was obtained, and the concentration was determined.

Next, the dyes previously prepared were thawed and allowed to reach room temperature. Once the dyes had reached desirable temperature, the samples were prepared for testing analysis. Sample aliquots of the each $\mathrm{MgO}-\mathrm{Cl}_{2}$ samples were dispensed into the corresponding microscope slide with $B$. cereus and fluorescent dyes. Next, the samples were analyzed with the $488 \mathrm{~nm}$ blue laser on fluorescent microscope. Live images were captured from each sample to view the interaction of 
Immunoliposome-nanoparticle complex sample with bacteria and fluorescent dyes. For the purpose of this procedure sample aliquots of the original samples were viewed under the fluorescent microscope at three time intervals time $=0$, time $=15$ and time $=1 \mathrm{hr}$. The samples volumes used in each test are listed below:

\begin{tabular}{|l|l|}
\hline \multicolumn{1}{|c|}{ Sample } & \multicolumn{1}{c|}{ Formulation** } \\
\hline $2 \mathrm{mg} / \mathrm{ml} \mathrm{MgO}-\mathrm{Cl}_{2}$ & $2 \mu \mathrm{l}$ of sample $+2 \mu \mathrm{l}$ B.cereus \\
\hline $24 \mathrm{mg} / \mathrm{ml} \mathrm{MgO}-\mathrm{Cl}_{2}$ & $2 \mu \mathrm{l}$ of sample $+2 \mu \mathrm{l}$ B. cereus \\
\hline
\end{tabular}

Table 7. Fluorescent Microscopy testing with $\mathrm{MgO}-\mathrm{Cl}_{2}$ and B. cereus

** All formulations consisted of $2 \mu \mathrm{l}$ Ethidium homodimer- 1 and $2 \mu 1$ of Syto-9

Each formulation was observed at different magnifications and the samples were visualized using the Blue laser for fluorescent excitation

\subsubsection{Bacteria testing with Immunoliposome-nanoparticle complex}

\subsubsection{Fluorescent Microscopy of interaction between Bacteria and Immunoliposome-nanoparticle complex}

All the samples were prepared for fluorescent microscopy by following the same protocol previous used for $\mathrm{MgO}-\mathrm{Cl}_{2}$ testing. All the samples were prepared directly on the microscope slide were the Immunoliposome-antibody complex samples, bacteria and fluorescent dyes were analyzed immediately at different time intervals. The samples volumes used in each test are listed below:

Additional fluorescent microscopy images were captured with another instrument, and similar studies were performed with this microscope to capture images of the 
interaction of B. cereus with liposomes. A sample slide of a $20 \mu 1(B$. cereus and liposome 12) suspension with a 1:1 ratio was dispensed onto a microscope slides. Images of the liposome and B. cereus interaction were captured at three intervals a time $=0$, time $=15$ and time $=1$ hour

\begin{tabular}{|l|l|}
\hline \multicolumn{1}{|c|}{ Sample } & Formulation** \\
\hline 13-5 Immunoliposome-complex & $2 \mu \mathrm{l}$ of sample $+2 \mu \mathrm{l}$ of $B$. cereus \\
\hline 14-7 Immunoliposome-complex & $2 \mu \mathrm{l}$ of sample $+2 \mu \mathrm{l}$ of $B$. cereus \\
\hline 14 Immunoliposome & $2 \mu \mathrm{l}$ of sample $+2 \mu \mathrm{l}$ of $B$. cereus \\
\hline 17 Immunoliposome & $2 \mu \mathrm{l}$ of sample $+2 \mu \mathrm{l}$ of $B$. cereus \\
\hline
\end{tabular}

Table 8. Fluorescent Microscopy testing with samples and B. cereus

\section{Data acquisition of Bacteria and Immunoliposome interaction using Flow Cytometry}

Flow cytometry was used to determine the effectiveness of the newly synthesized Immunoliposome-nanoparticle complex formulations in detecting and neutralizing the bacteria samples. The bacteria samples concentration of $5.0 \times 10^{8}$ were prepared for flow cytometry. From this bacteria culture, $200 \mu \mathrm{l}$ was extracted and dispensed into a conical tube containing $5 \mathrm{ml}$ of LB Broth (1:25). The new bacteria conical tube was set aside, as the Immunoliposome-nanoparticle complexes reached room temperature.

Next, the samples were prepared for flow cytometry testing with the following ratio: $25 \mu \mathrm{l}$ bacteria sample $+200 \mu \mathrm{l}$ of Immunoliposome-nanoparticle complex $+25 \mu \mathrm{l}$ Ethidium homodimer-1 (1:100 dilution). Once the samples were prepared, each sample 
Ethidium homodimer-1 (1:100 dilution). Once the samples were prepared, each sample was immediately analyzed by flow cytometry to determine bacteria detection and neutralization.

Bacteria detection was achieved by using the $488 \mathrm{~nm}$ laser of the flow cytometer, and triggering the yellow fluorescence of the nanoparticle within the Immunoliposomenanoparticle complex. The neutralization efficiency of the Immunoliposomenanoparticle complex formulations was determined by the presence of the membrane impermeable red fluorescent dye, Ethidium homodimer-1. Both the detection and the neutralization of each sample were analyzed at two intervals, time $=0$ and at time $=2$ hours. All the data obtained from flow cytometry were analyzed for live/dead bacteria cell viability and for sample interaction with the bacteria.

\subsection{RESULTS}

\subsection{Liposome Formulation}

\subsection{1 $\mathrm{MgO}-\mathrm{Cl}_{2}$ Drug concentration}

An $\mathrm{MgO}-\mathrm{Cl}_{2}$ serial dilution experimental design was created to determine the maximum concentration of nanoparticles that could be circulated through the mini extruder apparatus. All the serial dilution samples were tested under similar environmental conditions used in liposome formation. The concentrations created are shown in the Table below.

These serial dilutions samples were created by first starting with a high concentration of $5 \mathrm{mg} / \mathrm{ml}$ of $\mathrm{MgO}-\mathrm{Cl}_{2}$ nanoparticles, and diluting the sample by two 
folds, resulting in series of samples with high to low $\mathrm{MgO}-\mathrm{Cl}_{2}$ concentrations. A total of 6 samples were created with a theoretical concentration range from $5 \mathrm{mg} / \mathrm{ml}$ to 0.185 $\mathrm{mg} / \mathrm{ml}$.

\begin{tabular}{|c|c|}
\hline Sample no. & Concentration $(\mathrm{mg} / \mathrm{ml})$ \\
\hline 1 & 5 \\
\hline 2 & 2.5 \\
\hline 3 & 1.25 \\
\hline 4 & 0.75 \\
\hline 5 & 0.37 \\
\hline 6 & 0.185 \\
\hline
\end{tabular}

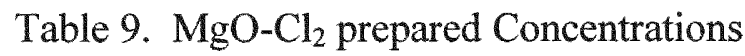

The main focus of this experiment was to answer three main questions. 1. How much resistance occurred when $\mathrm{MgO}-\mathrm{Cl}_{2}$ nanoparticles were circulated within the mini extruder Apparatus. 2. Could the sample be circulated within the mini extruder apparatus by alternating syringes for a total of 10 times? 3. Was nanoparticles buildup present on the filter membrane after extrusion?

Favorable results were to obtain the highest concentration of $\mathrm{MgO}-\mathrm{Cl}_{2}$ nanoparticles that would provide low resistance, capable of being circulated for a total of 10 times, and with no visible buildup on the filter membranes. A sample set of various $\mathrm{MgO}-\mathrm{Cl}_{2}$ concentrations were prepared extruded following the same protocol liposome procedure. All the experimentations were performed with each diluted sample listed 
above. The results obtained from each $\mathrm{MgO}-\mathrm{Cl}_{2}$ sample and experimental results obtained are shown below in Table 10.

\begin{tabular}{|l|c|l|l|}
\hline Sample No. & Concentration $(\mathbf{m g} / \mathbf{m l})$ & Resistance & Nanoparticle buildup \\
\hline 1 & 5 & Extremely High & High White cake buildup \\
\hline 2 & 2.5 & Extremely High & High White cake buildup \\
\hline 3 & 1.25 & High Resistance & Slight cake buildup \\
\hline 4 & 0.75 & Slight Resistance & No buildup \\
\hline 55 & 0.37 & Normal Resistance & No buildup \\
\hline 6 & 0.185 & No Resistance & No buildup \\
\hline
\end{tabular}

Table 10. $\mathrm{MgO}-\mathrm{Cl}_{2}$ testing with Mini extruder Apparatus

* Optimal Concentration for liposome formulation

\subsection{Lipid formulation}

Two main lipid film formulations were created to understand the interaction of the liposome mechanism in neutralizing and detecting the bacteria. These lipid formulations were divided into two main categories as shown below:

A. Formulation One

a. 7.5mg (biotin capped DSPE-PEG2000), $46 \mathrm{mg} \mathrm{PC}$, and $13 \mathrm{mg}$ Cholesterol

b. $7.5 \mathrm{mg}$ (biotin capped DSPE-PEG2000), $46 \mathrm{mg} \mathrm{PC}$, and $26 \mathrm{mg}$ Cholesterol

c. $7.5 \mathrm{mg}$ (biotin capped DSPE-PEG2000), $46 \mathrm{mg} \mathrm{PC}$

B. Formulation Two

d. $5 \mathrm{mg}$ Biotin-DSPE, 2.5 DSPE-PEG2000, 34mg PC, $9.7 \mathrm{mg}$ Cholesterol

A total of 12 films were created for testing, subdivided into four types of

formulation. These four formulations were developed from a two main formulations that were altered in lipid concentration, resulting in four final formulations. For testing 
purposes each sample was designated a numerical log number corresponding to the formulation category. A detail list of each type of formulation and each sample number are shown in the Table below.

\begin{tabular}{|l|l|}
\hline Sample No. & Formulation \\
\hline 12 & d \\
\hline 13 & a \\
\hline 14 & a \\
\hline 15 & a \\
\hline 16 & a \\
\hline 17 & d \\
\hline$* 18$ & a \\
\hline$* 19$ & d \\
\hline 20 & b \\
\hline 21 & d \\
\hline 22 & b \\
\hline 23 & c \\
\hline
\end{tabular}

Table 11. Liposome samples with corresponding formulation

The experimental steps in creating a lipid film formation are shown below. The step consists of dissolving lipids in solvent and evaporating the solvent creating a lipid film. 


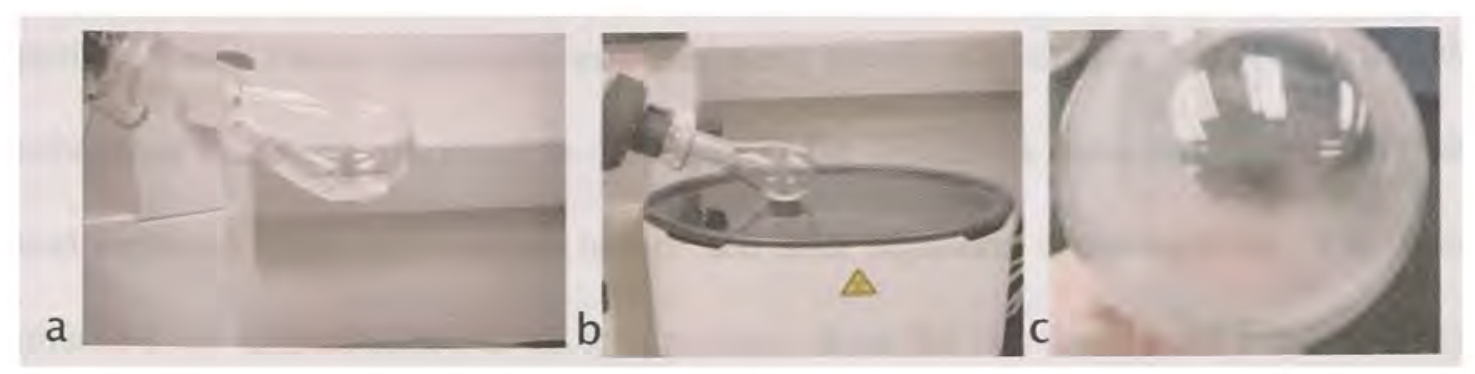

Figure 20. Lipid Film Steps A. Lipid in chloroform solvent B. Evaporating chloroform C. final lipid film

\subsection{Liposome}

All the lipid films were re-hydrated in HEPES buffer with $0.35 \mathrm{mg} / \mathrm{ml}$ of $\mathrm{MgO}-\mathrm{Cl}_{2}$ except for control samples 18 and 19. All these re-hydrated lipid films were freezethawed five times under liquid nitrogen, and were circulated for a total of 10 times within the Mini extruder apparatus, heated at $62^{\circ} \mathrm{C}$. After extrusion, sample appearance changed from an opaque white solution to a lucid solution, as shown in Figure 21. Note, the sample opacity diminishes when LUV liposomes were created.

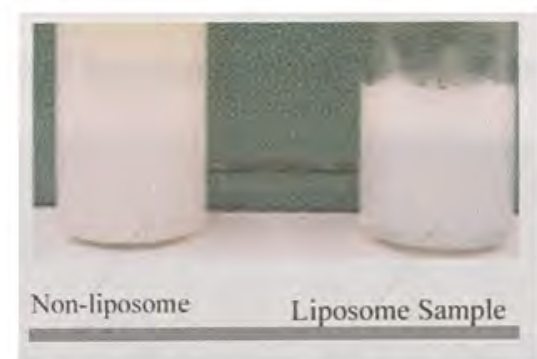

Figure 21. Liposomes of lipid film 16

\subsubsection{Liposome Purification verification}

Scanning Electron Microscopy (SEM) examined the Liposome samples before and after liposome purification via sephadex centrifugation. The SEM analysis was used to obtain a positive verification of the presence and size of the liposomes before and after 
purification. These liposomes samples were fixed onto modified carbon nanotubes substrates, and were examined to determine if the objectives were met. An SEM image was captured from each sample before and after sephadex centrifugation. The results obtained are shown below, note, both pictures show the circular shaped beads that are a positive identification for the presence of liposomes within the sample collection.
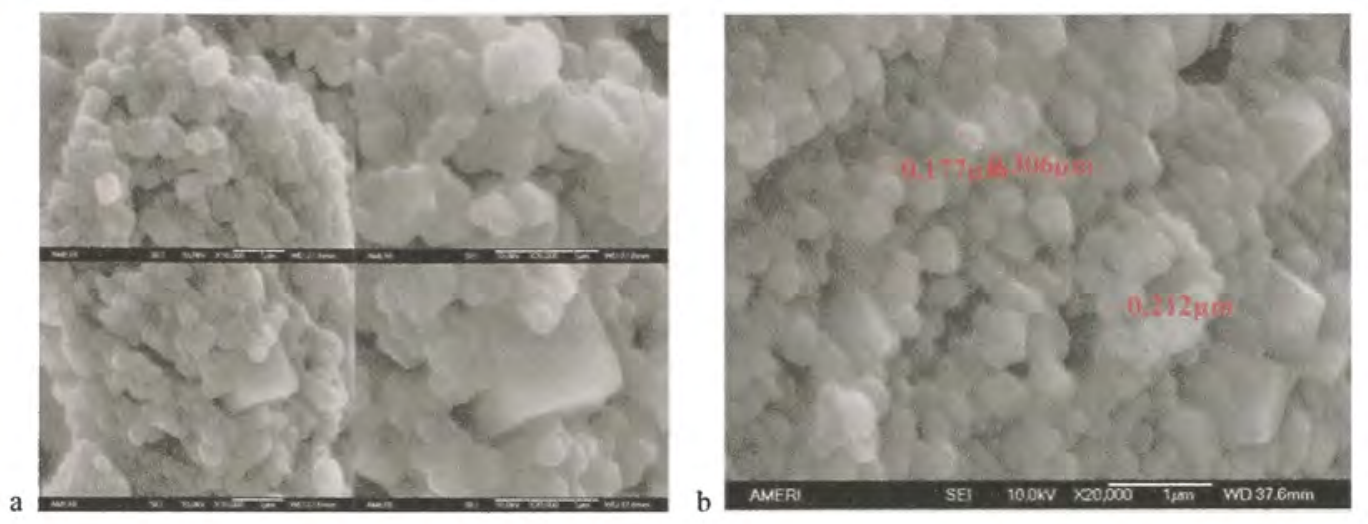

Figure 22. Liposome SEM Imaging. A. Overview of liposome sample B. Close-up of liposome sample

The purified liposome samples were analyzed by SEM, and the images obtained are shown below, note, observed liposomes have an approximate $300 \mathrm{~nm}$ diameter size.

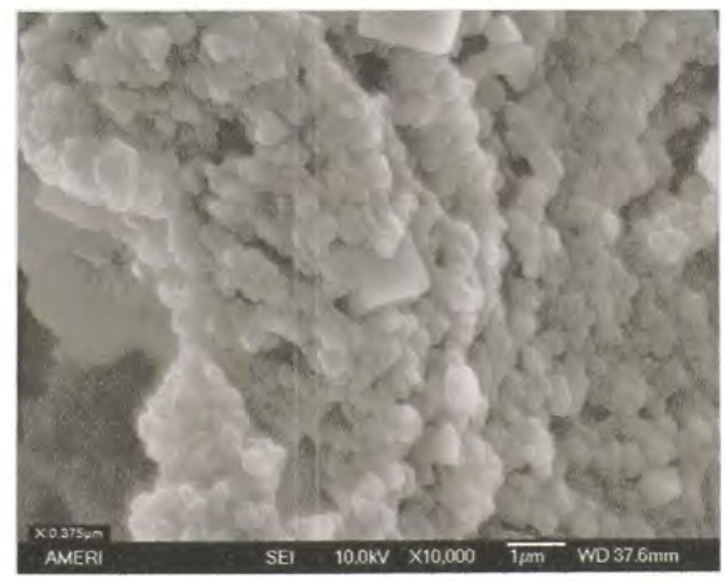

Figure 23. Purified liposome SEM 


\subsection{Streptavidin-nanoparticle antibody complex Synthesis}

\subsubsection{Synthesis reaction of Antibody and Streptavidin}

One main synthesis formulation was used to create eight samples of each Streptavidin-mbs and Antibody-Sh complexes. Each sample was purified by two independent methods. The Streptavidin-mbs complex was purified via ultrafiltration, and the antibody-Sh recovery was purified via Sephadex G-25.

\subsubsection{Antibody and Streptavidin Yield}

The Tecan spectrophotometer was used to determine the total protein yield for the thiolated antibody and Streptavidin-Mbs complex synthesis's. Quantitative protein recovery was determined by observing the sample absorbance at two specific wavelengths, $260 \mathrm{~nm}$ and $280 \mathrm{~nm}$. The protein recovery equation was implemented in each sample, and the results obtained are shown below.

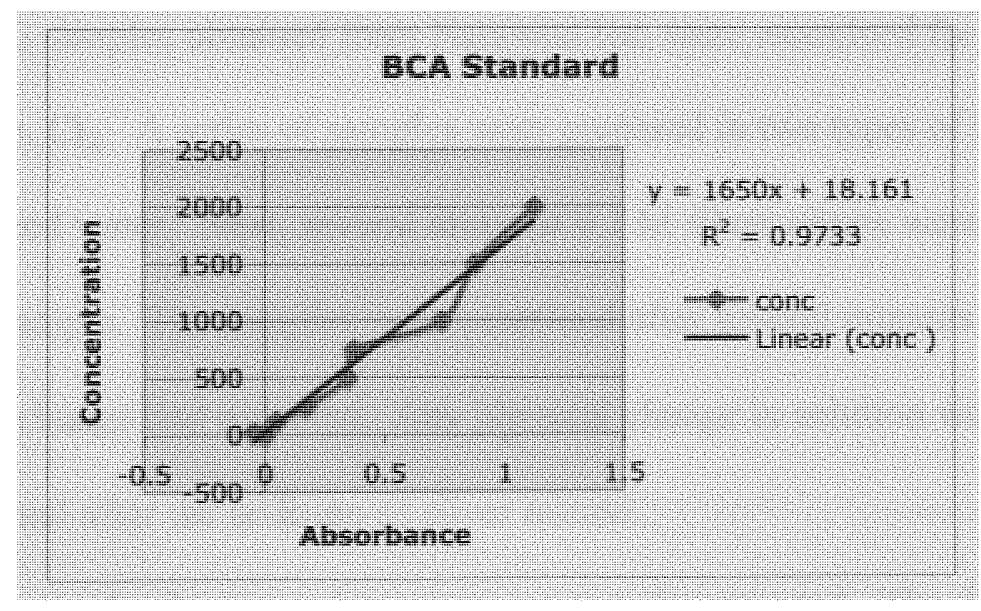

Figure 24. BCA Standard 
The BCA assay was performed on the streptavidin-nanoparticle antibody complex samples, and the data obtained was standardized and analyzed using a one-way ANOVA. A statistical model was created to determine if the streptavidin-antibody complex sample created from the same formulation was statistically significant. The empirical model for protein recovery was as follows:

$$
\mathrm{Y}=\mu+\mathrm{S}_{\mathrm{i}}+\varepsilon_{\mathrm{j}}
$$

Where $S=$ to the streptavidin-nanoparticle complex

The statistical results of the One-Way ANOVA produced a p-value of 0.000 for the samples; this implies that these samples are significantly different. Also, the data were normally distributed after natural log transformation.

\section{5 $\mathrm{MgO}-\mathrm{Cl}_{2}$ Testing}

\subsection{1 $\mathrm{MgO}-\mathrm{Cl}_{2}$ Testing with Silver Nitrate}

The $\mathrm{MgO}-\mathrm{Cl}_{2}$ samples obtained from Nanomat Inc. were examined for the presence of Chloride, $\mathrm{Cl}_{2}$. A series of samples were prepared in two types of buffers, HEPES and de-ionized water. Next, several drops of $0.1 \mathrm{M}$ silver nitrate were dispensed into each prepared sample. The samples were examined after several minutes to determine if a color change had occurred. Any physical change in solution was documented before and after the addition of silver nitrate.

After 10 minutes the final sample appearance was documented. The detailed table was created to show the effects of silver nitrate to each sample in buffer, refer to Table 13. 


\begin{tabular}{|l|l|l|}
\hline Sample & $\begin{array}{l}\text { Observation before } \\
\mathrm{AgNO}_{3}\end{array}$ & $\begin{array}{l}\text { Observation after } \\
\mathrm{AgNO}_{3}\end{array}$ \\
\hline $\mathrm{Cl}_{2}$ in DI & Clear solution & Clear solution \\
\hline $\mathrm{NaCl}$ in DI & Clear Solution & Opaque white Solution \\
\hline $\mathrm{MgO}-\mathrm{CL}_{2} \mathrm{HEPES}$ w/o salt & Clear Solution & Milky white solution \\
\hline${\mathrm{MgO}-\mathrm{Cl}_{2} \text { in DI }}^{\text {DI }}$ & Clear Solution & Brown solution \\
\hline $\mathrm{HEPES}$ w/o Salts & Clear Solution & Clear solution \\
\hline HEPES w/o Phenol Read & Clear Solution & Milky white solution \\
\hline $1 \%$ Triton X HEPES & Clear Solution & Milky white solution \\
\hline
\end{tabular}

Table 12. Silver Nitrate Test Results

\subsubsection{Spectrophotometer Scan of $\mathrm{MgO}-\mathrm{Cl}_{2}$}

An absorbance spectrum scan of $\mathrm{MgO}^{-\mathrm{Cl}_{2}}$ nanoparticles was taken with the Cary UV-Vis. The absorbance scan of $\mathrm{MgO}^{-\mathrm{Cl}_{2}}$ was analyzed, and it showed the highest peak at $259 \mathrm{~nm}$ with a corresponding absorbance of 0.4204 .

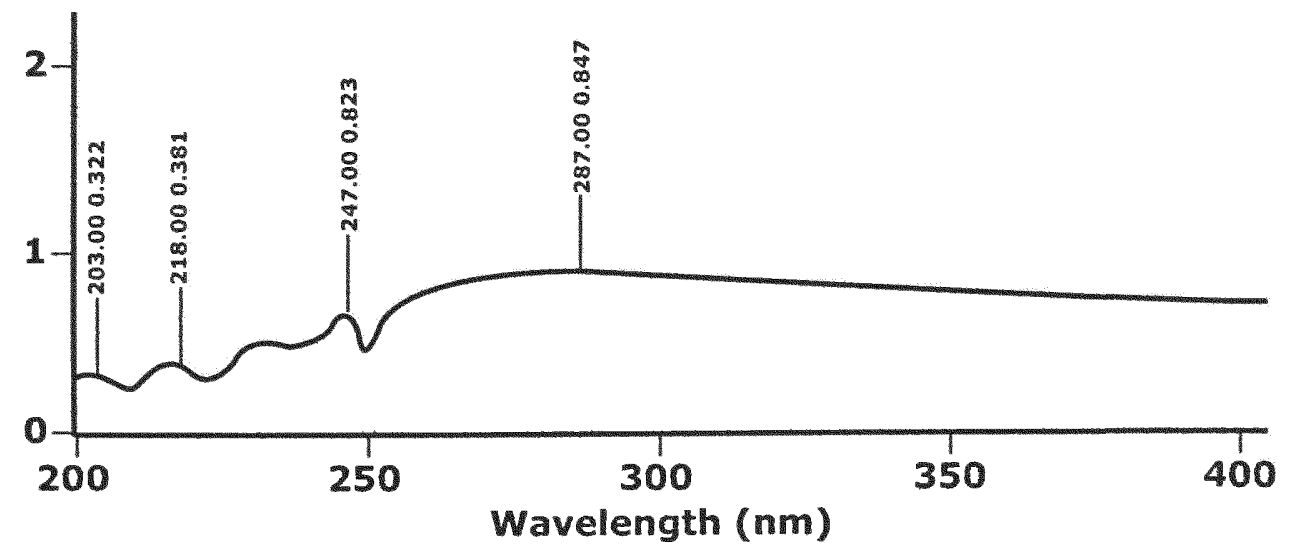

Figure 25. $\mathrm{MgO}-\mathrm{Cl}_{2}$ Absorbance Scan 


\subsubsection{X-Ray Microanalysis}

An additional chemical characterization of $\mathrm{MgO}-\mathrm{Cl}_{2}$ was performed via X-ray Microanalysis to determine the chemical element composition of these nanoparticles. When the samples were analyzed, the results attained indicated that these $\mathrm{MgO}-\mathrm{Cl}_{2}$ nanoparticles contained a high weight percentage of Magnesium $\left(\mathrm{Mg}^{2+}\right) 42.22$ and Oxygen $\left(\mathrm{O}^{-2}\right) 40.10$ with a 4.12 weight percentage of $\mathrm{Cl}_{2}$. These findings confirm that these nanoparticles do contain $\mathrm{Cl}_{2}$, refer to Figure 26.

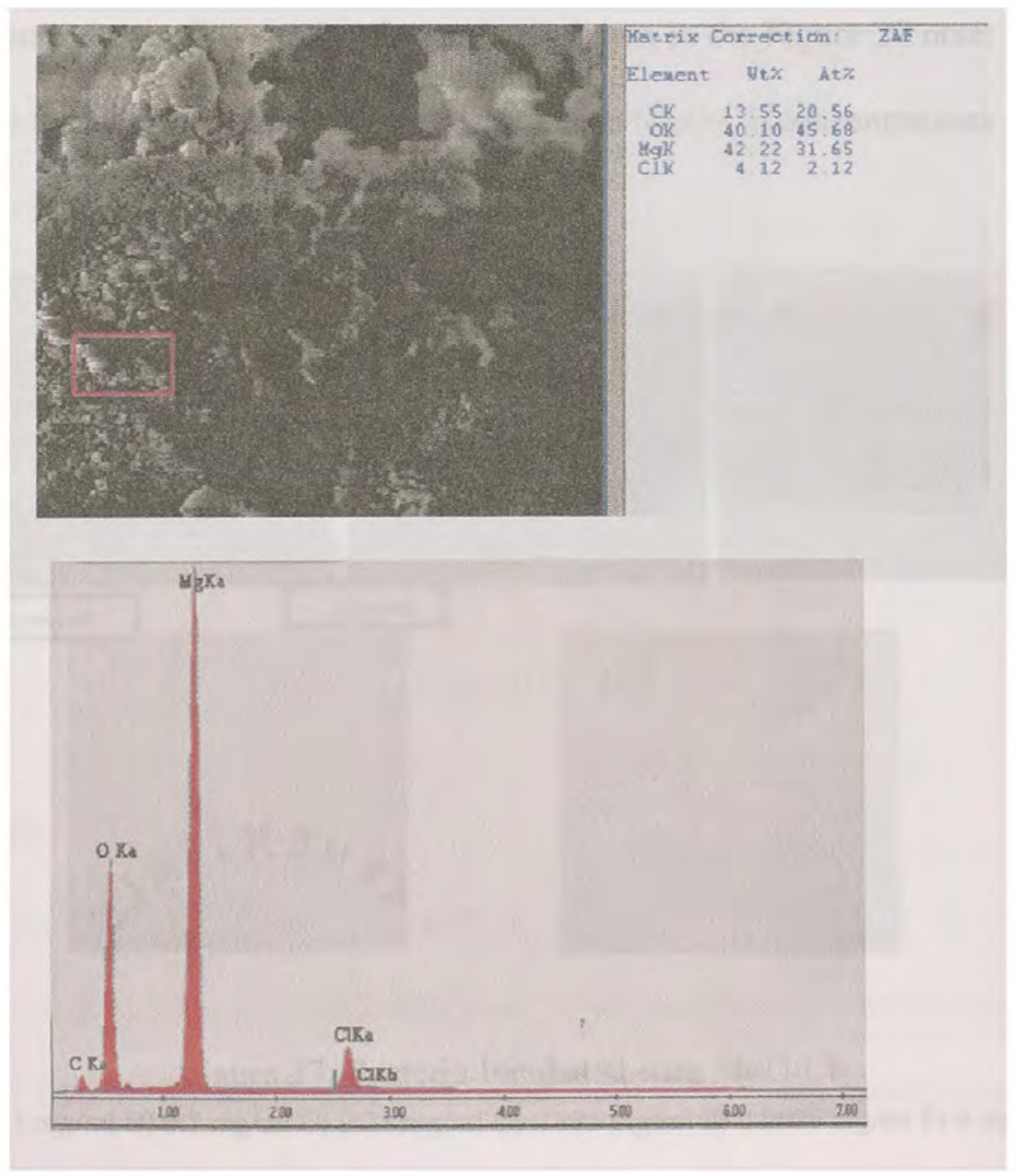

Figure 26. X-Ray microanalysis of $\mathrm{MgO}-\mathrm{Cl}_{2}$ nanoparticles 


\subsection{Live/Dead Bacteria Verification testing}

\subsubsection{Bacteria and $\mathrm{MgO}-\mathrm{Cl}_{2}$ Interaction Control Testing}

\subsubsection{Bacteria incubation with $\mathrm{MgO}-\mathrm{Cl}_{2}$}

The bacteria strain Bacillus cereus was tested with various concentrations of $\mathrm{MgO}$ $\mathrm{Cl}_{2}$, such as: a) $1 \mathrm{mg} / \mathrm{ml}$, b) $0.5 \mathrm{mg} / \mathrm{ml} \mathrm{c)} 0.25 \mathrm{mg} / \mathrm{ml} \mathrm{d)} 0.125 \mathrm{mg} / \mathrm{ml} \mathrm{e)} 0.0625 \mathrm{mg} / \mathrm{ml} \mathrm{f}$ ) $0 \mathrm{mg} / \mathrm{ml}$. When B. cereus samples were incubated with each $\mathrm{MgO}-\mathrm{Cl}_{2}$ concentration and plated onto agar plates, bacteria growth occurred with the majority of the incubated $\mathrm{MgO}-\mathrm{Cl}_{2}$ concentrations. The results obtained are shown in the Figure 27 note; samples $\mathrm{A}$ and $\mathrm{B}$ had no bacteria growth, which corresponded to $\mathrm{MgO}-\mathrm{Cl}_{2}$ concentrations $1 \mathrm{mg} / \mathrm{ml}$ and $0.5 \mathrm{mg} / \mathrm{ml}$.

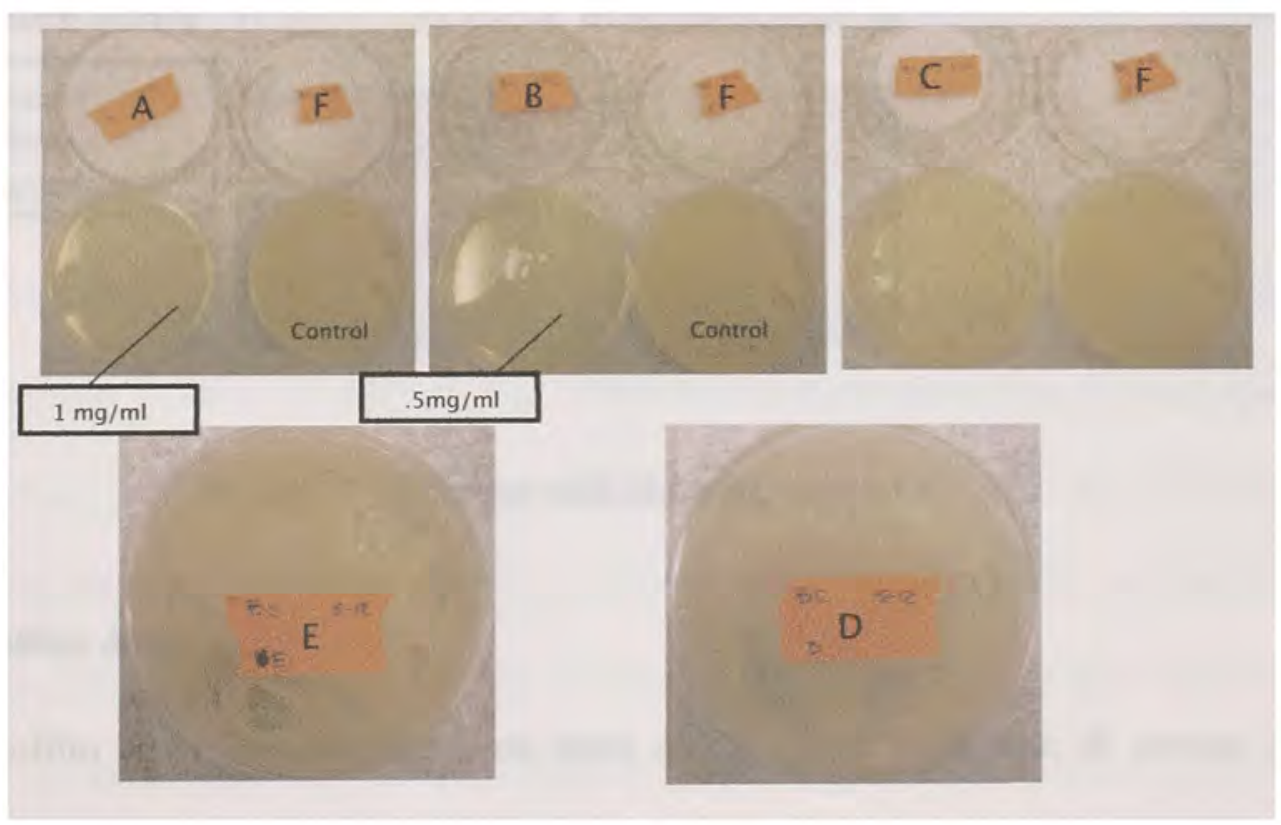

Figure 27. Bacteria Incubated with $\mathrm{MgO}-\mathrm{Cl}_{2}$

A) $1 \mathrm{mg} / \mathrm{ml} \mathrm{B}) 0.5 \mathrm{mg} / \mathrm{ml} \mathrm{C)} 0.25 \mathrm{mg} / \mathrm{ml}$ D) $0.125 \mathrm{mg} / \mathrm{ml} \mathrm{E)} 0.0625 \mathrm{mg} / \mathrm{ml} \mathrm{F)} 0 \mathrm{mg} / \mathrm{ml}$ 


\subsubsection{Halo Test}

The Halo test was performed on three specific bacteria strains, B. cereus, $B$. subtilis, and B. thuringiensis. These bacteria strains were grown and plated onto agar plates with $3 \mathrm{mg}$ of $\mathrm{MgO}-\mathrm{Cl}_{2}$ slurry administered into the center of each plate. After 48 hours, the plates were examined in the halo region for bacteria growth. The results obtained show that in a plated region with an initial high bacteria concentration, bacteria growth occurred within the halo region containing the $\mathrm{MgO}-\mathrm{Cl}_{2}$ slurry, refer to Figure 28 .

A.
A. B. cereus
B. B. subtilis
C. B. thuringiensis

B.

C.

Figure 28. Halo test with Bacteria samples

\subsubsection{Biofilm Assay I}

A biofilm assay was performed on three specific bacteria strains, B. cereus, $B$. thuringiensis, and B. subtilis. A 1:100 dilution of each bacterium culture was performed and then plated into the corresponding PVC plate. After $24 \mathrm{hrs}$ of incubation, biofilm formation occurred on the bottom of the well plate, and a variety of $\mathrm{MgO}-\mathrm{Cl}_{2}$ concentrations were dispensed into the corresponding well columns. 


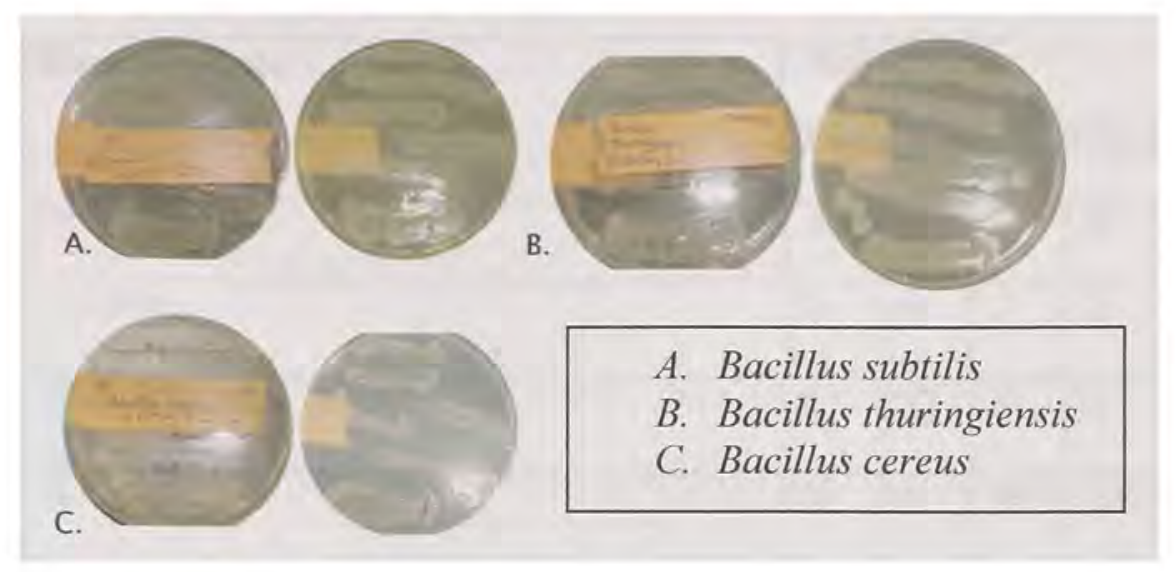

Figure 29. Bacteria Biofilm results using Biofilm assay I

The plates were incubated for 24 hours. Then, random column wells were scraped and streaked on specific areas on an agar plate. Then the plates were observed after 48 hours for bacteria growth, which occurred on every designated streaked area, shown above.

\subsubsection{Biofilm Assay II}

The MBEC assay was the second Biofilm assay performed with bacteria cultures, B. cereus, B. thuringiensis, and B. subtilis. All three strains were incubated in the MBEC device to generate biofilms on the peg lids. Once the biofilms were formed, each plate was treated with various $\mathrm{MgO}-\mathrm{Cl}_{2}$ concentrations for $24 \mathrm{hrs}$. Then, the peg lids were rinsed and transferred to a plate containing media, where the plates were sonicated to release the biofilms. The plates containing released biofilms were treated with $\mathrm{MgO}-\mathrm{Cl}_{2}$ plates were incubated for $24 \mathrm{hrs}$, and were visibly examined for bacteria colonies formation. All bacteria colonies were documented, and the results obtained are shown on Table 13. Additional bacteria colonies, absorbance counts were taken for each recovery biofilm plate by absorbance plate reading. 


\begin{tabular}{|l|l|l|l|l|l|l|}
\hline \multirow{2}{*}{ Bacteria plate } & \multicolumn{5}{|l|}{ MgO- $\mathrm{Cl}_{2}$ Conc. } \\
\cline { 2 - 8 } & \multicolumn{5}{|l|}{ \#卢s w/bacteria colonies } \\
\hline & A & B & C & D & E \\
\hline B. cereus & 0 & 6 & 1 & 2 & 15 \\
\hline B. thuringiensis & 1 & 11 & 3 & 3 & 14 \\
\hline B. subtilis & & 0 & 4 & 10 & 10 & 12 \\
\hline
\end{tabular}

Table 13. MBEC bacteria results after incubated with $\mathrm{MgO}-\mathrm{Cl}_{2}$

$\mathrm{MgO}-\mathrm{Cl}_{2}$ concentrations corresponding to:
A) $0.5 \mathrm{mg} / \mathrm{ml} \mathrm{B}$ ) $0.35 \mathrm{mg} / \mathrm{ml} \mathrm{C)} 0.125 \mathrm{mg} / \mathrm{ml}$
D) $0.0625 \mathrm{mg} / \mathrm{ml}$
E) $0 \mathrm{mg} / \mathrm{ml}$

The absorbance reading of each plate was statistically analyzed by a one-way ANOVA. A statistical model was created to determine if the $\mathrm{MgO}-\mathrm{Cl}_{2}$ concentration affected biofilm bacteria neutralization. The empirical model for bacteria neutralization was as follows:

$$
\mathrm{Y}=\mu+\mathrm{F}_{\mathrm{i}}+\varepsilon_{j}
$$

Where $\mathrm{F}=\mathrm{MgO}-\mathrm{Cl}_{2}$ formulations

A p-value $<0.05$ was obtained with respect to the bacteria colony presence after treatment of $\mathrm{MgO}-\mathrm{Cl}_{2}$ concentrations in regards to biofilms. The low $\mathrm{p}$ value indicates that the $\mathrm{MgO}-\mathrm{Cl}_{2}$ formulations within bacteria strains had adverse affects, thus were significantly different. Lastly, a statistical model for the three bacteria strains were also analyzed using an ANOVA test with two factors. The model for overall bacteria interaction with $\mathrm{MgO}-\mathrm{Cl}_{2,2}$ are shown below.

$$
Y=\mu+F_{i}+B_{j}+F_{i j}+\varepsilon_{k}
$$

Where $\mathrm{F}=$ Formulations and $\mathrm{B}=$ Bacteria strains 
The p-value of the new model for the affects of $\mathrm{MgO}-\mathrm{Cl}_{2}$ on three Bacillus strains were analyzed and formulation, bacteria strains, and the interaction had a p-value less than 0.05 , which indicates that they were significantly different.

\subsubsection{Fluorescent Microscopy of interaction between Bacteria and $\mathrm{MgO}-\mathrm{Cl}_{2}$}

The second sets of fluorescent images captured the effects of the bacteria sample, B. cereus, incubated with a stock concentration of $\mathrm{MgO}^{-\mathrm{Cl}_{2}}(2 \mathrm{mg} / \mathrm{ml})$. The fluorescent dyes Syto-9 (Green) and Ethidium homodimer-1 (Red) were used to determine the neutralization effects of $\mathrm{MgO}-\mathrm{Cl}_{2}$, when introduced to the bacteria cultures.

The green fluorescent bacteria rods represented the live bacterium, and the red fluorescent bacteria cells represented the dead bacteria cells. When the samples were analyzed at time $=0$, the sample had both red and green rods present. Within the samples, it was observed a large community of either red or green rods within a given sample. These images were captured when bacteria and $\mathrm{MgO}-\mathrm{Cl}_{2}$ were initially interacted, shown in Figure 30.

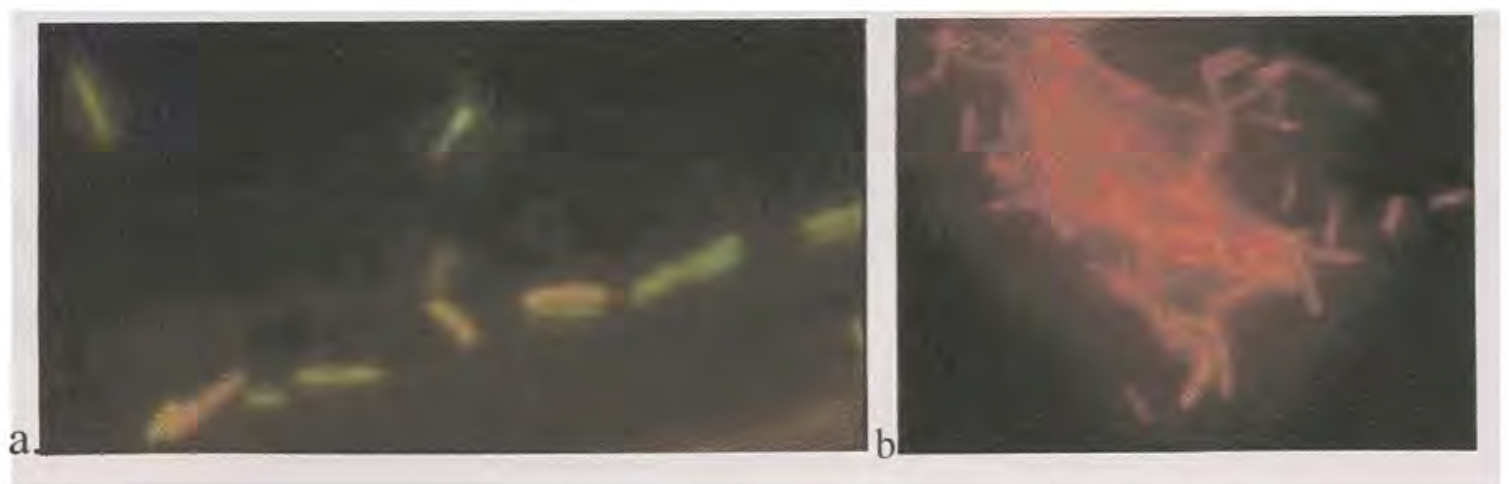

Figure 30. Fluorescent microscopy images of B. cereus and $\mathrm{MgO}-\mathrm{Cl}_{2} \mathrm{~A}$. B. cereus with $2 \mathrm{mg} / \mathrm{ml}$ of $\mathrm{MgO}_{-} \mathrm{Cl}_{2}$ at time $=0$ B. B. cereus with $2 \mathrm{mg} / \mathrm{ml}$ of $\mathrm{MgO}-\mathrm{Cl}_{2}$ at time $=0$ 


\subsection{Bacteria Testing with Immunoliposome nanoparticle Complex}

\subsubsection{Biofilm Assay II}

The same MBEC assay previously performed with $\mathrm{MgO}-\mathrm{Cl}_{2}$ was performed using B. cereus and the liposomes samples. In this test, each liposome sample was dispensed into specific wells in the MBEC device to treat bacteria biofilm. After $24 \mathrm{hrs}$, bacteria growth was observed and documented refer to figure 31. Also, absorbance reading of the plate were taken and then statistically examined.

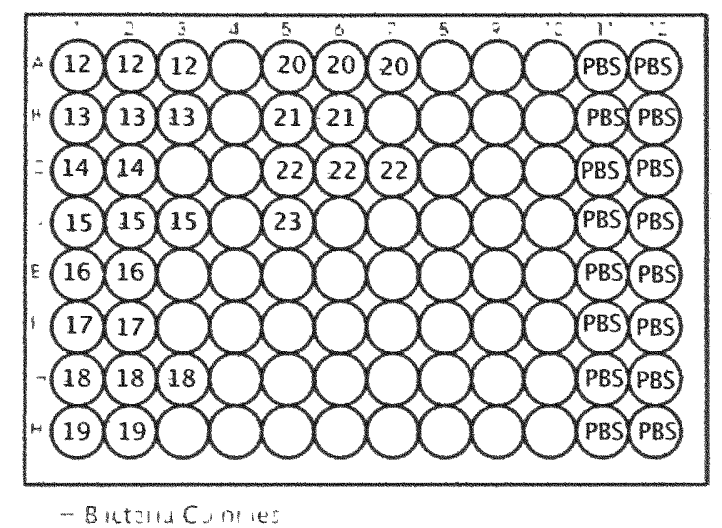

Figure 31. MBEC B. cereus biofilm results after incubated with Liposomes

The absorbance data obtained was statistically analyzed using a one-way ANOVA test. A statistical model was created to determine if the liposomes samples had an affect on neutralizing $B$. cereus. The empirical model used for bacteria neutralization was as follows:

$$
\mathrm{Y}=\mu+\mathrm{L}_{\mathrm{i}}+\varepsilon_{j}
$$

Where $\mathrm{L}=$ different liposome samples

A p-value of 0.153 was obtained from the ANOVA test, which indicates that the liposomes samples were not significantly different. 


\subsubsection{Fluorescent Microscopy testing}

Fluorescent microscopy captured the interaction of the bacteria with the Immunoliposome-nanoparticle complex. The liposome and bacteria interaction is shown on Figure 32(a) and (c), and the liposome antibody interaction is shown on Part b.

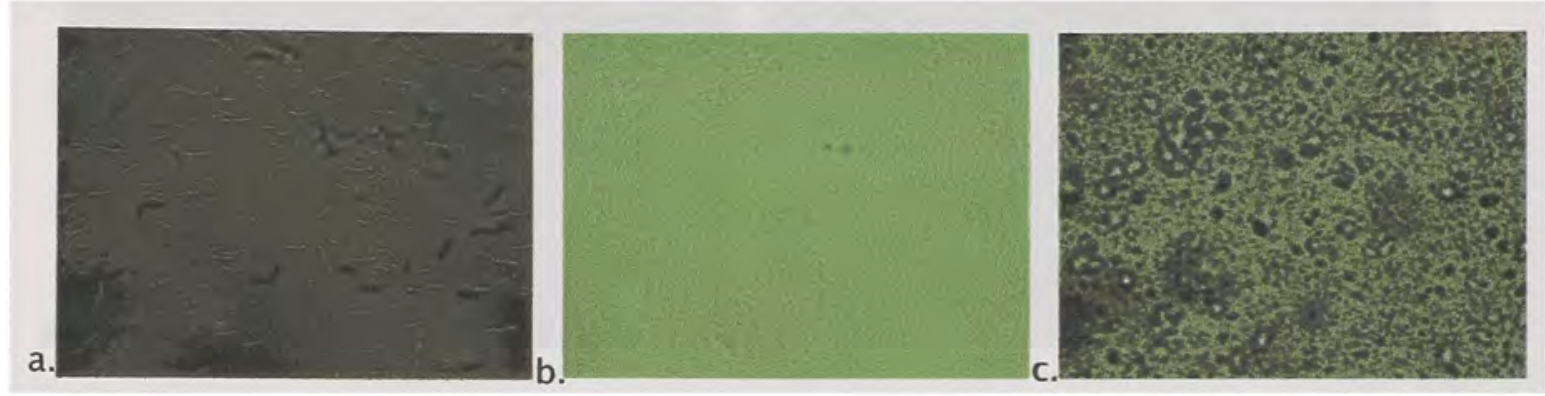

Figure 32. Fluorescent Microscopy Images of liposome and B. cereus. a. B cereus b. liposome 12 c. nanoparticle-antibody complex 5

The liposome sample and Bacillus cereus interaction were captured at three time interval, refer to Figure 33. All these were captured using a Fluorescent microscope and viewing the samples under three specific magnifications.

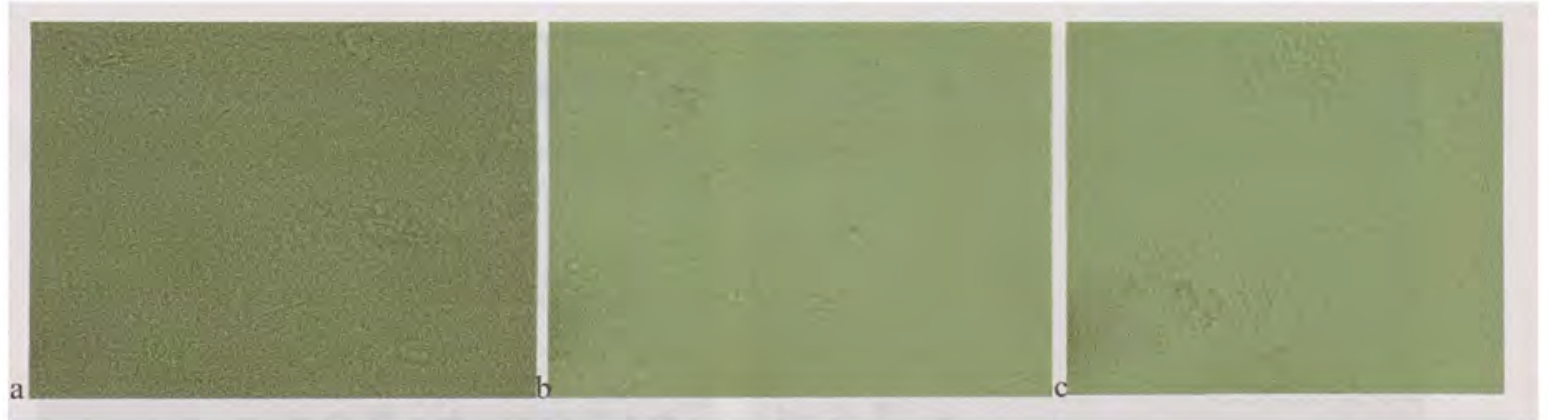

Figure 33. Fluorescent microscopy images of B. cereus and liposomes at time intervals a. Liposome 12 with $B$. cereus at time $=0$ b. Liposome 12 with B. cereus at time $=15$ minutes c. Liposome 12 with B. cereus at $1 \mathrm{hr}$. 
These samples were stained with DAPI and Ethidium homodimer-1 and images were captured at time $=30$ and after 60 minutes, refer to Figure 34 . In both staining after a 30-minute interval live bacteria were still seen.

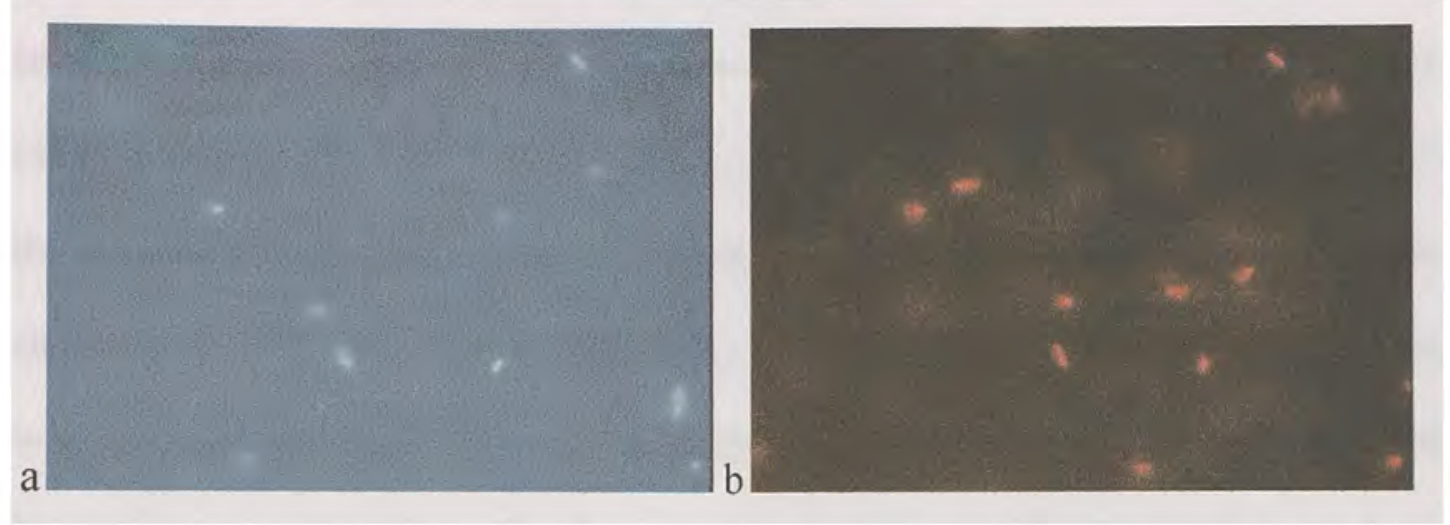

Figure 34. Fluorescent microscopy images of B. subtilis with sample 13-5 a. B. subtilis stained with DAPI interacting with Liposome complex 13-5 after 30 minutes b. $B$. subtilis stained with Ethidium homodimer-1 interacting with Liposome complex 13-5 after 30 minutes stained

Additional images were captured after the B. subtilis were incubated for an hour with the liposome-complex 13-5. When the images were analyzed, it showed a minimal amount of DAPI live cells, and a high concentration of dead red bacteria cells.
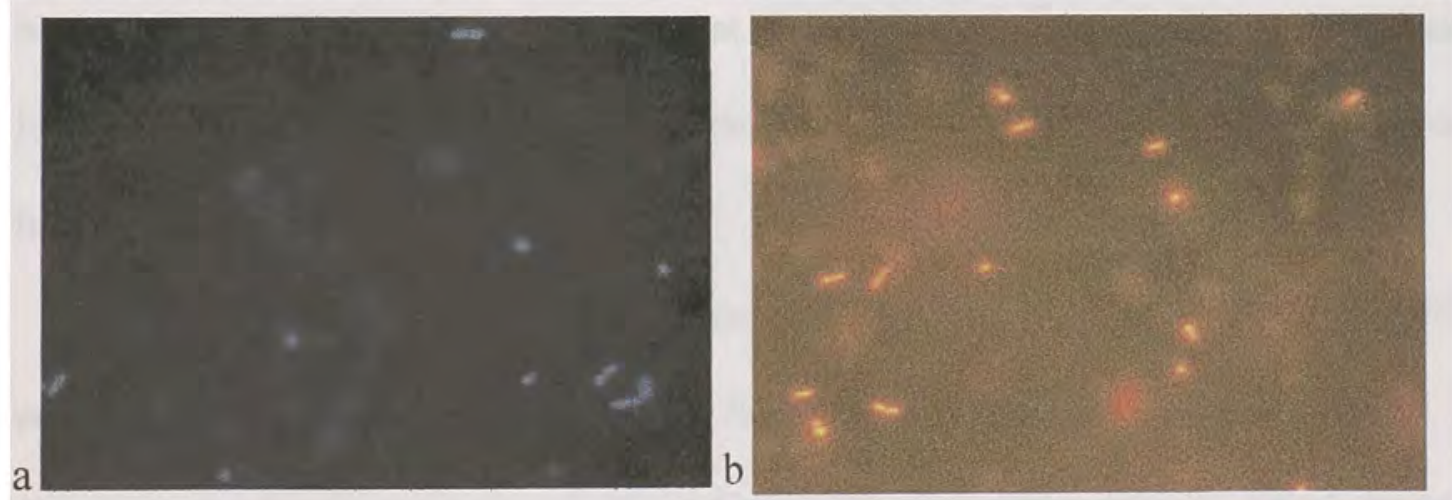

Figure 35 Fluorescent Micrographs of B. subtilis with Immunoliposome-nanoparticle complex. a. B. subtilis stained with DAPI interacting with Liposome complex 13-5 after an hour stained b. B. subtilis stained Ethidium homodimer-1 interacting with Liposome complex 13-5 after an hour 


\subsubsection{Data acquisition of Bacteria and Immunoliposome interaction using Flow Cytometry}

Flow cytometry was used to study the interaction of the bacteria samples with the immunoliposomes-nanoparticle complexes. These interactions were studied by using the ( $488 \mathrm{~nm}$ blue laser) of the flow cytometer, and by triggering the fluorescent property of the nanoparticle $(577 \mathrm{~nm})$ conjugated to the liposome complex to detect the bacteria, shown in the FL2 gated region $(580 / 30 \mathrm{~nm})$. The neutralization efficacy of the liposomes was analyzed by using a live dead assay with specific cell viability dye, Ethidium homodimer-1, activated in membrane-compromised cells shown in FL3 gated region $(630 / 30 \mathrm{~nm})$. The interaction of the novel complex with the bacteria sample resulted in a shift to the bacteria control gated region (ethanol treated), a positive indication of the neutralization efficacy of the liposomes.

The bacteria sample $B$. subtilis was interacted with the Immunoliposomenanoparticle complex number 13-5, and with two fluorescent dyes, Syto-9 and Ethidium homodimer-1. The sample was analyzed at time $=0$, and the data outputs were obtained in histograms (Figure 36). These histograms were gated at specific regions for accurate interpretations.

The first gated region, R1, represents the dead bacteria ethanol neutralized controlled region stained with Ethidium homodimer-1. The second gated region, R2, represents the live bacteria sample stained with Syto-9. Furthermore, the gated region R3 and R4 correspond to the "live" and "dead" peaks, based upon percentage of staining by Ethidium homodimer-1. 


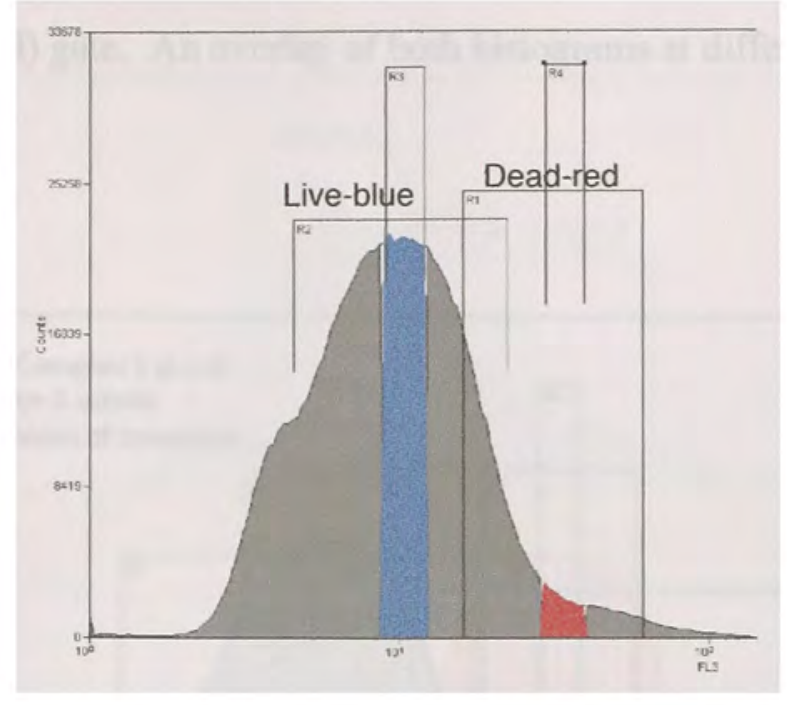

Figure 36. B. subtilis immunoliposomes-nanoparticle complex 13-5 at time zero As shown in Figure 36, a majority of the bacteria samples once interacted with the Immunoliposome-nanoparticle complex were still alive.

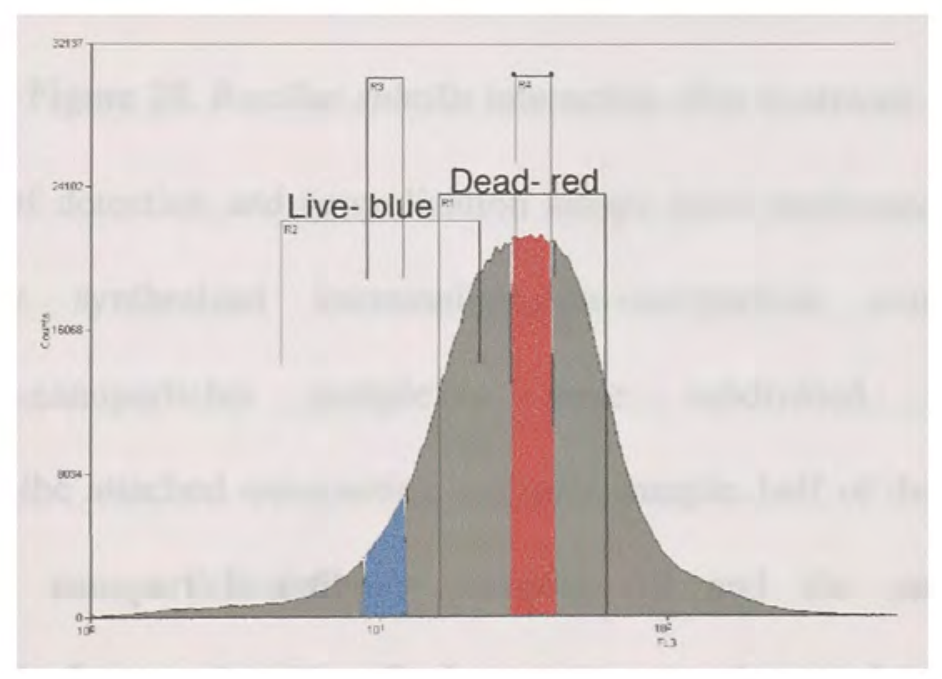

Figure 37. B subtilis immunoliposomes-nanoparticle-complex after 2 hours After two hours of the bacteria and Immunoliposome-nanoparticle complex interaction, a shift in fluorescent occurred, a portion of the cells in the R3 (blue) gate 
shifted to the R4 (red) gate. An overlay of both histograms at different time intervals is shown below.

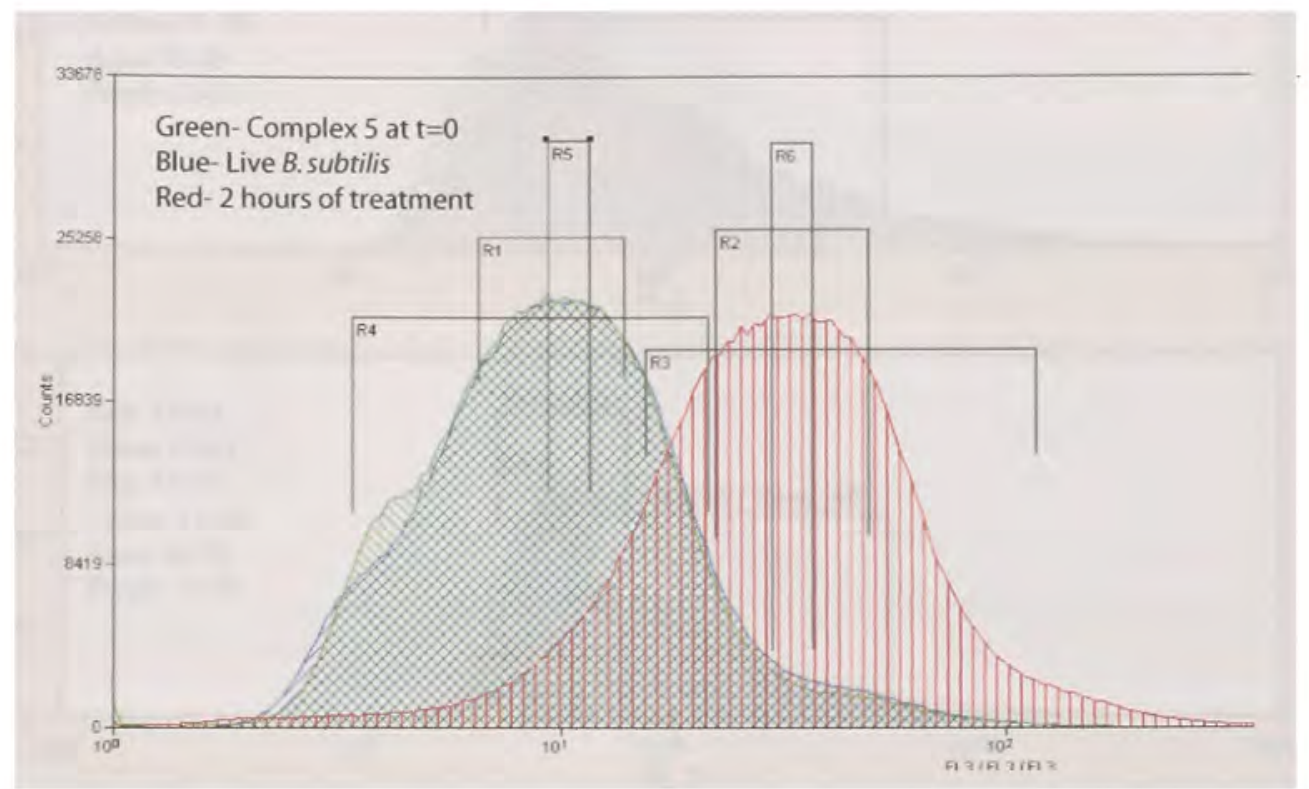

Figure 38. Bacillus subtilis interaction after treatment

A series of detection and neutralization assays were performed with B. cereus, and the newly synthesized Immunoliposome-nanoparticle complexes. The Immunoliposome-nanoparticles complexes were subdivided into categories corresponding to the attached nanoparticle-complex sample; half of the liposomes were conjugated with nanoparticle-antibody complex 10 and the second half with nanoparticles-antibody complex 11. Each complex sample was interacted with live bacteria and Ethidium homodimer-1. The samples were analyzed by flow cytometry at two time intervals, time $=0$ and time $=2$ hours, see Figure below. 


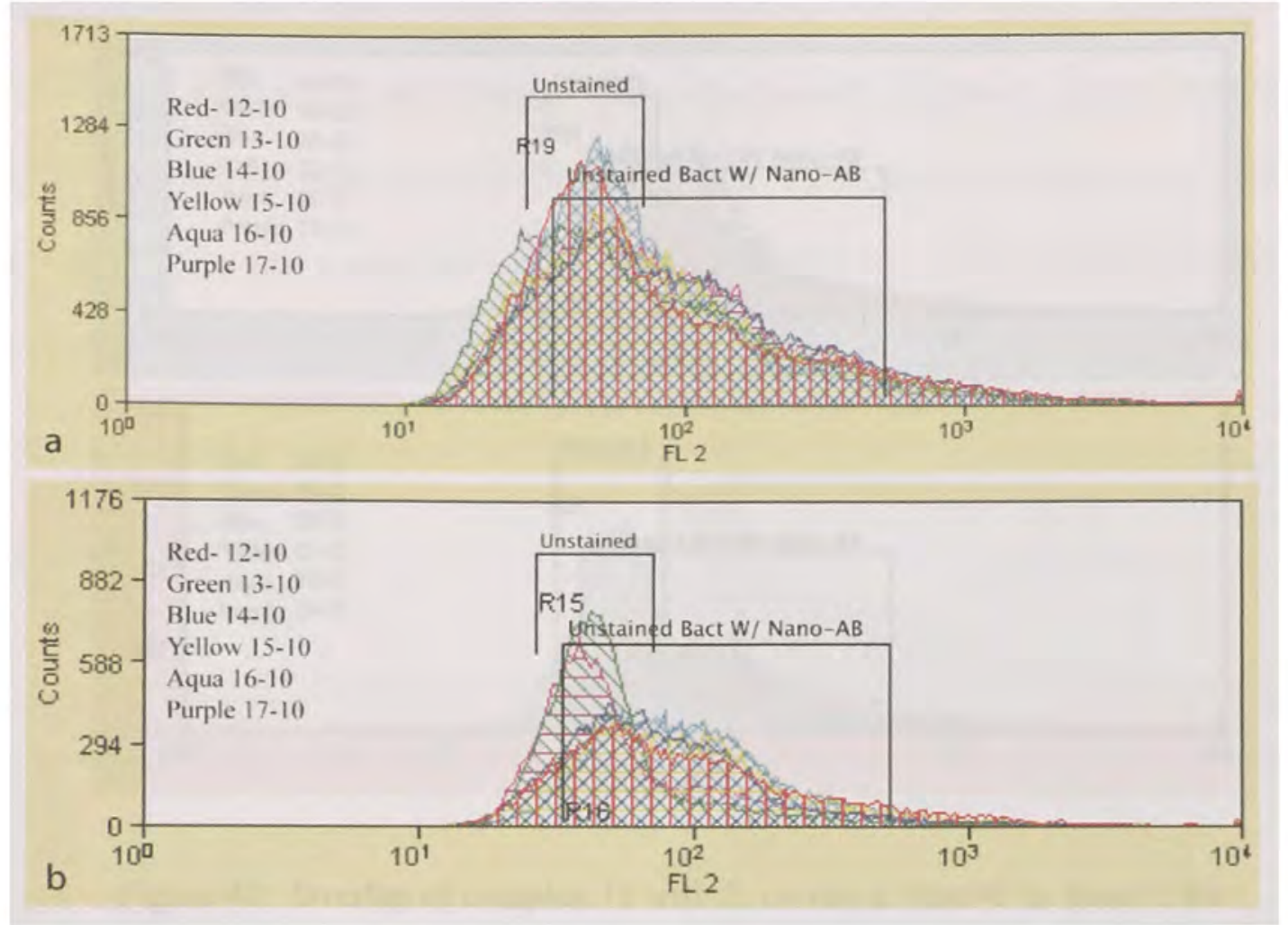

Figure 39. Overlap of complex 10 with $B$. cereus a. time $=0 \mathrm{~b}$. time $=2 \mathrm{hrs}$

Bacteria detection was observed with various types of liposomes and with both types of nanoparticle complexes. As shown in Figure 39, the greatest shift in fluorescent occurred after two hours with samples, 14-10, 15-10, 16-10, which all belonged to formulation (a), an indication of an increase of nanoparticles adhered to the bacteria. However, sample 12-10, 17-10 from formulation (d) did not show an increase in detection.

Also, it was examined that both samples 13-10 and 17-10 showed some dissociation from the bacteria after two hours, a negative indicator. Nonetheless, all liposome nanoparticle complex formulations interacted with bacteria resulted in an immediate detection with some outliers. 

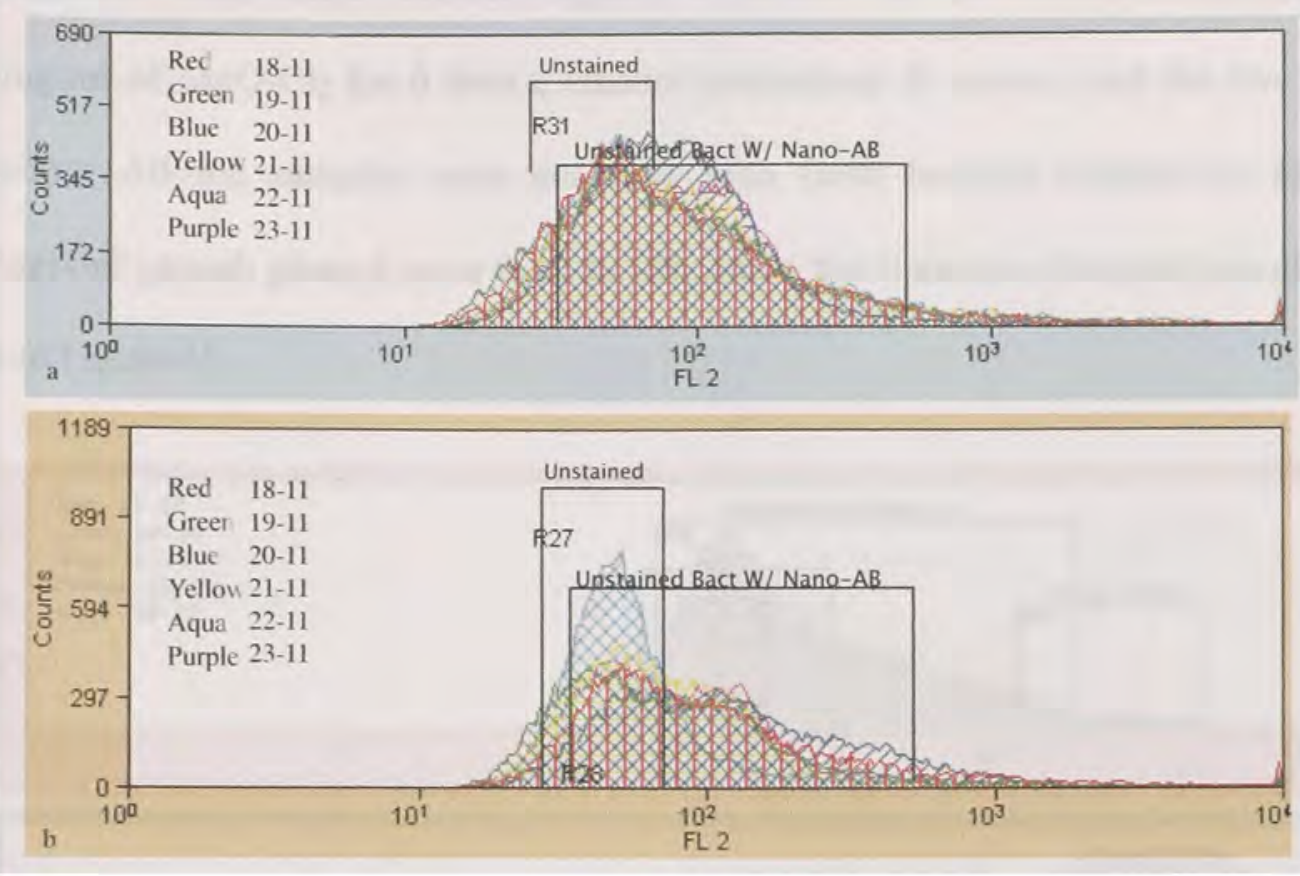

Figure 40 . Overlap of complex 11 with $B$. cereus a. time $=0$ b. time $=2 \mathrm{hrs}$

The liposome samples conjugated with the nanoparticle complex 11 were interacted with $B$. cereus and analyzed at two time intervals, shown Figure 40 . All the Immunoliposome-nanoparticle complex samples interacted with $B$. cereus resulted in bacteria detection indicated by the right tail in the histogram (figure 40.b). From these tests, it indicates that all the lipid formulation had similar results in detection at time $=0$. After 2 hours, detection slightly increased, represented by a broad histogram. Although, the lipid film formulation (b) sample 22-11, showed bacteria nanoparticle dissociation after $2 \mathrm{hr}$, apparent by a sharp histogram.

After the samples were analyzed for bacteria detection, they were further analyzed for bacteria neutralization using a "dead" fluorescent dye, Ethidium homodimer-1. For testing purposes, control regions were created for accurate interpretation of the 
experimental data, these control regions consisted of: B. cereus incubated with $0.35 \mathrm{mg} / \mathrm{ml}$ of $\mathrm{MgO}-\mathrm{Cl}_{2}$ for 6 hours, ethanol neutralized B. cereus, and the live region (syto-9). All the samples were analyzed with fresh bacteria cultures in assumed exponential growth phased were used to determine the liposome formulations efficacy, refer to Figure 41.

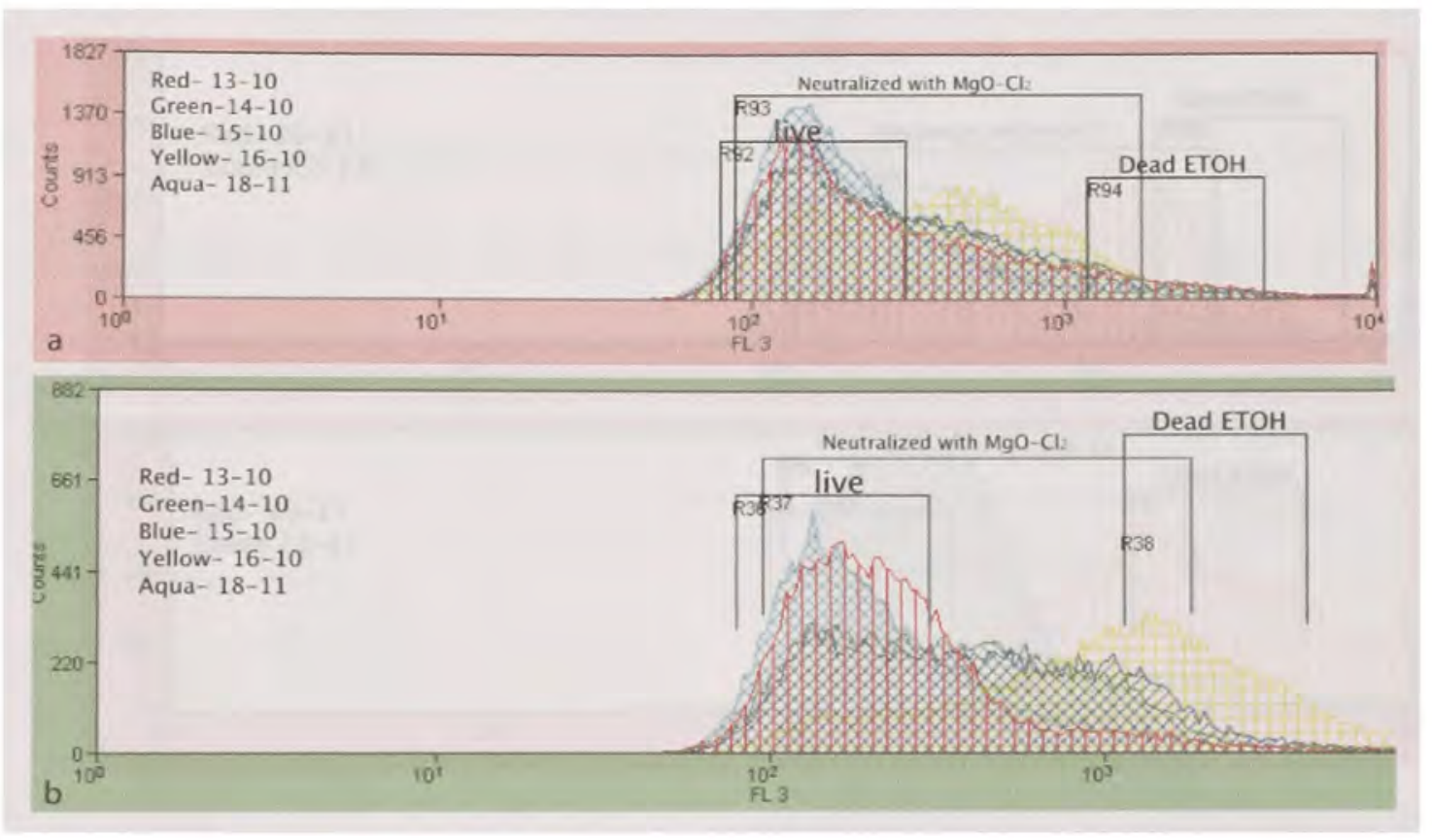

Figure 41. Immunoliposome Formulation (a) interacted with $B$. cereus a. time $=0$ b. time $=2 \mathrm{hrs}$

The lipid film formulations were grouped together in one histogram to demonstrate the effectiveness of the liposomes in neutralizing B. cereus. The lipid film Formulation (a) individual histograms were grouped together and analyzed to determine the effectiveness of the liposome in neutralizing bacteria. As shown in Figure 41, the five independent liposome samples acquired different bacteria neutralization rates.

The greatest neutralization effect at time $=0$ was achieved with sample $16-10$, and when analyzed after 2 hours the histogram peak was located in the ethanol neutralized 
region. Thus indicating that the greatest killing effect was achieved by sample 16-10. Also, the samples 14-10 and 15-10 displayed similar neutralization characteristics at both time intervals, with the highest effect after 2 hours. Additionally, the lipid film 13-10 and 18-11 both had similar histogram peaks throughout the time interval, while having a large percentage after two hours in the live-gated region.

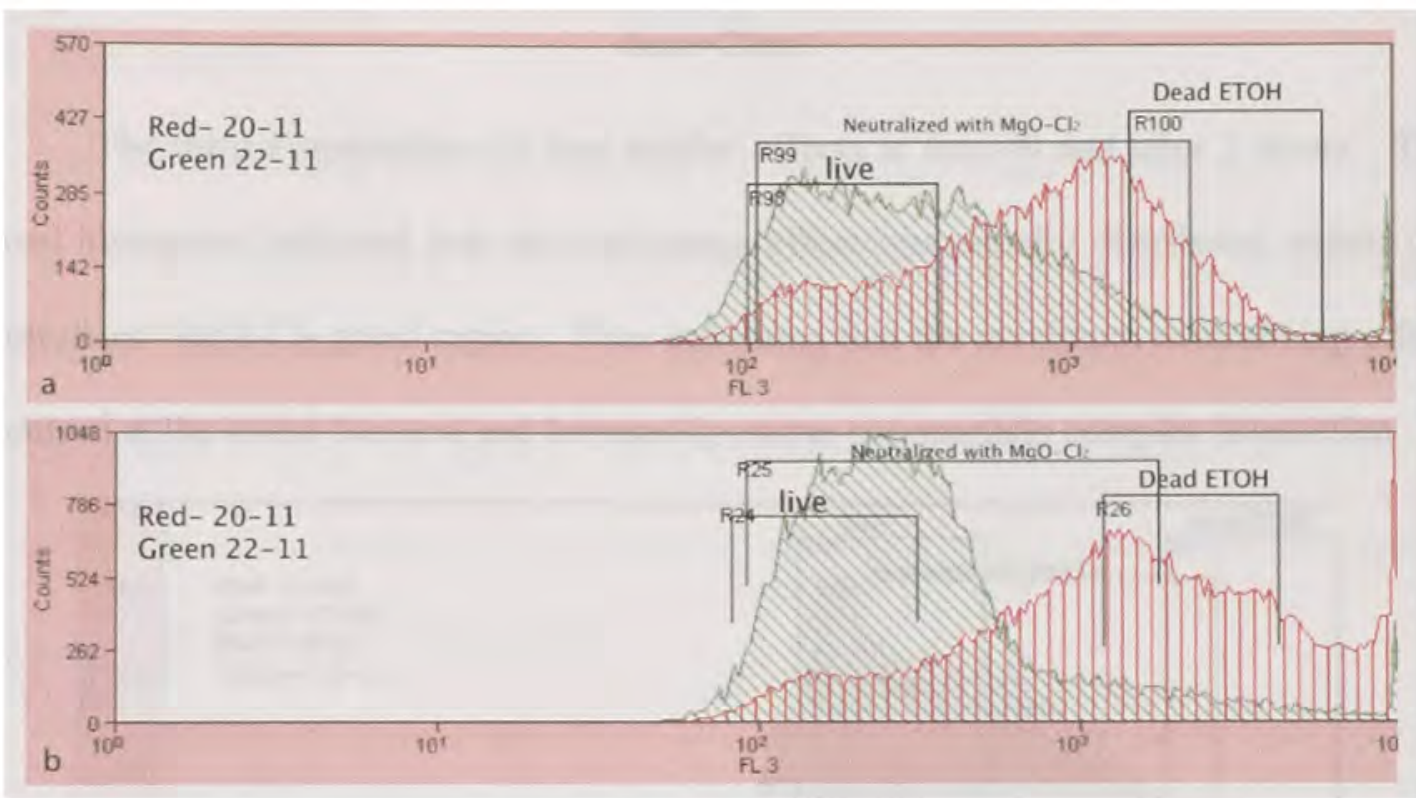

Figure 42. Immunoliposome Formulation (b) interacted with $B$. cereus a. time $=0 \mathrm{~b}$. time $=2$ hours.

The second Formulation (b) was analyzed to determine the effectiveness of lipid film in neutralizing bacteria. In this study the samples $20-11$ and $22-11$ were analyzed, and both the results were analyzed showed wide variability in neutralizing bacteria. Hence, the greatest killing effect at time $=0$ was achieved with the lipid film $20-11$, which increased eradication when incubation time was increased. Note, the greatest histogram peak of sample 20-11 occurred beyond the ethanol gated control region (Figure 42). 


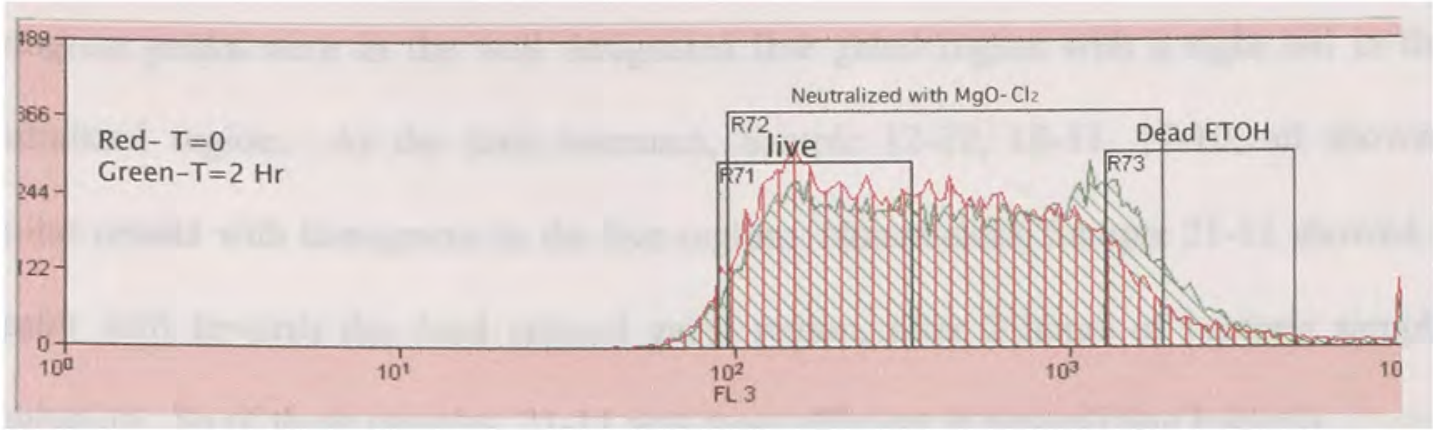

Figure 43. Immunoliposome Formulation (c) interacted with $B$. cereus at time $=0$ and time $=2 \mathrm{hrs}$

The third Formulation (c) had similar effects at time $=0$ and after 2 hours. The broad histogram indicated that the eradication effect was equally distributed within the neutralized $\mathrm{MgO}-\mathrm{Cl}_{2}$ gated region. Thus indicating that the maximum neutralizing effect occurred at the initial bacteria and Immunoliposome-nanoparticle complex interaction.

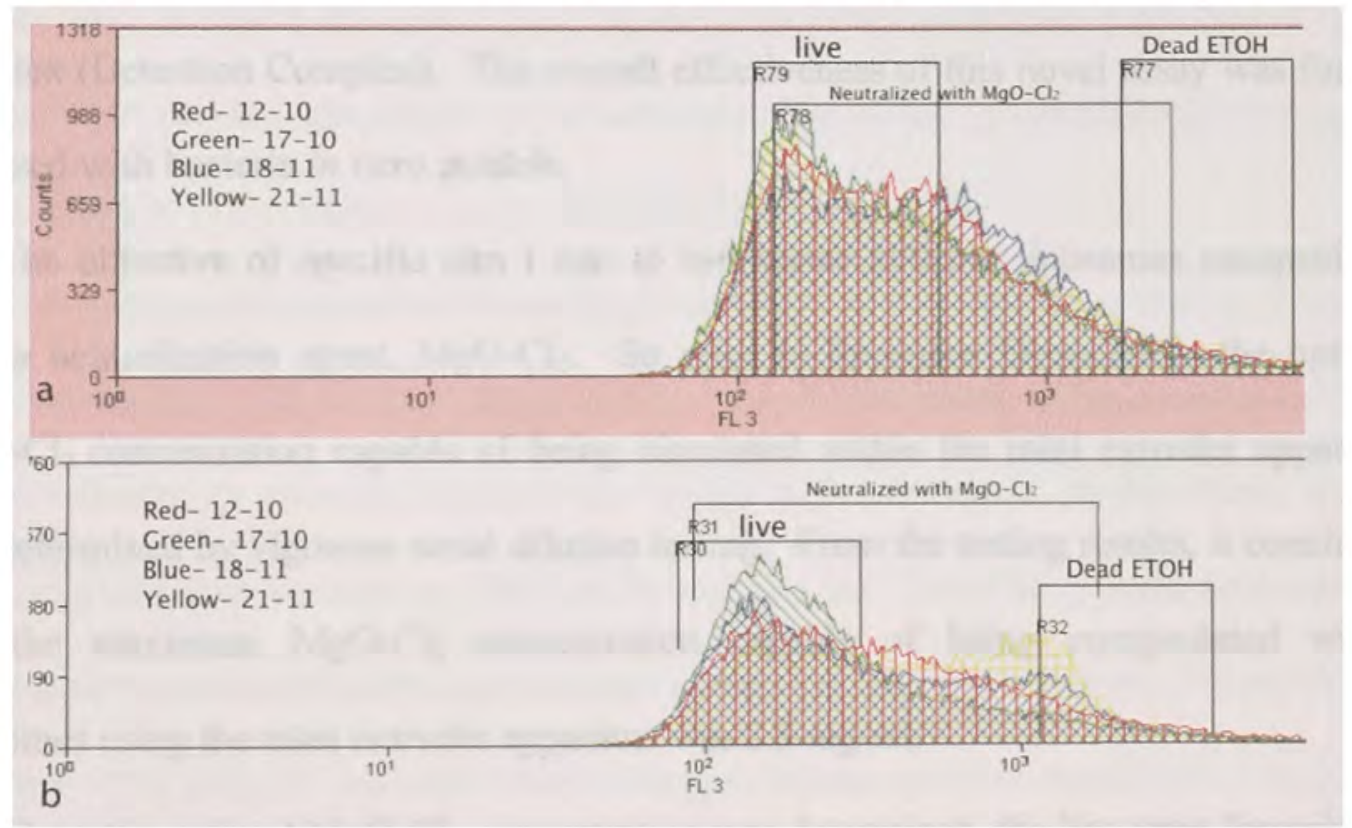

Figure 44. Immunoliposome Formulation (d) interacted with B. cereus a. time $=0$ b. time $=2 \mathrm{hrs}$

The last lipid film Formulation (d) histograms when analyzed at both time intervals, showed similar bacteria killing effects. When the sample was examined at time $=0$, all the 
histogram peaks were in the well designated live gated region with a right tail in the neutralized region. As the time increases, Sample 12-10, 18-11, 17-10, all showed similar results with histograms in the live region. Nonetheless, Sample 21-11 showed a greater shift towards the dead ethanol gated region, after 2 hours of bacteria sample incubation. So of these samples, 21-11 was more efficient in neutralizing bacteria.

\subsection{DISCUSSION}

The task to develop a new method that can effectively detect and neutralize bacterial biohazards in a short interval is very challenging. In this project, the novel detection and neutralization assay was achieved by using liposomes encapsulated with $\mathrm{MgO}^{-\mathrm{Cl}_{2}}$ (Neutralization Agent) conjugated with a modified streptavidin-nanoparticle antibody complex (Detection Complex). The overall effectiveness of this novel assay was further analyzed with bacteria in vitro models.

The objective of specific aim I was to synthesize $100 \mathrm{~nm}$ liposomes encapsulated with a neutralization agent, $\mathrm{MgO}-\mathrm{Cl}_{2}$. So prior to liposome formulation, the optimal $\mathrm{MgO}-\mathrm{Cl}_{2}$ concentration capable of being circulated within the mini extruder apparatus was determined by vigorous serial dilution testing. From the testing results, it concluded that the maximum $\mathrm{MgO}-\mathrm{Cl}_{2}$ concentration capable of being encapsulated within liposomes using the mini extruder apparatus was $2.5 \mathrm{mg} / \mathrm{ml}$.

Once the optimal $\mathrm{MgO}-\mathrm{Cl}_{2}$ concentration was determined, the liposome formulation protocols were developed taking in consideration the two main project objectives being:

1. Rapid bacteria detection 2.Rapid bacterial neutralization. With these two objectives in mind, two main lipid formulations were created to assist in determining the optimal 
liposome formulation for rapid bacteria detection. These two main lipid formulations differed by the type of biotin lipid attachment added to the main formulation. The importance of the biotin component is crucial for the attachment site of the detection portion (streptavidin coated nanoparticle antibody complex) to adhere to the bacteria. The structure formation of the attachment of Streptavidin and Biotin formation can provide either favorable or unfavorable structure formation that can either promote or dissociate attachment to the bacteria. With this reasoning, the biotin additive in both formulations can help determine the nominal biotin compound necessary to enhance bacteria detection.

Additional liposome formulations were created to gain an understanding exactly how lipids components such as Cholesterol play an essential role in the releasal of the encapsulated material in neutralizing bacteria. So two additional formulations were created with varying concentrations of cholesterol in order to establish the successful formation in both detecting and neutralizing bacteria pathogens.

The first specific aim called to verify the presence of liposomes in solution. This was accomplished by SEM analysis, the positive visual identification of the presence and size of these liposomes was confirmed. One of the main objectives of this thesis was to produce a solution containing $100 \mathrm{~nm}$ liposomes, but from the images captured the smallest liposome size visibly analyzed had a diameter size ranging from $177 \mathrm{~nm}$ to 212 $\mathrm{nm}$. The SEM analysis indicates that a widespread liposome size distribution is apparent within the sample specimen.

The Liposome diameter size can be altered from the initial liposome extrusion to the final purification procedure. So creating an exact $100 \mathrm{~nm}$ liposome solution is nearly impossible given the current membrane porosity of $100 \mathrm{~nm}$. So in order to achieve a 
liposome solution containing a wide spread size distribution of $100 \mathrm{~nm}$, a smaller pore less than a $100 \mathrm{~nm}$ would be required.

The projects second specific aim addressed the synthesis and recovery (yield) of both the antibody-Sh and the streptavidin-nanoparticle complex. The absorbance reading of each recovered sample showed a widespread viability with an antibody concentration ranging from $0.085 \mathrm{mg} / \mathrm{ml}$ to $0.288 \mathrm{mg} / \mathrm{ml}$, achieved from sample 8 and 4 . These samples were all created following the same protocol formulation. The Streptavidinnanoparticle-mbs complex samples recovered showed a range of sample recovery from a low $0.267 \mathrm{mg} / \mathrm{ml}$ to a high $0.918 \mathrm{mg} / \mathrm{ml}$, achieved from sample 9 and 5 . The widespread variability demonstrated that each individual sample recovered achieved similar results from the final sample, calculated by the BCA assay. So manual generation of streptavidin and antibody extraction with the initial synthesis reaction could account for the protein recovery (yield) variability.

The third specific aim of this project consisted of general live/dead verification testing of bacteria with $\mathrm{MgO}-\mathrm{Cl}_{2}$ and Immunoliposome-antibody complexes. Before any cytoxitiy testing was performed, the $\mathrm{MgO}-\mathrm{Cl}_{2}$ was tested for the presence of Chloride ions. The Silver nitrate testing was the first assay performed to determine the presence of chlorine within the nanoparticles. When the reactant, silver nitrate, was dispensed into each sample prepared, a brown precipitate color change was observed in de-ionized water. A typical positive identification for chlorine ions with the silver nitrate reagent produces a white precipitate. Although with our samples a brown precipitate occurred that could be attributed to the high levels of magnesium with $\mathrm{MgO}-\mathrm{Cl}_{2}$ nanoparticles. 
Furthermore, the results obtained provided substantial evidence indicating that the sample of $\mathrm{MgO}-\mathrm{Cl}_{2}$ obtained from Nanomat Inc. contained chlorine.

When attempting to use the silver nitrate assay with the liposomes solution to determine the concentration of the $\mathrm{MgO}-\mathrm{Cl}_{2}$ encapsulant, a slight dilemma occurred. The buffer reacted with silver nitrate producing a white precipitate. So the silver nitrate assay could not be performed to identify the presence of $\mathrm{MgO}-\mathrm{Cl}_{2}$ within the liposomes.

An additional assay was performed attempting to determine the concentration of $\mathrm{MgO}-\mathrm{Cl}_{2}$ within the liposome solution. An absorbance scan reading of the $\mathrm{MgO}-\mathrm{Cl}_{2}$ nanoparticles suspended in de-ionized water was performed with the Cary UV-Vis. The results were analyzed and suggested that the $\mathrm{MgO}-\mathrm{Cl}_{2}$ absorbance spectrum has a slight peak at $259 \mathrm{~nm}$, which continues down a steady straight line on all absorbance wavelengths. Thus, the absorbance characteristics of $\mathrm{MgO}-\mathrm{Cl}_{2}$ cannot be used to identify the concentration of $\mathrm{MgO}-\mathrm{Cl}_{2}$ within the liposome. So, future independent assay will have to be developed to determine the concentration of $\mathrm{MgO}-\mathrm{Cl}_{2}$.

A series of control tests were performed to determine the nominal concentration of $\mathrm{MgO}-\mathrm{Cl}_{2}$ necessary to neutralize bacteria in different environments. The first bacterial cyto-toxicity test was performed with fresh $B$. cereus bacteria suspension cultures incubated with various $\mathrm{MgO}-\mathrm{Cl}_{2}$ concentrations for 24 hours. After several $\mathrm{MgO}-\mathrm{Cl}_{2}$ concentrations were incubated within the bacterial culture suspension, sample aliquots of each sample were plated into independent agar plates, and incubated for a day. The following day, the plates were observed for bacteria colonies growth, which occurred in every plate except for sample (a) and (b), corresponding to $\mathrm{MgO}-\mathrm{Cl}_{2}$ concentration of 1 $\mathrm{mg} / \mathrm{ml}$ and $0.5 \mathrm{mg} / \mathrm{ml}$. Note, after 24 hours of bacteria and $\mathrm{MgO}-\mathrm{Cl}_{2}$ incubation, a strong 
chlorine odor was apparent in conical tube A and B. So from the observed results, the optimum concentration of $\mathrm{MgO}-\mathrm{Cl}_{2}$ need to neutralize bacteria in suspension would be 1 to $0.5 \mathrm{mg} / \mathrm{ml}$. Also, the bacteria conical tube with a concentration of $0.35 \mathrm{mg} / \mathrm{ml}$ still achieved bacteria growth, which is the same concentration theoretically encapsulated within the liposomes. So theoretically from these results it suggested that bacteria neutralization in a sample of bacteria suspension should readily occur if $\mathrm{MgO}-\mathrm{Cl}_{2}$ concentration encapsulated within the liposome.

Additional control test were performed with bacteria in different environments with the neutralizing Agent, $\mathrm{MgO}-\mathrm{Cl}_{2}$. One test was the Biofilm assay I and the other test was Halo test, which were both performed with various Bacillus bacteria strains with $\mathrm{MgO}-\mathrm{Cl}_{2}$. The biofilm assay I was performed with three bacillus strains and treated with various concentrations of $\mathrm{MgO}-\mathrm{Cl}_{2}$. Interesting, all the bacteria strains that were treated with various $\mathrm{MgO}-\mathrm{Cl}_{2}$ concentrations achieved bacteria growth.

One reason for bacteria growth in Biofilm I could be attributed to bacteria biofilms formation occurring on the bottom of the PVC flat plates. The issue with this assay is that the treatment $\left(\mathrm{MgO}-\mathrm{Cl}_{2}\right)$ is administered on the top of the biofilm. So bacteria can still be viable on the very bottom of the plates, since $\mathrm{MgO}-\mathrm{Cl}_{2}$ penetration does not occur. Also, since the bottom of random wells were scraped and plated onto agar plates to test the effectiveness of the assay, viable cells can exist. Therefore, bacteria growth may have resulted from error in technique.

As a result of this variability a second biofilm assay referred as the MBEC assay was performed, which is less susceptible to technique error, in regards to bacteria biofilm assay. These MBEC biofilms are created on Pegs located on the well plate lid, and are 
released when sonicated. So the $\mathrm{MgO}-\mathrm{Cl}_{2}$ nanoparticle is incubated within a homogenous bacteria solution. Thus, it is a better determinant of bacteria growth or neutralization via $\mathrm{MgO}-\mathrm{Cl}_{2}$ nanoparticles.

The MBEC biofilm study results differed from the previous results attained from bacteria $\mathrm{MgO}-\mathrm{Cl}_{2}$ (neat) incubation. When three bacteria strains were treated with various $\mathrm{MgO}-\mathrm{Cl}_{2}$ concentrations in the $\mathrm{MBEC}$ study, observations varied with each bacterium strain. Generally, all three bacteria strains had the highest bacteria neutralization achieved with $0.5 \mathrm{mg} / \mathrm{ml}$ of $\mathrm{MgO}_{-} \mathrm{Cl}_{2}$. When the individual bacterium strain was examined, it was found that particularly B. subtilis had the second highest neutralization achieved with $\mathrm{MgO}-\mathrm{Cl}_{2}$ concentration of $0.35 \mathrm{mg} / \mathrm{ml}$. This is particularly important because the theoretical concentration of $\mathrm{MgO}-\mathrm{Cl}_{2}$ within the liposomes was assumed to be $0.35 \mathrm{mg} / \mathrm{ml}$. On the contrary, both bacteria strains (B. thuringiensis and $B$. cereus) had the second best bacteria neutralization at concentration of $0.125 \mathrm{mg} / \mathrm{ml}$ and $0.0625 \mathrm{mg} / \mathrm{ml}$. So the neutralizing effect of $\mathrm{MgO}-\mathrm{Cl}_{2}$ differed when treated in biofilms and bacteria cells suspensions.

When statistical analysis was performed on these three bacteria strains the p-value obtained concluded that the two statistical factors, formulations, bacteria, and the interaction were significantly different. So the $\mathrm{MgO}-\mathrm{Cl}_{2}$ formulations had a different reaction with different bacteria strains, and that each bacterium examined from the same genus does not exhibit the same reaction to the neutralization agent. Since, these bacteria strains share very similar properties, it was suggested that similar killing effect was supposed to be seen with all $\mathrm{MgO}-\mathrm{Cl}_{2}$ formulations. Because the statistically results obtained contradicted this hypothesis, it can be stated that $\mathrm{MgO}-\mathrm{Cl}_{2}$ could have a different 
killing effect on different bacteria strains, or the variability seen could be attributed to wide distribution of $\mathrm{MgO}-\mathrm{Cl}_{2}$ particle size.

Currently, there is not an assay to quantitatively determine the concentration of $\mathrm{MgO}-\mathrm{Cl}_{2}$ within the liposomes, but a correlation between liposome and bacteria death can be determined. For this reason, the MBEC assay was performed with $B$. cereus and treated with the liposome samples experimentally created. After 24 hours, each individual well was examined for bacteria growth. The experimental results obtained with this bacterium assay gave a prediction of the neutralization property of the $\mathrm{MgO}-\mathrm{Cl}_{2}$ and liposome formulation in bacteria biofilm neutralization. Some variability occurred within the experimental results, for example, bacteria growth was attained after treatment of the biofilm with liposome samples $16,17,19$, and 23 , which produced bacteria growth on average $1 / 3$ of the time. Nonetheless, in the MBEC assay bacteria growth was inhibited by the three liposome samples, which all had similar results when examined under flow cytometry. The empty liposome sample 19 when examined under flow cytometry achieved bacteria killing; this indicates that this control must have been contaminated with $\mathrm{MgO}^{-\mathrm{Cl}_{2}}$. Furthermore, the best liposome sample that showed bacteria neutralization was achieved by sample 16 , which was observed with this MBEC biofilm.

Moreover, the goal of this MBEC assay was used to determine if altering the concentration of cholesterol within the lipid bilayer would achieve faster bacteria neutralization. The results achieved from the original liposomes formulation with cholesterol, and without cholesterol within the lipid membrane had similar effect on killing the bacteria biofilms. So the actual significance of cholesterol within the lipid 
bilayer in releasing the encapsulant $\mathrm{MgO}-\mathrm{Cl}_{2}$ could not be strongly concluded. From the experimental results it could not be stated that the cholesterol concentration was significant. In order to gain a better understanding on the cholesterol role in liposomal encapsulant releasal, further studies would have to be assessed.

The results of the MBEC biofilm assay when exposed to different liposome formulations samples showed bacteria growth inhibited in the presence of these liposomes. From the MBEC assay, it was clearly seen that some liposome samples were more efficient then other in the treatment of biofilms, but from the p-values obtained it confirmed that the formulations were significantly different in terms of bacteria growth inhibition. Therefore, our finding suggest that the cholesterol concentration within the lipid bilayer did not produce a significant killing effect, but again further studies would have to be performed to determine if cholesterol plays a direct role in bacteria neutralization.

Additional evidence of the interaction of the bacteria cells with the liposomes was apparent from the fluorescent micrographs. The images showed large quantities of the Immunoliposome-nanoparticle complex interacted with the bacteria, and as the liposomes surrounded the bacteria, bacteria death was increased. Also, it was evident that the nanoparticle-antibody complex did adhere to the bacteria cell wall. The positive indication of the nanoparticle-antibody complex attachment indicates that complex can be used to detect the bacteria. Also, the increased bacteria occurred when liposomes surrounded bacteria, indicating that liposomal encapsulant is released, and the direct contact with $\mathrm{MgO}-\mathrm{Cl}_{2}$, close proximity is responsible for bacteria death. 
Fluorescent microscopy with fluorescent dyes was used to provide additional evidence of the neutralization power of both the liposomes and $\mathrm{MgO}-\mathrm{Cl}_{2}$ alone. The bacteria sample $B$. cereus was treated with $2 \mathrm{mg} / \mathrm{ml}$ of $\mathrm{MgO}-\mathrm{Cl}_{2}$ and stained with Syto-9 and Ethidium homodimer-1. From the images obtained, it showed that when the bacteria were in immediate contact with $\mathrm{MgO}-\mathrm{Cl}_{2}$ death occurred slowly. This is evident by a strong population of green stained live bacteria with small amount of dead cells. It was observed that when the bacteria cells were slowly dying they were transforming from green (live) to red (dead). This same behavior was apparent when B. subtilis was interacted with Immunoliposome-nanoparticle complex. At time $=30$ minutes a strong presence of live bacteria cells highly fluorescent in blue were visualized, and as the incubation time was increased, a dramatically shift was observed to the red cells (dead). After two hours, the bacteria cells were all bright red. Similar results were obtained when the same samples were analyzed under flow cytometry, which occurred after two hours of incubation.

The preliminary flow cytometry results obtained with $B$. subtilis and the Immunoliposome-nanoparticle complex were promising. These samples were incubated with Syto-9 and Ethidium homodimer-1 and were examined using the fluorescent property of the nanoparticle and dyes in determining cell viability. The shift in fluorescence observed from green (Syto-9) to red (Ethidium homodimer-1) occurred during bacteria death.

When B. subtilis and the immunoliposome-nanoparticle complex were initially tested, an interaction with the bacteria was seen on the flow cytometer by triggering the fluorescence of the nanoparticle, shown in the FL2 filter. A minimum amount of dead 
cells was viewed at time $=0$, but as the bacteria and Immunoliposome-nanoparticle complex exposure time were increased a visible shift in fluorescent from green syto- 9 to deep red from Ethidium homodimer-1 was viewed in FL3 filter. So from these preliminary results, it is understood that the maximum bacteria neutralization was achieved after 2 hours of bacteria incubation with the Immunoliposome-nanoparticle complex, indicating that a time factor in neutralizing the bacteria exists with this new assay. Since a fluorescent cross talk may have occurred with the Syto- 9 fluorescent dye and the streptavidin-nanoparticle, future experiments were performed with only Ethidium homodimer-1.

The final flow cytometry testing was performed with Bacillus cereus (closest relative to $B$. anthracis) and the immunoliposome-nanoparticle samples. The initial testing was performed to determine, if the nanoparticle-antibody complex could be used to detect and neutralize bacteria. So, the detection portion was subdivided into two main categories, dependent of the conjugated fluorescent nanoparticle-antibody complex, 10 and 11 . These samples were analyzed at two intervals, at time $=0$ and time $=2$ hrs to detect the bacteria samples. The fluorescence of the nanoparticles was triggered, and the results were obtained in histograms in the FL2 filter.

The results obtained from complex 10 all showed bacteria detection occurred when introduced to the bacteria cultures. All the samples at time $=0$ had almost identical detection histograms. As the time progressed and the liposomes samples were introduced, two samples dissociated from the bacterial wall, indicating bacteria detection decreased after 2 hours. This dissociation occurred with the samples 13-10 and 17-10. 
Interesting the lipid film sample Formulation (d) and (a) both had only one sample with bacteria dissociation.

The histograms of complex 11 were examined at two specific intervals. When the complex was analyzed with $B$. cereus, bacteria detection occurred immediately. The detection of the bacteria is apparent by a shift to the right in the histogram within the gated region. When this same gate was examined after 2 hours, similar histogram profiles were obtained, except sample 22-11 had high bacterium dissociation.

One of the hypotheses attempted to determine if optimizing by using different types biotin linker on the lipid membrane could up regulate bacteria detection. From the results, trends suggest that our hypothesis was not supported. Formulation (d), corresponding to samples $12,17,19$, and 21 , did not show substantial increase in detection when compared to Formulation (a). Sample 17 showed dissociation after 2 hours of bacteria incubation, this was not observed in other complex 10 samples. Dissociation in complex 11 occurred with Sample 22 corresponding to Formulation (b), containing double the concentration of cholesterol.

So from our findings currently suggests that there is no correlation between liposome formulation and bacteria to increases bacteria detection, since reduced bacteria detection occurred with one sample of each of the four-liposome formulation. Therefore because of insufficient evidence from the experiments performed, no assessment could be made to either accept or deny the notion that using a different biotin linker in the lipid membrane could increase bacteria detection.

In addition, in order to clearly determine if altering the type of biotin within the lipid membrane has a direct correlation with detection, a new fluorescent nanoparticle would 
have to be used. Since the fluorescent profile of these nanoparticles have a very broad excitation and emission spectrum, it was challenging to obtain a strong fluorescent signal. The use of brighter nanoparticles with a narrow fluorescent spectrum would better assist in detecting the presence of bacteria by flow cytometry, and determine if the type of biotin linker used did actually affect detection.

Bacteria neutralization with the newly created Immunoliposome-nanoparticle complex was examined with flow cytometry. All the liposome samples created were analyzed immediately with a red fluorescent membrane impermeable dye, Ethidium homodimer-1. The Immunoliposome-nanoparticle complex and bacteria samples were analyzed individually, and the data histograms were overlaid and plotted. The first set of liposome samples that were analyzed belonged to Formulation (a), sample 16-10,14$10,15-10,16-10,18-11$. When these samples were examined at time $=0$, they all showed similar histogram profiles, except for sample 16 , which had at time $=0$ had a histogram peak very close to the ethanol treated dead control region. Both samples 14-10 and 15-10 had the identical histograms in the $\mathrm{MgO}-\mathrm{Cl}_{2}$ neutralized gated region. Also, samples 1310 and 18-11 both had similar neutralizing affect on the bacteria sample; note sample 1811 was the control sample.

The second Formulation (b) samples were interacted with the B. cereus with flow cytometry, at two intervals. The data histograms were overlaid and the neutralization effectiveness was analyzed. From the histogram data, it showed that the greatest killing effect occurred with the liposome sample $20-11$ at time $=0$ with a majority of the cells in the ethanol neutralized controlled region. As the incubation time was increased, the killing effect increased and a sharp histogram appeared further from the ethanol treated 
bacteria cell gate. However, the rapid and effective killing effect of sample 20-11 was not observed with sample 22-11. So it is not clear if the formulation was responsible for instant bacteria death. So a new liposome sample with the same formulation would have to be created and re-analyzed in order to create a strong statement on this formulation.

The third lipid Formulation (c) was observed with flow cytometry to determine the effectiveness of the liposomes, in neutralizing the bacteria sample. When this sample was analyzed, it was observed that the histogram showed a broad distribution within the $\mathrm{MgO}-\mathrm{Cl}_{2}$ neutralized gated region at time $=0$. As the incubation time increased with the liposome sample 23-11 and $B$. cereus a slight histogram shift towards the ethanol-killed bacteria gated region was observed. The widespread broad histogram of the liposomes with bacteria showed that although the killing effect was not as substantial as observed by sample 20-11, these bacteria cells were not content.

The Formulation (d) was interacted with B. cereus and was monitored with flow cytometry. The histogram data obtained were analyzed and the samples $12-10,18-11$, and 17-10, all showed similar results with histograms in the live region. Nonetheless, sample 21-11 showed a greater shift towards the ethanol dead gated region after 2 hours of bacteria sample incubation. The results obtained suggests that the greatest killing effect occurred with the sample 21-11, which was represented by a broad histogram after two hours of incubation that spilled over to the ethanol treated region.

From all the data obtained, we can suggest that the lipid composition of the liposomes does have an affect in neutralizing the bacteria. The liposome that had showed the greatest killing effect occurred with sample 16-10 (a), 20-11(b), 23-11 (c), and 21-11 (d). The greatest killing effect of these four was observed with 20-11. Thus, we cannot 
make a clear indication if the concentration of cholesterol within the lipid membrane can account for the rapidly neutralizing effect of this liposome sample. These samples would have to be analyzed further to determine if cholesterol is an important component for releasal of $\mathrm{MgO}-\mathrm{Cl}_{2}$ within the liposome.

\subsection{SUMMARY AND CONCLUSION}

The experimental results obtained from this thesis can be used to formulate strong statements about the effectiveness of the novel detection and neutralization assay for bacteria biohazards. First, it can be stated that this newly developed assay can be used not only to neutralize bacteria, as seen from the flow cytometry results, but also in the treatments of bacteria biofilms. The flow cytometry results indicated that the streptavidin nanoparticle-antibody complex adheres rapidly and effectively to the bacterial cell membrane producing a distinct fluorescent signal, indicating this new assay can be used to detect the presence of bacteria biohazards.

Furthermore, bacteria neutralization was enhanced by liposome drug delivery. From our experimental results, it was determined that the actual concentration $\mathrm{MgO}-\mathrm{Cl}_{2}$ within the liposomes was not a critical factor in neutralizing the bacteria. The actual delivery density of these nanoparticles introduced to the surface of the bacteria was more effective with a lower concentration, then, a higher concentration of pure nanoparticles incubated with the bacteria. This could have attributed to the bactericidial properties of the surface area of the nanparticles in interacting with the bacterial cell membrane. So the encapsulation of these nanoparticles within the liposomes resulted in a higher bacteria and biofilm neutralization. 
So the drug delivery of the neutralization agent is not completely dependent on the concentration but the density within the liposomes that target the bacteria biohazards. Previous finding suggested that when these nanoparticles are in close proximately to each other, they form clusters that attack aggressively the cell membrane with high chlorine activity. This could be attributed to the increased cell death with minimal drug concentration. Also, since these liposomes are modified with fluorescent nanoparticlesantibody complex the neutralization agent are immediately delivered at very close proximately to the bacteria cell wall, this is attributed to the antibody attachment to the antigen on the bacteria surface.

So this novel detection and neutralization assay can be used on bacteria and spores that have germinated when introduced to a nutrient environment. This statement is supported from results obtained in flow cytometry, since the bacteria samples used were within culture media. So the environment does not affect the assays effectiveness, and can be used on any surface to treat bacteria in any environment.

In order to increase detection time and achieve a time sensitive assay, a fluorescent streptavidin nanoparticle with a tighter excitation and emission peak should be utilized. By using a nanoparticle with a tighter excitation/emission spectrum will allow for this assay to be tested with several cytotoxity fluorescent dyes. This flexibility could assist in producing a multirange peak from not only the fluorescent dyes but the nanoparticles. This could in results assist in achieving a quicker and cleaner positive identification for the detection and neutralization of the assay with additional Anthrax models. 


\section{REFERENCES}

1. The Biofilm Institute, T. b. (1996), http://www.biofilmsonline.com/cgibin/biofilmsonline/ed_where_primer.html

2. Schuch, R. A bacteriolytic agent that detects and kills Bacillus anthracis. Nature $418,884-888$ (2002).

3. Pierre N. Floriano, N. C., Dwight Romanovicz, Bruce Bernard, Glennon W. Simmons, Myles Cavell and John T. McDevitt. Membrane-based on-line optical analysis system for rapid detection of bacteria and spores. Biosensors and Bioelectronics 20, 2079-2088 (2005).

4. Wilson, S. C. et al. Effect of chlorine dioxide gas on fungi and mycotoxins associated with sick building syndrome. Appl Environ Microbiol 71, 5399-403 (2005).

5. Readlich, C. a., Sparer, J. \& Cullen, M. R. Sick-building syndrome. Lancet 349, 1013-1016 (1997).

6. Robinson, A. M., Bannister, M., Creeth, J. E. \& Jones, M. N. The interaction of phospholipid liposomes with mixed bacterial biofilms and their use in the delivery of bactericide. Colloids and Surfaces A: Physicochemical and Engineering Aspects 186, 43 (2001).

7. Swartz, M. N. Recognition and Management of Anthrax -- An Update. N Engl J Med 345, 1621-1626(2001).

8. Shafazand, S., Doyle, R., Ruoss, S., Weinacker, A. \& Raffin, T. A. Inhalational Anthrax: Epidemiology, Diagnosis, and Management. Chest 116, 1369-1376 (1999).

9. Coursin, D, Bioterrorism May Overwhelm Medical Resources New and Different Patient Safety Challenges Must be Anticipated.

10. Overview, B.-c, http://www.millenniumark.net/News Files/Newsletters/News010106 30f5NCB/News_NBC Pt3C.html.

11. Pe, G. Bacillus Cereus: In food Microbiology: Fundamentals and frontiers (ed. Dolye, M. P., Beuchat, L.R. and Montville, T.D.) (ASM Press, Washington, D.C, 1997).

12. Berkeley, R. Applications and Systematics of Bacillus and Relatives (Blackwell Publishing Company, Malden, 2002). 
13. Helgason, E. et al. Bacillus anthracis, Bacillus cereus, and Bacillus thuringiensis One species on the basis of genetic evidence. Applied and Environmental Microbiology 66, 2627-2630 (2000).

14. Bell, C. A. et al. Detection of Bacillus anthracis DNA by LightCycler PCR. J Clin Microbiol 40, 2897-902 (2002).

15. Smith, A. W. Biofilms and antibiotic therapy: Is there a role for combating bacterial resistance by the use of novel drug delivery systems? Advanced Drug Delivery Reviews 57, 1539 (2005).

16. Godish, T. Sick Building Definition, Diagnosis, and Mitigation (Lewis Publisher, Boca Raton, 1995).

17. Jones, M. N. in Methods in Enzymology 211 (Academic Press, 2005).

18. Webb, J. S., Lau, M. \& Kjelleberg, S. Bacteriophage and Phenotypic Variation in Pseudomonas aeruginosa Biofilm Development. J. Bacteriol. 186, 8066-8073 (2004).

19. Francis, C. A., Lockley, A.C., Sartory, D.P., Watkins, J., 2001. A simple modified membrane filtration medium for the enumeration of aerobic spore-bearing bacilli in water. Water Resource 35, 3758-3761 (2001).

20. chemicon, Introduction to Antibodies - Enzyme-Linked Immunosorbent Assay (ELISA).

21. Cure Researc, http://www.cureresearch.com/a/anthrax/treatments.htm.

22. M. K. Templeton, W. H. W. Decomposition of phosphonate esters adsorbed on aluminum oxide. J. Am. Chem. Soc 107, 774-779 (1985).

23. Huang, L. et al. Controllable preparation of Nano-MgO and investigation of its bactericidal properties. Journal of Inorganic Biochemistry 99, 986 (2005).

24. Sawai. Antibacterial characteristics of magnesium oxide powder. World Journal of Microbiology and Biotechnology 16, 187-194 (2000).

25. Stoimenov, P. K., Klinger, R. L., Marchin, G. L. \& Klabunde, K. J. Metal Oxide Nanoparticles as Bactericidal Agents. Langmuir 18, 6679-6686 (2002).

26. Lin, Y. J., Li, D. Q., Wang, G., Huang, L. \& Duan, X. Preparation and bactericidal property of $\mathrm{MgO}$ nanoparticles on gamma-Al2O3. J Mater Sci Mater Med 16, 53-6 (2005). 
27. Torchilin, V. P. Fluorescence microscopy to follow the targeting of liposomes and micelles to cells and their intracellular fate. Adv Drug Deliv Rev 57, 95-109 (2005).

28. Huwyler, J., Wu, D. \& Pardridge, W. M. Brain drug delivery of small molecules using immunoliposomes. Proc Natl Acad Sci U S A 93, 14164-9 (1996).

29. Edwards, K. A. \& Baeumner, A. J. Liposomes in analyses. Talanta In Press, Corrected Proof.

30. Marcotte, L., Barbeau, J., Edwards, K., Karlsson, G. \& Lafleur, M. Influence of the lipid composition on the membrane affinity, and the membrane-perturbing ability of cetylpyridinium chloride. Colloids and Surfaces A: Physicochemical and Engineering Aspects In Press, Corrected Proof.

31. Avanti Lipids, Preparation of Liposomes, http://www.avantilipids.com/PreparationOfLiposomes.html

32. Torchilin, V. P. liposomes (ed. Weissig, V.) (Oxford University Press, New York, 2003).

33. Avidin-Biotin Chemistry: A handbook.

34. Hermanson, G. Bioconjugate Techniques (Academic Press, San Diego, 1996).

35. Dinauer, N. et al. Selective targeting of antibody-conjugated nanoparticles to leukemic cells and primary T-lymphocytes. Biomaterials 26, 5898-906 (2005).

36. Dwarakanath, S. et al. Quantum dot-antibody and aptamer conjugates shift fluorescence upon binding bacteria. Biochem Biophys Res Commun 325, 739-43 (2004).

37. Immunology. Antibody Structure.

38. Palsson, B. Tissue Engineering (Prentice Hall, Upper Saddle River, 2004).

39. Tissue, B. in Science Hypermedia (1996).

40. biosciences, E. Absorbance Assay.

41. Pierce. Protein Assay. Technical Handbook.

42. Adilakshami, T. a. L., R.O. BCA Protein Assay.

43. biosciences, B. Introduction to flow cytometry. 
44. Yokomaku, D., Yamaguchi, N. \& Nasu, M. Improved Direct Viable Count Procedure for Quantitative Estimation of Bacterial Viability in Freshwater Environments. Applied and Enviro nmental Microbiology 66, 5544-5548 (2000).

45. Probes, M. Flow cytometry. 


\section{APPENDICES}

\section{Liposome Formulation (a)}

1. Lipid solution: Add $7.5 \mathrm{mg}$ Peg2000-Biotin $+17.5 \mathrm{mg}$ Phosphatidylcholine + $13.11 \mathrm{mg}$ Cholesterol to a round bottom flask with $5 \mathrm{ml}$ of chloroform.

2. Place the flask on the Rotovap evaporator until all the chloroform has evaporated and a film is obtained approximately $1.5 \mathrm{hr}$.

3. Place the lipid film in a vacuum pump under $-20^{\circ} \mathrm{C}$ overnight

4. Rehydrate lipid film with $7 \mathrm{ml}$ of HEPES solution of $3 \mathrm{~mm}$ Trehalose solution with $0.25 \mathrm{mg} \mathrm{MgO}-\mathrm{Cl}_{2}$.

5. Freeze dry lipid film 10 times under liquid nitrogen

6. Soak membrane filter in HEPES Solution

7. Assemble the Extruder apparatus with soaked filter and membranes

8. Heat Extruder apparatus until temperature is constant $62^{\circ} \mathrm{F}$

9. Draw $1 \mathrm{ml}$ of sample with the extruder syringe

10. Circulate the sample for a total of 10 times alternating syringes.

11. Decant liposome and non-liposome samples into freezer vials and freeze under $80^{\circ} \mathrm{C}$

\section{Liposome Formulation (b)}

1. Obtain a round bottom flask and coat with chloroform solvent.

2. Create a lipid solution composed of: $7.5 \mathrm{mg}$ (Biotin Capped DSPE-Peg2000), 26 $\mathrm{mg}$ (Cholesterol), $46 \mathrm{mg}$ (egg Phosphatidylcholine) dissolve in $5 \mathrm{ml}$ of Choloform Solvent

3. Place the round bottom flask on Rotovap evaporator. Set the conditions of the evaporator equipment to the following:

a. Water bath temperature to $39^{\circ} \mathrm{C}$

b. Water Circulator $14^{\circ} \mathrm{C}$

c. Flask under Vacuum

d. Rotation speed $155 \mathrm{rpm}$

4. Allow the flask to rotate for 1 hour or until the solvent has completely evaporated

5. Once a film has been obtained, remove flask from the Rotovap. Dip the Flask in liquid nitrogen for approximately 1 minute.

6. Then place the frozen film in the lypholizer, and allow the film to dry overnight.

7. The following day pre-set the temperature on the Rotovap to the following:

a. Water bath $55^{\circ} \mathrm{C}$

b. Water Circulator $14^{\circ} \mathrm{C}$

8. Dispense $7 \mathrm{ml}$ of $3 \mathrm{mM}$ Trehalose HEPES solution into lipid film containing round bottom flask

9. Add $2.5 \mathrm{mg} \mathrm{MgO}-\mathrm{Cl}_{2}$ to flask.

10. Place the flask into the Buchii Rotovap. Adjust the angle of the rotovap to ensure full submerge in of the lipid film in the buffer. Set the rotation speed to $165 \mathrm{rpm}$ and allow the film to dissolve for approximately 1 hour. I 
11. While the lipid film is rotating, soak the extruder membranes in HEPES buffer. Assemble Mini extruder and place it onto a heating block. Set the temperature of the heating block to low to achieve a steady $62^{\circ} \mathrm{C}$.

12. Once the lipid film has dissolved, freeze thaw the lipid sample under liquid nitrogen for 5 times.

13. Once the extruder has reached desired condition. Extract $1 \mathrm{ml}$ of lipid solution and place it to one side of the extruder apparatus. Place an empty $1 \mathrm{ml}$ syringe in the opposite side of the extruder.

Pass through lipid solution through the extruder membranes a total of 10 times alternating sides. Dispense the liposome solution into a glass container, and store sample at $-20^{\circ} \mathrm{C}$

\section{Liposome Formulation (c)}

1. Obtain a round bottom flask and coat with chloroform solvent.

2. Create a lipid solution composed of: $7.5 \mathrm{mg}$ (Biotin Capped DSPE-Peg2000), 46 $\mathrm{mg}$ (egg Phosphatidylcholine) dissolved in $5 \mathrm{ml}$ of Choloform Solvent

3. Place the round bottom flask on Rotovap evaporator. Set the conditions of the evaporator equipment to the following:

a. Water bath temperature to $39^{\circ} \mathrm{C}$

b. Water Circulator $14^{\circ} \mathrm{C}$

c. Flask under Vacuum

d. Rotation speed 155rpm

4. Allow the flask to rotate for 1 hour or until the solvent has completely evaporated

5. Once a film has been obtained, remove flask from the Rotovap. Dip the Flask in liquid nitrogen for approximately 1 minute.

6. Then place the frozen film in the lypholizer, and allow the film to dry overnight.

7. The following day pre-set the temperature on the Rotovap to the following:

e. Water bath $55^{\circ} \mathrm{C}$

f. Water Circulator $14^{\circ} \mathrm{C}$

8. Dispense $7 \mathrm{ml}$ of $3 \mathrm{mM}$ Trehalose HEPES solution into lipid film containing round bottom flask

9. Add approximate $\mathrm{MgO}-\mathrm{Cl}_{2}$ concentration to flask ( $2.5 \mathrm{mg}$ ).

10. Place the flask into the Buchii Rotovap. Adjust the angle of the rotovap to ensure full submerge in of the lipid film in the buffer. Set the rotation speed to $165 \mathrm{rpm}$ and allow the film to dissolve for approximately 1 hour.

11. While the lipid film is rotating, soak the extruder membranes in HEPES buffer. Assemble Mini extruder and place it onto a heating block. Set the temperature of the heating block to low to achieve a steady $62^{\circ} \mathrm{C}$.

12. Once the lipid film has dissolved, freeze thaw the lipid sample under liquid nitrogen for 5 times. 


\section{Liposome Formulation (d)}

1. Obtain a round bottom flask and coat with chloroform solvent.

Create a lipid solution composed of: Biotin-DSPE, DSPE-PEG2000,

Phosphatidylcholine, and Cholesterol ( $5 \mathrm{mg}, 2.5 \mathrm{mg}, 34 \mathrm{mg}, 9.7 \mathrm{mg}$ )

2. Place the round bottom flask on Rotovap evaporator. Set the conditions of the evaporator equipment to the following:

a. Water bath temperature to $39^{\circ} \mathrm{C}$

b. Water Circulator $14^{\circ} \mathrm{C}$

c. Flask under Vacuum

d. Rotation speed $155 \mathrm{rpm}$

3. Allow the flask to rotate for 1 hour or until the solvent has completely evaporated

4. Once a film has been obtained, remove flask from the Rotovap. Dip the Flask in liquid nitrogen for approximately 1 minute.

5. Then place the frozen film in the lypholizer, and allow the film to dry overnight.

6. The following day pre-set the temperature on the Rotovap to the following:

g. Water bath $55^{\circ} \mathrm{C}$

h. Water Circulator $14^{\circ} \mathrm{C}$

7. Dispense $7 \mathrm{ml}$ of $3 \mathrm{mM}$ Trehalose HEPES solution into lipid film containing round bottom flask

8. Add approximate $\mathrm{MgO}-\mathrm{Cl}_{2}$ concentration to flask ( $2.5 \mathrm{mg}$ ).

9. Place the flask into the Buchii Rotovap. Adjust the angle of the rotovap to ensure full submerge in of the lipid film in the buffer. Set the rotation speed to $165 \mathrm{rpm}$ and allow the film to dissolve for approximately 1 hour. I

10. While the lipid film is rotating, soak the extruder membranes in HEPES buffer. Assemble Mini extruder and place it onto a heating block. Set the temperature of the heating block to low to achieve a steady $62^{\circ} \mathrm{C}$.

11. Once the lipid film has dissolved, freeze thaw the lipid sample under liquid nitrogen for 5 times.

\section{Separation of low molecular weight solutes from liposomes by centrifugation through a mini column}

\section{Equipment:}

Centrifuge with swinging bucket rotor

Barrels of $5 \mathrm{ml}$ plastic syringes

Sephadex G50

Glass wool

HEPES Buffer

Procedures:

1. Swell Sephadex G-50 in HEPES buffer

2. Place small amount of glass wool in a beaker containing HEPES buffer

3. Place the soaked glass wool into plastic syringe and press firmly with plunger to pack tightly glass wool 
4. Degas sephadex $\mathrm{G}-50$ and pour into the syringe

5. Place the mini column into a $15 \mathrm{ml}$ conical tube, and place inside the centrifuge.

6. Spin for 3 minutes at $1000 \mathrm{~g}$ to remove excess buffer from the gel

7. Transfer syringe into a new conical tube and apply $1 \mathrm{ml}$ of liposome sample to the column

8. Spin the column at $50 \mathrm{~g}$ for 10 minutes

9. Then spin the column for 3 minutes for $1000 \mathrm{~g}$ to expel the liposome material from the column into the test tube

10. Discard the column and store purified liposome sample in $-20^{\circ} \mathrm{C}$ freezer

\section{Synthesis of streptavidin-conjugated $\mathbf{m A b}$}

1. Dissolve the antibody to be modified at a concentration of $1-10 \mathrm{mg} / \mathrm{ml}$ in .1 M sodium phosphate, $0.15 \mathrm{M} \mathrm{NaCl}, \mathrm{pH} 7.2$, containging $10 \mathrm{mM}$ EDTA.

2. Add 2-iminothiolane ( Traut's reagent: Sigma) to this solution to give a molar excess of $40 \mathrm{X}$ over the amount of antibody present. The greater the molar excess of traut's reagent added, the higher level of thiolation and the greater the incorporation of Maleimide-Streptavidin.

3. React for $30 \mathrm{~min}$ at $37^{\circ} \mathrm{C}$ or 1 hour at room temperature

4. Purify the thiolated antibody by gel filtration using a desalting matrix such as sephadex G-25. Perform the chromatography using $0.1 \mathrm{M}$ sodium phosphate, $0.15 \mathrm{M} \mathrm{NaCl}, \mathrm{pH} 7.2$, containing $10 \mathrm{mM}$ EDTA as the buffer. To obtain efficient separation between the reduced antibody and excess reductant, the sample size applied to the column should be at a ratio of no more than $5 \%$ sample volume to the total column volume. Collect $0.5 \mathrm{ml}$ fractions and monitor for proteins at 280 $\mathrm{nm}$. To monitor the separation of the second peak (excess Traut's reagent), the $\mathrm{BCA}$ protein assay reagent (Pierce). The $\mathrm{BCA}$ - copper reagent reacts with both the protein fractions and the sulfhydryl groups of MEA to produce a colored product.

5. Dissolve the streptavidin ( $2 \mathrm{mg}, 33 \mathrm{nmol}$ ) in $200 \mu \mathrm{l}$ of $0.1 \mathrm{M}$ PBS ( $100 \mathrm{mM}$ phosphate/150 mM sodium chloride, $\mathrm{pH} 7.4$ ) and activate by 20:1 Molar excess of $\mathrm{m}$-maleimidobenzoyl-N-hydroxysuccinimide ester (MBS).

6. Incubate for 1 hour at $20^{\circ} \mathrm{C}$ with gentle shaking.

7. Purify the mixture by Sephadex G-75 gel-filtration chromatography and UV detection at $280 \mathrm{~nm}$.

8. The thiolated antibody is conjugated with the activated streptavidin at a molar ratio 1:3 (antibody:streptavidin).

9. Incubate overnight at $20^{\circ} \mathrm{C}$ with gentle shaking.

10. Purify the reaction product with Sephacryl-200 gel filtration chromatography and $\mathrm{mAb}$-streptavidin containing samples detected by measuring the absorbance at $280 \mathrm{~nm}$.

11. Store the samples in $0.01 \mathrm{M} \mathrm{Pbs}$ at $-20^{\circ} \mathrm{C}$

12. $\mathrm{BCA}$ protein assay reagent (Pierce) with $\mathrm{BSA}$ as the reference for protein concentration. The $\mathrm{BCA}$ - copper reagent reacts with both the protein fractions and the sulfhydryl groups of MEA to produce a colored product. 


\section{Centriprep 30 Procedure Protocol}

1. Removal of Glycerin in membranes

a. Add $15 \mathrm{ml}$ of Buffer in the sample container.

b. Centrifuge the Centriprep 30 at $3000 \mathrm{G}$

c. Decant the solution from the filtrate cavity.

d. Re-suspend the membranes with $5 \mathrm{ml}$ buffer

e. Centrifuge the centriprep filter again at $3000 \mathrm{G}$ for 10 minutes to remove all traces of glycerin

f. Decant the buffer in the filtrate cavity.

g. Leave the buffer in the sample cavity until it is ready to be used with samples. Once the membranes are soaked it must be used immediately.

2. Sample filtration (Streptavidin-MBS)

a. Decant buffer from the sample cavity.

b. Add the sample to be purified in the sample cavity. The maximum volume that can be placed is $15 \mathrm{ml}$.

c. Place the filtrate collector inside the sample cavity and make sure it is lock and secure.

d. Insert the Centriprep device into the centrifuge and counterbalance with a weigh balance.

e. Spin the Centriprep device at the appropriate g-force until the fluid levels inside and outside the filtrate collector equilibrate.

i. Biofuge Primo up to $3000 \times \mathrm{G}$ without lid

f. Remove the device from the centrifuge and snap off the air cap seal. Decant the filtrate.

g. Loosen the twist lock cap and remove filtrate collector.

h. Add $2 \mathrm{ml}$ of HEPES buffer in the sample cavity.

i. Push filtrate collector against buffer to release the nanoparticles on the surface of the membrane

j. Decant purified sample into a $15 \mathrm{ml}$ conical tube and store in the refrigerator.

Materials:

\section{Protocol for Bca Assay Standard}

BCA kit

96-well plate

Tecan Genios Spectrophotometer

Procedures:

1. Take the BSA ( $2 \mathrm{mg} / \mathrm{ml})$ capsule out of the box . Carefully break the glass tube and transfer the albumin into a 1.5 eppendorf tube.

2. Then perform dilutions of the standard following the Table below. 


\begin{tabular}{|l|l|l|l|}
\hline Vial & Volume of Dilutent $\mu \mathrm{l}$ & Volume of BSA $\mu \mathrm{l}$ & $\begin{array}{l}\text { Final Concentration } \\
\mu \mathrm{g} / \mathrm{ml}\end{array}$ \\
\hline $\mathrm{A}$ & 0 & 300 & 2000 \\
\hline $\mathrm{B}$ & 125 & 375 & 1500 \\
\hline $\mathrm{C}$ & 325 & 325 & 1000 \\
\hline $\mathrm{D}$ & 175 & 175 & 750 \\
\hline $\mathrm{E}$ & 325 & 325 & 500 \\
\hline F & 325 & 325 & 250 \\
\hline $\mathrm{G}$ & 400 & 325 & 125 \\
\hline $\mathrm{H}$ & 400 & 100 & 25 \\
\hline I & 400 & 0 & \\
\hline
\end{tabular}

3. Prepare the working reagent by adding $1 \mathrm{ml}$ of reagent $B$ and $50 \mathrm{ml}$ of reagent $\mathrm{A}$.

4. Pipette $25 \mu \mathrm{l}$ of each standard and dispense into microtiter plate well.

5. Add $200 \mu$ l of the working reagent to each well.

6. Place the standard in and $37^{\circ} \mathrm{C}$ incubator for approximately 2 hours.

7. Take the plate out of the incubator and allow the plates to cool down to room temperature.

8. Then load the plate into the Tecan spectrophotometer. Set the setting to shake for 30 seconds.

9. Read the absorbance of the plate at $595 \mathrm{~nm}$ and $520 \mathrm{~nm}$.

10. Record the data and subtract the values obtained from the blank from each individual sample or unknown.

11. Perform a standard curve to determine protein concentration of each unknown sample.

\section{Bacteria Inoculation}

\section{Scope and Applicability}

Inoculation is necessary to grow out a population of bacteria. Using a portion of a single colony, a population of bacteria on the order of $10^{9}$ bacteria, depending on the doubling time, can be obtained

\section{Summary of Method}

Use aseptic technique to add a sample of bacteria to a $125 \mathrm{~mL}$ flask containing LB media. Use a loop to remove a single colony from a culture dish. Dip the tip of the loop containing the colony into the flask containing the LB media. Mix, and incubate the flask as prescribed for the strain it contains.

\section{Definitions}

Inoculation: seeding a container of nutrients with a small number of bacteria to be grown out 


\section{Equipment and Supplies}

Auto pipette

$10 \mathrm{~mL}$ of recently sterilized LB media

$10 \mathrm{~mL}$ pipette tip

$125 \mathrm{~mL}$ Erlenmeyer Flask

Bunsen burner

"Loop"

Culture dish of bacteria strain

\section{Procedure}

The following is an explicit example of aseptic technique on the desktop:

1. Label a sterile $125 \mathrm{~mL}$ flask with name, date, and strain to be inoculated with.

2. Light the Bunsen burner, and keep all materials as close as safely possible to the burner (to minimize risk of contamination).

3. Loosen the lid of the LB vessel.

4. Loosen the stopper of the empty flask.

5. Open the bag of sterile loops, and set back on the desk.

6. Open the insertion end of the $10 \mathrm{~mL}$ glass pipette wrapper just enough to insert the pipette into the auto pipetter. Do not touch any part of the pipette.

7. Flame the pipeter by flaming the length of the glass for a total time of 2 seconds.

8. Keeping the pipette close to the flame, either:

9. With the other hand, uncap the vessel of LB, then flame the cap quickly and set it down open side up. Or

- With the pinky of the hand with holding the autopippete, uncap the vessel of LB media, and hold the cap with that pinky, taking care not to touch the rim of it or the underside to anything. Flame the under half of the cap.

10. Flame the neck and opening of the LB vessel for 2 seconds.

11. Keeping the pipette within $20^{\circ}$ of vertical, withdraw $10 \mathrm{~mL}$ of LB from the LB vessel.

12. Re-flame the vessel as before.

13. Flame the underpart of the vessel cap.

14. Re-cap the vessel, with either the hand holding the pippete or the other hand, as appropriate.

15. Taking care to keep the pipette within $20^{\circ}$ of vertical, grasp the stopper flask in the other hand.

16. Using the pinky of the hand holding the auto pipette, remove the foam stopper of the flask, and hold it with that pinky. Be sure not to allow the bottom half of the stopper to touch anything.

17. Flame the neck and top of the flask, as done previously with the LB vessel.

18. Without touching the pipette tip to the flask, deposit the $10 \mathrm{~mL}$ of media held in the pipette.

19. Flame the neck and top of the flask as before.

20. Recap the stopper to the flask. 
21. Remove the glass pipette from the autopipetter and place the glass in the disposal container.

22. Re-examine the agar plate for a single colony, and note it by memory.

23. Place the plate back on the desk.

24. Remove a loop from the loop bag. Do this by:

25. Grasp the bag with loops in one hand.

26. Grasp the middle of a single loop with the other hand and push it out through the opening of the bag, until the middle shaft of the loop is exposed. Be sure not to allow another loop to become exposed to any extent.

27. Taking care not to touch the tip of the loop with anything, grasp the shaft of the loop and pull it from the bag.

28. Put the bag of loops back on the desk.

29. Grasp the top plate of the agar plate (containing the agar) with the hand not holding the loop.

30. With the loop tip at a $45^{\circ}$ angle, remove the single colony noted before from the agar. Do this quickly, and with a sweeping motion just enough to carry off the colony (or at least a significant portion of the colony). Take special care not to include any portion whatsoever of any other colony in the sweep.

31. Re-cover the plate.

32. Using the hand holding the loop, remove the stopper to the flask as before, with the pinky.

33. Flame the neck and top of the flask, as before.

34. Taking care not to touch the shaft of the loop to anything, including the flask, quickly insert the tip of the loop into the flask opening, and allow the tip to touch the media.

35. Re-flame the flask.

36. Re-cap the flask.

37. Incubate the flask as required for the strain it contains.

\section{SOP Spectrophotometry}

\section{Summary of Method}

Set the spectrophotometer to read a sample at the required wavelength of the substance being tested. Read a blank with the machine. Then determine the absorbance of the experimental sample.

\section{Equipment and Supplies}

- Spectrophotometer

- $1 \mathrm{~mL}$ cuvet

- Sample of bacteria

- $1,000 \mu \mathrm{L}$ pipette

- $1,000 \mu \mathrm{L}$ pipette tip 


\section{Procedure}

1. Using the $1,000-\mu \mathrm{L}$ pipette, add $1 \mathrm{~mL}$ of culture minus bacteria (a blank) to a 1 $\mathrm{mL}$ cuvet. Make sure not to touch below the top half of the cuvet.

2. In the same manner, add $1 \mathrm{~mL}$ of sample culture to another cuvet (experimental sample).

3. Insert the blank cuvet into the cuvet holder with the textured sides of the cuvet facing the sides of the square opening.

4. Set the frequency on the machine to OD 600 . This is the frequency of absorption for most bacteria studied in the lab.

5. Push the "Read Blank" button.

6. Remove the blank cuvet and set aside.

7. Insert the experimental cuvet into the cuvet opening of the machine, in the same orientation as before.

8. Push the "Read Sample" button.

9. The spectrophotometer will then read the sample and display its absorbance and concentration of bacteria. Note these values. The machine will also store the value of all readings taken until the memory is cleared. (see note below)

\section{Bacteria and $\mathrm{MgO}-\mathrm{Cl}_{2}$ Testing}

1. Obtain five $50 \mathrm{ml}$ sterile conical tubes and fill them with $50 \mathrm{ml}$ of sterile PBS.

2. Then prepare a variety of drug standard to be tested against the bacteria. Such as :

a. $1 \mathrm{mg} / \mathrm{ml}$ need $50 \mathrm{mg}$

b. $0.5 \mathrm{mg} / \mathrm{ml}$ need $25 \mathrm{mg}$

c. $0.25 \mathrm{mg} / \mathrm{ml}$ need $12.5 \mathrm{mg}$

d. $0.125 \mathrm{mg} / \mathrm{ml}$ need $6.25 \mathrm{mg} / \mathrm{ml}$

e. $0.0625 \mathrm{mg} / \mathrm{ml}$ need $3.125 \mathrm{mg}$

f. $0 \mathrm{mg} / \mathrm{ml}$

3. Then add $.5 \mathrm{ml}$ of bacteria cell of concentration of $10^{5} \mathrm{cfu} / \mathrm{ml}$ to each conical tube

4. Shake each conical tube vigorously

5. Then place each conical tube in a mechanical shaker for $24 \mathrm{~h}$ at $37^{\circ} \mathrm{C}$

6. After $24 \mathrm{hr}$, extract $0.5 \mathrm{ml}$ out of each conical tube and dispense it into a sterile plate with culture medium.

7. Culture the bacteria and drug sample for $48 \mathrm{hrs}$ at $37^{\circ} \mathrm{C}$

8. Next, count all the bacteria colonies by eye and record experimental values

9. Finally, determine the bactericidal efficacy (\%) by using the following equation

Bactericidal efficacy $(\%)$ Alive number in reference group-alive number in experimental group $\mathrm{x}$
100

Alive number in reference group

Protocol for biofilm formation Biofilm Assay I

1. Strains are inoculated into LB Broth and grown overnight $(\mathrm{ON})$ 1:100 dilution ON LB culture standardized 
2. Poly vinylchloride plates inoculated with $100 \mu \mathrm{l}$ of dilution

3. Plates placed in a Microbiological incubator at $37^{\circ} \mathrm{C}$ for $24 \mathrm{hrs}$.

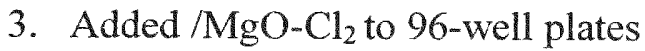

Protocol for viewing bacteria and liposome under Fluorescent microscope testing

1. Bacteria culture were grown for $18 \mathrm{hr}$ in $37^{\circ} \mathrm{C}$ and prepared by lance

2. Obtain a $5 \mathrm{ml}$ sample of the bacteria and place in a conical tube

3. Spin the bacteria sample at $2000 \mathrm{X} g$ for 15 minutes

4. Discard the supernatant and resuspend with $3 \mathrm{ml}$ of sterile PBS

5. Spin the bacteria again for $2000 \mathrm{Xg}$ and then resuspend in PBS perform this 3 times.

6. Aliquot $200 \mu \mathrm{l}$ of bacteria and place in an $1.5 \mathrm{ml}$ eppendorf tube

7. Add $100 \mu \mathrm{l}$ of liposome containing $\mathrm{MgO}-\mathrm{Cl}_{2}$

8. Gently mix the sample for about one minute. Then swab a small amount of the sample onto a glass slide and view under the microscope. Take a picture of the sample

9. After viewing add $3 \mu \mathrm{l}$ of propidium iodine stain to the bacteria liposome sample

10. View again under the fluorescent microscope and view if the fluorescent is detected.

11. Repeat steps 6-10 again but instead of using liposomes add liposome-antibodystreptavidin, non-liposome, antibody-nanoparticle, and $\mathrm{MgO}^{-\mathrm{Cl}_{2}}$. 